\title{
A Concise Construction of the Chlorahololide Heptacyclic Core
}

\author{
Yin-Suo Lu and Xiao-Shui Peng* \\ Department of Chemistry and State Key Laboratory on Synthetic Chemistry \\ The Chinese University of Hong Kong, Shatin, New Territories, Hong Kong SAR, China \\ Email: xspeng@cuhk.edu.hk
}

\section{Table of contents:}

Experimental Section. S3-S18

NMR spectra of compounds 11-29 S19-S61

Selected HMBC Correlations and Key NOESY Correlations of compound 27. S62

X-ray crystallographic data of compounds $\mathbf{2 0}$ and $\mathbf{2 8}$ S63-S64 


\section{General Information}

All reagents and solvents were reagent grade. Further purification and drying by standard methods were employed when necessary. The plates used for thin-layer chromatography (TLC) were E. Merck silica gel 60 F254 (0.24 nm thickness) precoated on aluminum plates, and then visualized under UV light ( $365 \mathrm{~nm}$ and $254 \mathrm{~nm}$ ) or through staining with acidic ceric ammonium molybdate and subsequent heating. Column chromatography was performed using E. Merck silica gel (230-400 mesh). NMR spectra were recorded on a Bruker Advance III 400 spectrometer (400.00

MHz for ${ }^{1} \mathrm{H}$ and $100 \mathrm{MHz}$ for $\left.{ }^{13} \mathrm{C}\right)$ and a Bruker $400 \mathrm{MHz}$ NMR AV400Q (400.00 MHz for ${ }^{1} \mathrm{H}$ and $100 \mathrm{MHz}$ for ${ }^{13} \mathrm{C}$ ) at room temperature. Mass spectra (ESI, EI and FAB) were obtained with a ThermoFinnigan MAT $95 \mathrm{XL}$ spectrometer and determined at an ionized voltage of $70 \mathrm{eV}$ unless otherwise stated. Elemental analyses were performed at Shanghai Institute of Organic Chemistry, The Chinese Academy of Sciences, China. 


\section{Experimental Section}

\section{Synthesis of Cyclopropane 19}<smiles>C[C@]12CCC(=O)C=C1CCCC2=O</smiles>

11

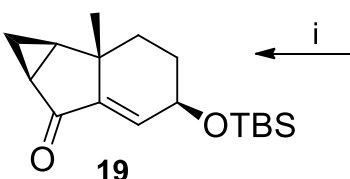<smiles>C[C@@H]1CCC2=CC(=O)CC[C@H]2[C@H]1O</smiles>

$11 \mathrm{a}$

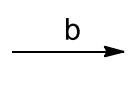

OTBS<smiles>CO[C@H]1CCCC2=CC(=O)CC[C@@]21S</smiles>

12<smiles>CO[C@H]1CCC=C2C=C(OC(C)=O)CC[C@@]21S(C)(=O)=O</smiles>

13

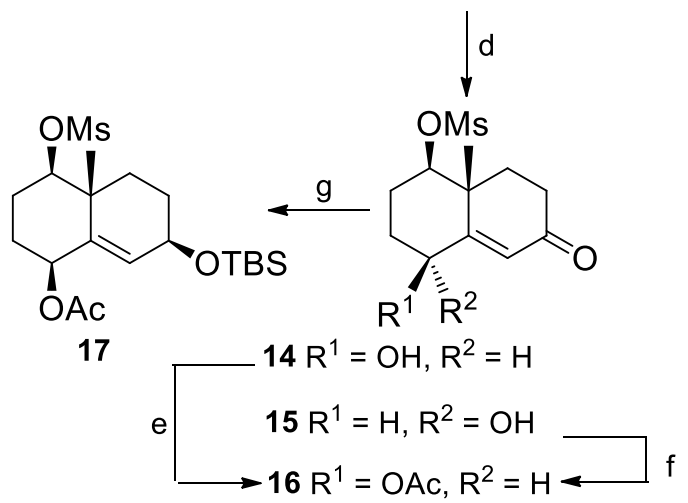

Reagents and conditions: a) $\mathrm{NaBH}_{4}, \mathrm{EtOH}, 0{ }^{\circ} \mathrm{C}, 98 \%$; b) $\mathrm{MsCl}, \mathrm{Et}_{3} \mathrm{~N}, \mathrm{CH}_{2} \mathrm{Cl}_{2}, 20{ }^{\circ} \mathrm{C}, 86 \%$; c) $\mathrm{Me}_{3} \mathrm{SiCl}, \mathrm{NaI}, \mathrm{Ac} 2 \mathrm{O}, 20{ }^{\circ} \mathrm{C}, 76 \%$; d) $m$-CPBA, dioxane, buffer $(p \mathrm{H}=8.0), 20^{\circ} \mathrm{C}, 65 \%$ ( $\left.c a \alpha: \beta=1: 3\right)$; e) $\mathrm{Ac}_{2} \mathrm{O}$, pyridine, DMAP, $\mathrm{CH}_{2} \mathrm{Cl}_{2}, 20{ }^{\circ} \mathrm{C}, 97 \%$; f) PPh 3 , DIAD, AcOH, THF, $0{ }^{\circ} \mathrm{C}, 95 \%$; g) (1) $\mathrm{NaBH}_{4}, \mathrm{CeCl}_{3} \cdot 7 \mathrm{H}_{2} \mathrm{O}, \mathrm{MeOH},-78{ }^{\circ} \mathrm{C}$; (2) $t$ - $\mathrm{BuMe}_{2} \mathrm{SiCl}$, imizole, DMAP, DMF, $\left.20{ }^{\circ} \mathrm{C}, 92 \%, \alpha: \beta=1: 19 ; \mathrm{h}\right)(1)$ $\mathrm{K}_{2} \mathrm{CO}_{3}, \mathrm{MeOH}$, THF, $20{ }^{\circ} \mathrm{C}$; (2) Dess-Martin periodinane, $\mathrm{NaHCO}_{3}, \mathrm{CH}_{2} \mathrm{Cl}_{2}, 20{ }^{\circ} \mathrm{C}, 95 \%$; i) $\mathrm{KHMDS}, \mathrm{THF},-5{ }^{\circ} \mathrm{C}, 90 \%$. $\mathrm{Ms}=$ methanesulfonyl, $m$-CPBA $=$ meta-chloroperbenzoic acid, DMAP = 4-dimethylaminopyridine, DIAD = diisopropyl azodicarboxylate, KHMDS = potassium bis(trimethylsilyl)amide

\section{Preparation of compound 11a}<smiles>C[C@]12CCC(=O)C=C1CCC[C@@H]2O</smiles>

11a

To a stirred solution of ketone $11(15.7 \mathrm{~g}, 88 \mathrm{mmol})$ in $\mathrm{EtOH}(200 \mathrm{~mL})$ at $0{ }^{\circ} \mathrm{C}$ was added portionwise $\mathrm{NaBH}_{4}(1.1 \mathrm{~g}, 30 \mathrm{mmol})$ and then the mixture was stirred for 15 min at this temperature. The mixture was treated with $\mathrm{AcOH}(10 \mathrm{~mL})$ carefully and the mixture was stirred for another $15 \mathrm{~min}$ at $0{ }^{\circ} \mathrm{C}$. The solvent was allowed to evaporate in vacuo and the residue was partitioned between EtOAc $(300 \mathrm{~mL})$ and water $(150 \mathrm{~mL})$. The aqueous was extracted with EtOAc $(300 \mathrm{~mL} \times 2)$ and the combined organic layers were washed with saturated aqueous $\mathrm{NaHCO}_{3}(250$ $\mathrm{mL})$ to remove all $\mathrm{AcOH}$ and then washed with brine $(150 \mathrm{~mL})$. The organic layer was dried over $\mathrm{Na}_{2} \mathrm{SO}_{4}$, filtered and concentrated. The residue was purified by column chromatography on silica 
gel (Hexanes/EtOAc 2:1) to give compound 11a $(15.4 \mathrm{~g}, 98 \%)$ as colorless oil: $R_{\mathrm{f}}=0.15$ (Hexanes/EtOAc 2:1); ${ }^{1} \mathrm{H}$ NMR (400 MHz, $\left.\mathrm{CDCl}_{3}\right) \delta 5.79(\mathrm{~d}, J=1.6 \mathrm{~Hz}, 1 \mathrm{H}), 3.43(\mathrm{dd}, J=4.4$, $11.6 \mathrm{~Hz}, 1 \mathrm{H}), 2.45-2.37(\mathrm{~m}, 2 \mathrm{H}), 2.35-2.29(\mathrm{~m}, 1 \mathrm{H}), 2.24-2.15(\mathrm{~m}, 2 \mathrm{H}), 1.91-1.80(\mathrm{~m}, 3 \mathrm{H})$, 1.76-1.66 (m, 1H), 1.46-1.39 (m, 1H), 1.20 ppm (s, 3H); ${ }^{13} \mathrm{C}$ NMR $\left(100 \mathrm{MHz}, \mathrm{CDCl}_{3}\right) \delta$ 199.6, $168.5,125.5,78.3,41.6,34.2,33.7,32.0,30.3,23.1,15.2 \mathrm{ppm}$.

\section{Preparation of Ms-ester 12}

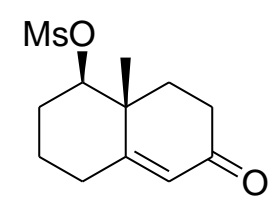

12

To a stirred solution of $11 \mathrm{a}(5.40 \mathrm{~g}, 30.0 \mathrm{mmol})$ in dry $\mathrm{CH}_{2} \mathrm{Cl}_{2}(140 \mathrm{~mL})$ under argon atmosphere at $0{ }^{\circ} \mathrm{C}$ was added $\mathrm{Et}_{3} \mathrm{~N}(8.4 \mathrm{~mL}, 60.0 \mathrm{mmol})$ and $\mathrm{MsCl}(4.2 \mathrm{~mL}, 54.0 \mathrm{mmol})$ slowly. After stirring at $0{ }^{\circ} \mathrm{C}$ for about $5 \mathrm{~min}$, the reaction was warmed to $20^{\circ} \mathrm{C}$ and kept stirring at this temperature overnight. Then the reaction was cooled to $0{ }^{\circ} \mathrm{C}$ before diluted with $\mathrm{CH}_{2} \mathrm{Cl}_{2}(400 \mathrm{~mL})$ followed by quenched with saturated aqueous $\mathrm{NH}_{4} \mathrm{Cl}(100 \mathrm{~mL})$. The organic layer was washed with saturated aqueous $\mathrm{NaHCO}_{3}(100 \mathrm{~mL} \times 2)$ and brine $(100 \mathrm{~mL})$, dried over $\mathrm{Na}_{2} \mathrm{SO}_{4}$, filtered and concentrated. The residue was purified by column chromatography on silica gel (Hexanes/EtOAc 2:1) to give compound 12 (6.66 g, 86\%) as white solid: $R_{\mathrm{f}}=0.25$ (Hexanes/EtOAc 1:1); m.p.: 147.8-148.2 ${ }^{\circ} \mathrm{C}$; IR (film): $v=3032,2946,1685,1621,1341,1169,927,865,540 \mathrm{~cm}^{-1} ;{ }^{1} \mathrm{H}$ NMR (400 MHz, $\left.\mathrm{CDCl}_{3}\right) \delta 5.83(\mathrm{~d}, J=2.0 \mathrm{~Hz}, 1 \mathrm{H}), 4.46(\mathrm{dd}, J=4.4,11.6 \mathrm{~Hz}, 1 \mathrm{H}), 3.05(\mathrm{~s}, 3 \mathrm{H}), 2.46-2.42(\mathrm{~m}, 2 \mathrm{H})$, 2.37-2.32 (m, 1H), 2.29-2.24 (m, 1H), 2.20-2.11 (m, 2H), 2.04-1.94 (m, 3H), 1.55-1.43 (m, $1 \mathrm{H})$, $1.28 \mathrm{ppm}(\mathrm{s}, 3 \mathrm{H}) ;{ }^{13} \mathrm{C} \mathrm{NMR}\left(100 \mathrm{MHz}, \mathrm{CDCl}_{3}\right) \delta 198.4,165.1,126.4,87.3,40.9,39.0,34.2,33.4$, 31.4, 28.4, 22.8, 16.4 ppm; HRMS (ESI) $\mathrm{m} / \mathrm{z}$ calcd for $\mathrm{C}_{12} \mathrm{H}_{19} \mathrm{O}_{4} \mathrm{~S}[\mathrm{M}+\mathrm{H}]^{+}$259.0999, found 259.0992; Anal. Calcd for $\mathrm{C}_{12} \mathrm{H}_{18} \mathrm{O}_{4} \mathrm{~S}: \mathrm{C}, 55.79 ; \mathrm{H}, 7.02$, found: C, 55.90; H, 7.25. 


\section{Preparation of dienol acetate 13}

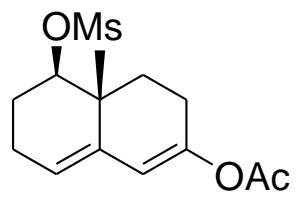

13

A solution of $12(4.95 \mathrm{~g}, 19.2 \mathrm{mmol})$ and $\mathrm{NaI}(8.63 \mathrm{~g}, 57.6 \mathrm{mmol})$ in $\mathrm{Ac}_{2} \mathrm{O}(150 \mathrm{~mL})$ was treated with trimethylsilyl chloride $(7.4 \mathrm{~mL}, 57.6 \mathrm{mmol})$ at $0{ }^{\circ} \mathrm{C}$ under argon atmosphere. The reaction was warmed to $20{ }^{\circ} \mathrm{C}$ and kept stirring at this temperature for $2 \mathrm{~h}$, then cooled to $0{ }^{\circ} \mathrm{C}$ and quenched with saturated aqueous $\mathrm{Na}_{2} \mathrm{~S}_{2} \mathrm{O}_{3}(50 \mathrm{~mL})$ carefully. The mixture was concentrated in vacuo, extracted with EtOAc $(100 \mathrm{~mL} \times 3)$. The combined organic layers were washed with saturated aqueous $\mathrm{NaHCO}_{3}(100 \mathrm{~mL} \times 2)$ and then brine $(100 \mathrm{~mL})$. The organic layer was dried over $\mathrm{Na}_{2} \mathrm{SO}_{4}$, filtered and concentrated. The residue was purified by column chromatography on silica gel (Hexanes/EtOAc 6:1) to give dienol acetate $\mathbf{1 3}(4.37 \mathrm{~g}, 76 \%)$ as white solid: $R_{\mathrm{f}}=0.75$ (Hexanes/EtOAc 1:1); M.p.: 151.2-151.8 ${ }^{\circ} \mathrm{C}$; IR (film): v= 2957, 2842, 1746, 1667,1347, 1213, 1118, 940, $537 \mathrm{~cm}^{-1} ;{ }^{1} \mathrm{H}$ NMR $\left(400 \mathrm{MHz}, \mathrm{CDCl}_{3}\right) \delta 5.75(\mathrm{~d}, J=2.0 \mathrm{~Hz}, 1 \mathrm{H}), 5.37(\mathrm{t}, J=4.0 \mathrm{~Hz}$, $1 \mathrm{H}), 4.64-4.60(\mathrm{~m}, 1 \mathrm{H}), 3.04(\mathrm{~s}, 3 \mathrm{H}), 2.53-2.45(\mathrm{~m}, 1 \mathrm{H}), 2.35-2.31(\mathrm{~m}, 2 \mathrm{H}), 2.21-2.11(\mathrm{~m}, 3 \mathrm{H})$, $2.14(\mathrm{~s}, 3 \mathrm{H}), 1.98(\mathrm{ddd}, J=1.2,5.6,12.8 \mathrm{~Hz}, 1 \mathrm{H}), 1.53(\mathrm{td}, J=6.0,12.4 \mathrm{~Hz}, 1 \mathrm{H}), 1.12 \mathrm{ppm}(\mathrm{s}$, $3 \mathrm{H}) ;{ }^{13} \mathrm{C} \mathrm{NMR}\left(100 \mathrm{MHz}, \mathrm{CDCl}_{3}\right) \delta 169.2,147.8,136.7,123.0,115.9,86.8,38.7,36.6,32.7,24.7$, 24.7, 24.3, 21.0, 17.6 ppm; HRMS (ESI) $\mathrm{m} / z$ calcd for $\mathrm{C}_{14} \mathrm{H}_{20} \mathrm{O}_{5} \mathrm{SNa}[\mathrm{M}+\mathrm{Na}]^{+}$323.0924, found 323.0933.

\section{Preparation of compound 14 and 15}

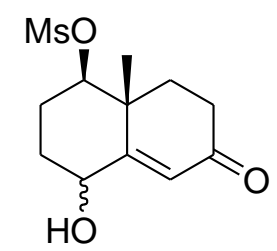

A solution of $m$-CPBA $(70 \%, 2.41 \mathrm{~g}, 9.76 \mathrm{mmol})$ in a mixture of dioxane $(20 \mathrm{~mL})$ and buffer $(p \mathrm{H}$ $=8,20 \mathrm{~mL})$ was added over a period of $1 \mathrm{~h}$ to a stirred solution of dienol acetate $\mathbf{1 2}(2.44 \mathrm{~g}, 8.13$ mmol) in a mixture of dioxane $(20 \mathrm{~mL})$ and buffer $(p \mathrm{H}=8,20 \mathrm{~mL})$ at $0{ }^{\circ} \mathrm{C}$. Stirring was continued overnight at $20{ }^{\circ} \mathrm{C}$. After addition of $\mathrm{Na}_{2} \mathrm{~S}_{2} \mathrm{O}_{3}(1.42 \mathrm{~g})$ and $\mathrm{NaHCO}_{3}(3.11 \mathrm{~g})$ at $0{ }^{\circ} \mathrm{C}$ the reaction was stirred for $15 \mathrm{~min}$ at $20^{\circ} \mathrm{C}$, extracted with EtOAc $(100 \mathrm{~mL} \times 3)$. The combined organic layers 
were washed with water $(100 \mathrm{~mL} \times 2)$ and then brine $(100 \mathrm{~mL})$. The organic layer was dried over $\mathrm{Na}_{2} \mathrm{SO}_{4}$, filtered and concentrated. The residue was purified by column chromatography on silica gel (Hexanes/EtOAc 1:1) to give compounds $15(0.36 \mathrm{~g}, 16 \%)$ as white solid and 14 (1.07 g, $49 \%)$ as white solid:

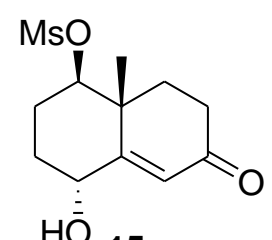

HŌ 15

15: $R_{\mathrm{f}}=0.10$ (Hexanes/EtOAc 1:1); m.p.: 152.7-153.2 ${ }^{\circ} \mathrm{C}$; IR (film): $v=3339,3038,2940,1651$, $1352,1168,958,926,864,531 \mathrm{~cm}^{-1} ;{ }^{1} \mathrm{H}$ NMR $\left(400 \mathrm{MHz}, \mathrm{CDCl}_{3}\right) \delta 6.26(\mathrm{~d}, J=1.6 \mathrm{~Hz}, 1 \mathrm{H}), 4.48$ $(\mathrm{dd}, J=4.4,12.0 \mathrm{~Hz}, 1 \mathrm{H}), 4.37(\mathrm{ddd}, J=2.0,5.6,12.0 \mathrm{~Hz}, 1 \mathrm{H}), 3.07(\mathrm{~s}, 3 \mathrm{H}), 2.49-2.38(\mathrm{~m}, 2 \mathrm{H})$, 2.29-2.20 (m, 2H), 2.15-1.97 (m, 3H), 1.56-1.45 (m, 1H), 1.29 ppm (s, 3H); ${ }^{13} \mathrm{C}$ NMR (100 MHz, $\left.\mathrm{CDCl}_{3}\right) \delta 198.4,165.5,122.8,85.9,67.5,40.8,38.9,34.8,33.2,32.0,26.4,17.4$ ppm; HRMS (ESI) $m / z$ calcd for $\mathrm{C}_{12} \mathrm{H}_{19} \mathrm{O}_{5} \mathrm{~S}[\mathrm{M}+\mathrm{H}]^{+}$275.0948, found 275.0943; Anal. Calcd for $\mathrm{C}_{12} \mathrm{H}_{18} \mathrm{O}_{5} \mathrm{~S}: \mathrm{C}, 52.54$; H, 6.61, found: C, 52.73; H, 6.86 .

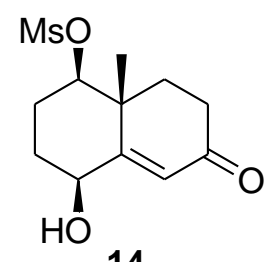

14

14: $R_{\mathrm{f}}=0.15$ (Hexanes/EtOAc 1:1); m.p.: 134.5-134.8 ${ }^{\circ} \mathrm{C}$; IR (film): $v=3489,3034,2934,1670$, 1341, 1172, 927, 880, $541 \mathrm{~cm}^{-1} ;{ }^{1} \mathrm{H}$ NMR (400 MHz, $\left.\mathrm{CDCl}_{3}\right) \delta 5.93(\mathrm{~s}, 1 \mathrm{H}), 4.47(\mathrm{dd}, J=4.4$, $12.0 \mathrm{~Hz}, 1 \mathrm{H}), 4.33(\mathrm{t}, J=2.8 \mathrm{~Hz}, 1 \mathrm{H}), 3.07(\mathrm{~s}, 3 \mathrm{H}), 2.58-2.38(\mathrm{~m}, 3 \mathrm{H}), 2.16$ (ddd, $J=3.2,4.8$, $13.6 \mathrm{~Hz}, 1 \mathrm{H}), 2.11(\mathrm{ddd}, J=3.2,6.0,14.8 \mathrm{~Hz}, 1 \mathrm{H}), 2.02(\mathrm{ddd}, J=4.0,7.2,12.4 \mathrm{~Hz}, 1 \mathrm{H}), 1.94(\mathrm{td}$, $J=5.6,13.6 \mathrm{~Hz}, 1 \mathrm{H}), 1.74(\mathrm{tt}, J=3.6,14.4 \mathrm{~Hz}, 1 \mathrm{H}), 1.48 \mathrm{ppm}(\mathrm{s}, 3 \mathrm{H}) ;{ }^{13} \mathrm{C}$ NMR $(100 \mathrm{MHz}$, $\left.\mathrm{CDCl}_{3}\right) \delta 199.2,163.6,128.6,87.3,71.3,40.2,39.0,35.7,33.7,29.8,23.0,18.3$ ppm; HRMS (ESI) $m / z$ calcd for $\mathrm{C}_{12} \mathrm{H}_{19} \mathrm{O}_{5} \mathrm{~S}[\mathrm{M}+\mathrm{H}]^{+}$275.0948, found 275.0952; Anal. Calcd for $\mathrm{C}_{12} \mathrm{H}_{18} \mathrm{O}_{5} \mathrm{~S}$ : C, 52.54; H, 6.61, found: C, 52.50; H, 6.74 . 


\section{Preparation of compound 16}

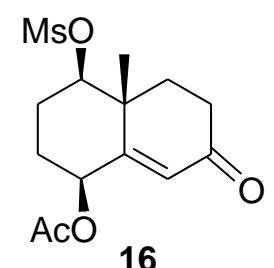

From 14: To a solution of $14(5.0 \mathrm{~g}, 18.2 \mathrm{mmol})$ in dry $\mathrm{CH}_{2} \mathrm{Cl}_{2}(150 \mathrm{~mL})$ and pyridine $(25 \mathrm{~mL})$ was added $\mathrm{Ac}_{2} \mathrm{O}(3.0 \mathrm{~mL}, 27.3 \mathrm{mmol})$ and DMAP $(445 \mathrm{mg}, 3.65 \mathrm{mmol})$ at $0{ }^{\circ} \mathrm{C}$ under argon atmosphere. The reaction was stirred for about $2 \mathrm{~h}$ at $20{ }^{\circ} \mathrm{C}$, quenched with ice, diluted with $\mathrm{CH}_{2} \mathrm{Cl}_{2}(300 \mathrm{~mL})$, and washed with saturated aqueous $\mathrm{NH}_{4} \mathrm{Cl}(100 \mathrm{~mL} \times 2)$, water $(100 \mathrm{~mL})$ and then brine $(100 \mathrm{~mL})$. The organic layer was dried over $\mathrm{Na}_{2} \mathrm{SO}_{4}$, filtered and concentrated. The residue was purified by column chromatography on silica gel (Hexanes/EtOAc 2:1) to give compound $16(5.6 \mathrm{~g}, 97 \%)$ as white solid.

From 15: To a solution of $15(0.21 \mathrm{~g}, 0.77 \mathrm{mmol})$ in dry THF $(28 \mathrm{~mL})$ was added $\mathrm{PPh}_{3}(0.42 \mathrm{~g}$, $1.61 \mathrm{mmol}), \mathrm{DIAD}(0.41 \mathrm{~mL}, 2.07 \mathrm{mmol})$ and $\mathrm{AcOH}(92 \mu \mathrm{L}, 1.61 \mathrm{mmol})$ at $0{ }^{\circ} \mathrm{C}$ under argon atmosphere. The reaction was stirred at this temperature for $2 \mathrm{~h}$, quenched with saturated aqueous $\mathrm{NH}_{4} \mathrm{Cl}(20 \mathrm{~mL})$, extracted with $\mathrm{CH}_{2} \mathrm{Cl}_{2}(50 \mathrm{~mL} \times 3)$. The combined organic layers were washed with saturated aqueous $\mathrm{NaHCO}_{3}(50 \mathrm{~mL} \times 2)$ and then brine $(50 \mathrm{~mL})$. The organic layer was dried over $\mathrm{Na}_{2} \mathrm{SO}_{4}$, filtered and concentrated. The residue was purified by column chromatography on silica gel (Hexanes/EtOAc2:1) to give compound $16(0.23 \mathrm{~g}, 95 \%)$ as white solid:

16: $R_{\mathrm{f}}=0.45$ (Hexanes/EtOAc1:1.5); m.p.: 159.8-160.0 ${ }^{\circ} \mathrm{C}$; IR (film): $v=2971,1734,1680$, 1367, 1349, 1240, 1171, 969, 870, $537 \mathrm{~cm}^{-1} ;{ }^{1} \mathrm{H}$ NMR $\left(400 \mathrm{MHz}, \mathrm{CDCl}_{3}\right) \delta 6.06(\mathrm{~s}, 1 \mathrm{H}), 5.38(\mathrm{~d}, J$ $=2.4 \mathrm{~Hz}, 1 \mathrm{H}), 4.48(\mathrm{dd}, J=4.0,12.0 \mathrm{~Hz}, 1 \mathrm{H}), 3.07(\mathrm{~s}, 3 \mathrm{H}), 2.55-2.43(\mathrm{~m}, 2 \mathrm{H}), 2.34-2.45(\mathrm{~m}, 1 \mathrm{H})$, 2.19-2.07 (m, 3H), $2.06(\mathrm{~s}, 3 \mathrm{H}), 1.95(\mathrm{td}, J=6.4,13.2 \mathrm{~Hz}, 1 \mathrm{H}), 1.81-1.72(\mathrm{~m}, 1 \mathrm{H}), 1.38 \mathrm{ppm}(\mathrm{s}$, $3 \mathrm{H}) ;{ }^{13} \mathrm{C} \mathrm{NMR}\left(100 \mathrm{MHz}, \mathrm{CDCl}_{3}\right) \delta 198.6,169.3,157.7,131.1,86.5,72.0,40.1,39.0,35.6,33.6$, 28.1, 23.6, 21.2, 17.5 ppm; HRMS (ESI) $\mathrm{m} / \mathrm{z}$ calcd for $\mathrm{C}_{14} \mathrm{H}_{21} \mathrm{O}_{6} \mathrm{~S}[\mathrm{M}+\mathrm{H}]^{+}$317.1053, found 317.1052 


\section{Preparation of compound 17}

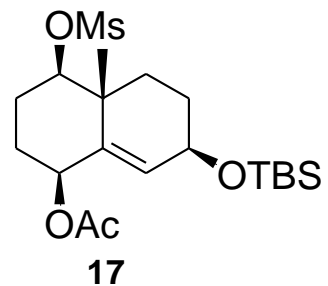

To a solution of compound $16(0.48 \mathrm{~g}, 1.51 \mathrm{mmol})$ and $\mathrm{CeCl}_{3} \cdot 7 \mathrm{H}_{2} \mathrm{O}(0.68 \mathrm{~g}, 1.81 \mathrm{mmol})$ in $\mathrm{MeOH}$ (15 mL) was added $\mathrm{NaBH}_{4}(68.5 \mathrm{mg}, 1.81 \mathrm{mmol})$ at $-78{ }^{\circ} \mathrm{C}$ under argon atmosphere. The reaction was warmed slowly and it was complete at $-25{ }^{\circ} \mathrm{C}$ about $1.5 \mathrm{~h}$ later monitored by TLC (Hexanes/EtOAc 1:1.5). Quench the reaction with saturated aqueous $\mathrm{NH}_{4} \mathrm{Cl}(10 \mathrm{~mL})$, and evaporate $\mathrm{MeOH}$ out in vacuo. The residue was diluted with EtOAc $(100 \mathrm{~mL})$, washed with water (30 $\mathrm{mL} \times 2)$ and then brine $(30 \mathrm{~mL})$. The organic layer was dried over $\mathrm{Na}_{2} \mathrm{SO}_{4}$, filtered and concentrated. To a solution of the crude product in DMF $(2.0 \mathrm{~mL})$ was added TBSCl $(0.46 \mathrm{~g}, 3.02$ mmol), imidazole (0.31 g, $4.53 \mathrm{mmol})$ and DMAP (56 $\mathrm{mg}, 0.453 \mathrm{mmol})$. The reaction was stirred at $20{ }^{\circ} \mathrm{C}$ overnight, diluted with EtOAc $(100 \mathrm{~mL})$, and washed with water $(30 \mathrm{~mL} \times 2)$ and then brine $(30 \mathrm{~mL})$. The organic layer was dried over $\mathrm{Na}_{2} \mathrm{SO}_{4}$, filtered and concentrated. The residue was purified by column chromatography on silica gel (Hexanes/EtOAc 6:1) to give compound 17 $(0.60 \mathrm{~g}, 92 \%)$ as colorless oil: $R_{\mathrm{f}}=0.75($ Hexanes/EtOAc 1:1.5); IR (film): $v=2952,2857,1736$, 1358, 1335, 1242, 1175, 1083, 932, 871, 836, 777, $517 \mathrm{~cm}^{-1} ;{ }^{1} \mathrm{H}$ NMR (400 MHz, $\left.\mathrm{CDCl}_{3}\right) \delta 5.76$ $(\mathrm{s}, 1 \mathrm{H}), 5.22(\mathrm{t}, J=2.4 \mathrm{~Hz}, 1 \mathrm{H}), 4.34(\mathrm{dd}, J=4.0,12.0 \mathrm{~Hz}, 1 \mathrm{H}), 4.20(\mathrm{ddd}, J=1.6,5.6,9.2 \mathrm{~Hz}$, 1H), $3.02(\mathrm{~s}, 3 \mathrm{H}), 2.24-2.14(\mathrm{qd}, J=3.6,12.8 \mathrm{~Hz}, 1 \mathrm{H}), 2.02(\mathrm{~s}, 3 \mathrm{H}), 2.01-1.94(\mathrm{~m}, 2 \mathrm{H}), 1.90-1.77$ $(\mathrm{m}, 2 \mathrm{H}), 1.67-1.46(\mathrm{~m}, 3 \mathrm{H}), 1.27(\mathrm{~s}, 3 \mathrm{H}), 0.88(\mathrm{~s}, 9 \mathrm{H}), 0.07(\mathrm{~s}, 3 \mathrm{H}), 0.06 \mathrm{ppm}(\mathrm{s}, 3 \mathrm{H}) ;{ }^{13} \mathrm{C}$ NMR $\left(100 \mathrm{MHz}, \mathrm{CDCl}_{3}\right) \delta 169.7,137.5,136.7,88.7,73.3,68.4,39.4,38.9,35.5,29.1,28.3,25.9,24.2$, 21.5, 19.2, 18.3, -4.6, -4.7 ppm; HRMS (ESI) $\mathrm{m} / \mathrm{z}$ calcd for $\mathrm{C}_{20} \mathrm{H}_{36} \mathrm{O}_{6} \mathrm{SSiNa}[\mathrm{M}+\mathrm{Na}]^{+} 455.1894$, found 455.1902

\section{Preparation of enone 18}<smiles>CO[C@H]1CCC(=O)C2=C[C@@H]([OH+])CC[C@@]21S</smiles>

18 
To a solution of enone $\mathbf{1 7}(6.48 \mathrm{~g}, 15.0 \mathrm{mmol})$ in $\mathrm{MeOH}(225 \mathrm{~mL})$ was added $\mathrm{K}_{2} \mathrm{CO}_{3}(3.11 \mathrm{~g}, 22.5$ mmol) at $0{ }^{\circ} \mathrm{C}$. The reaction was raised to $20^{\circ} \mathrm{C}$ and stirred overnight. Quench the reaction with saturated aqueous $\mathrm{NH}_{4} \mathrm{Cl}(50 \mathrm{~mL})$, and evaporate $\mathrm{MeOH}$ away in vacuo. The residue was diluted with EtOAc $(500 \mathrm{~mL})$, washed with water $(100 \mathrm{~mL} \times 2)$ and then brine $(100 \mathrm{~mL})$. The organic layer was dried over $\mathrm{Na}_{2} \mathrm{SO}_{4}$, filtered and concentrated. To a solution of the crude product and $\mathrm{NaHCO}_{3}(6.60 \mathrm{~g}, 78.5 \mathrm{mmol})$ in dry $\mathrm{CH}_{2} \mathrm{Cl}_{2}(340 \mathrm{~mL})$ was added DMP $(10.00 \mathrm{~g}, 23.5 \mathrm{mmol})$ at 0 ${ }^{\circ} \mathrm{C}$ under argon atmosphere. The reaction was kept stirring at $20{ }^{\circ} \mathrm{C}$ for about $0.5 \mathrm{~h}$, cooled to $0{ }^{\circ} \mathrm{C}$, and quenched by saturated aqueous $\mathrm{Na}_{2} \mathrm{~S}_{2} \mathrm{O}_{3}(50 \mathrm{~mL})$. The mixture was diluted with $\mathrm{CH}_{2} \mathrm{Cl}_{2}(250$ $\mathrm{mL})$, washed with water $(100 \mathrm{~mL} \times 2)$ and then brine $(100 \mathrm{~mL})$. The organic layer was dried over $\mathrm{Na}_{2} \mathrm{SO}_{4}$, filtered and concentrated. The residue was purified by column chromatography on silica gel (Hexanes/EtOAc 4:1) to give enone $18(5.53 \mathrm{~g}, 95 \%)$ as white solid: $R_{\mathrm{f}}=0.25$ (Hexanes/EtOAc 2:1); m.p.: 188.1-188.5 ${ }^{\circ} \mathrm{C}$; IR (film): $v=2953,2932,2858,1688,1626,1353$, $1178,1108,927,868,841,781,522 \mathrm{~cm}^{-1} ;{ }^{1} \mathrm{H}$ NMR $\left(400 \mathrm{MHz}, \mathrm{CDCl}_{3}\right) \delta 6.35(\mathrm{~s}, 1 \mathrm{H}), 4.74(\mathrm{dd}, J$ $=5.6,11.6 \mathrm{~Hz}, 1 \mathrm{H}), 4.31-4.27(\mathrm{~m}, 1 \mathrm{H}), 3.07(\mathrm{~s}, 3 \mathrm{H}), 2.65(\mathrm{ddd}, J=2.0,5.6,17.2 \mathrm{~Hz}, 1 \mathrm{H})$, 2.48-2.22 (m, 3H), 1.96-1.86 (m, 2H), 1.66-1.61 (m, 3H), $1.13(\mathrm{~s}, 3 \mathrm{H}), 0.89$ (s, 9H), $0.08(\mathrm{~s}, 3 \mathrm{H})$, $0.08 \mathrm{ppm}(\mathrm{s}, 3) ;{ }^{13} \mathrm{C} \mathrm{NMR}\left(100 \mathrm{MHz}, \mathrm{CDCl}_{3}\right) \delta 198.4,140.5,139.4,84.9,67.7,39.6,38.9,37.1$, 33.5, 27.7, 25.8, 25.6, 19.2, 18.2, -4.7, $-4.8 \mathrm{ppm}$; HRMS (ESI) $\mathrm{m} / z$ calcd for $\mathrm{C}_{18} \mathrm{H}_{33} \mathrm{O}_{5} \mathrm{SSi}[\mathrm{M}+\mathrm{H}]^{+}$ 389.1812, found 389.1807 .

\section{Preparation of cyclopropyl enone 19}

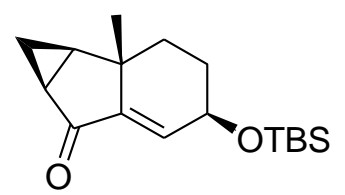

19

To a solution of enone $18(1.70 \mathrm{~g}, 4.4 \mathrm{mmol})$ in dry THF $(62 \mathrm{~mL})$ was added KHMDS (11.3 mL, $5.7 \mathrm{mmol}, 0.5 \mathrm{M}$ in toluene) slowly at $-78{ }^{\circ} \mathrm{C}$ under argon atmosphere. The temperature was raised slowly to $-5^{\circ} \mathrm{C}$, and the reaction was complete monitored by TLC (Hexanes/EtOAc 3:1). Cool the reaction to $-78{ }^{\circ} \mathrm{C}$ again, quench it using saturated aqueous $\mathrm{NH}_{4} \mathrm{Cl}(20 \mathrm{~mL})$, and evaporate THF away in vacuo. The residue was diluted with EtOAc $(200 \mathrm{~mL})$, washed with water $(50 \mathrm{~mL} \times$ 2) and then brine $(50 \mathrm{~mL})$. The organic layer was dried over $\mathrm{Na}_{2} \mathrm{SO}_{4}$, filtered and concentrated. 
The residue was purified by column chromatography on silica gel (Hexane/EtOAc 12:1) to give cyclopropyl enone 19 (1.15 g, 90\%) as white solid: $R_{\mathrm{f}}=0.75$ (Hexanes/EtOAc 3:1); m.p.: 53.6-54.2 ${ }^{\circ} \mathrm{C}$; IR (film): $v=2957,2930,2895,2857,1705,1635,1254,1210,1092,864,840,778$ $\mathrm{cm}^{-1} ;{ }^{1} \mathrm{H}$ NMR $\left(400 \mathrm{MHz}, \mathrm{CDCl}_{3}\right) \delta 6.17(\mathrm{~d}, J=5.2 \mathrm{~Hz}, 1 \mathrm{H}), 4.41(\mathrm{td}, J=5.2,7.2 \mathrm{~Hz}, 1 \mathrm{H})$, 2.04-1.85 (m, 4H), $1.75(\mathrm{dt}, J=4.8,7.6 \mathrm{~Hz}, 1 \mathrm{H}), 1.65(\mathrm{td}, J=4.8,12.8 \mathrm{~Hz}, 1 \mathrm{H}), 1.28$ (ddd, $J=5.6$, 7.6, $10.4 \mathrm{~Hz}, 1 \mathrm{H}), 1.19(\mathrm{~s}, 3 \mathrm{H}), 1.13-1.10(\mathrm{~m}, 1 \mathrm{H}), 0.87$ (s, 9H), 0.06 (s, 3H), $0.05 \mathrm{ppm}(\mathrm{s}, 3 \mathrm{H})$; ${ }^{13} \mathrm{C}$ NMR $\left(100 \mathrm{MHz}, \mathrm{CDCl}_{3}\right) \delta 202.7,149.9,130.8,66.8,38.9,36.4,30.1,29.8,29.2,25.8,23.6$, 18.1, 14.3, -4.5, -4.7 ppm; HRMS (ESI) $\mathrm{m} / z$ calcd for $\mathrm{C}_{17} \mathrm{H}_{29} \mathrm{O}_{2} \mathrm{Si}[\mathrm{M}+\mathrm{H}]^{+}$293.1931, found 293.1928.

\section{Synthesis of diene 21 and dienophiles $24 \& 26$}

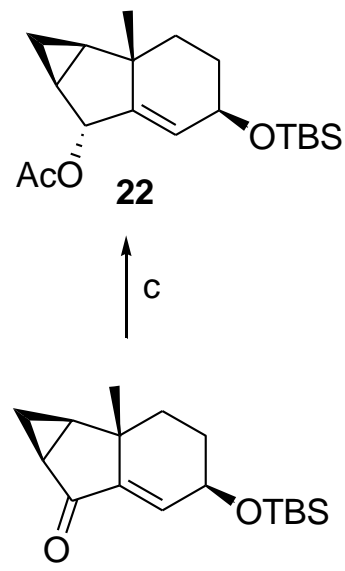

19
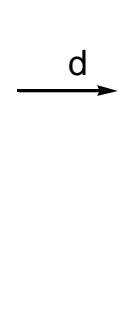

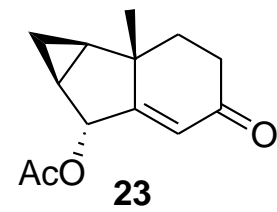

23

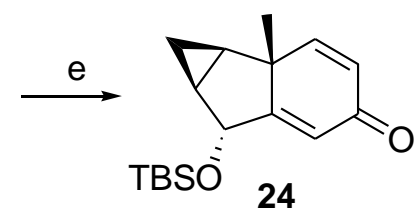

24

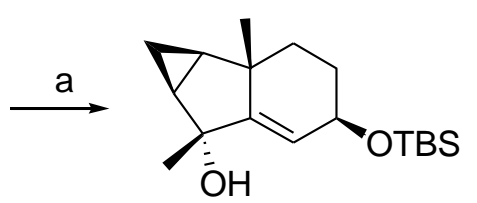

20

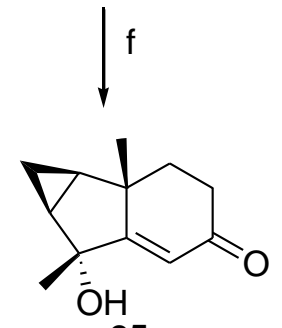

25

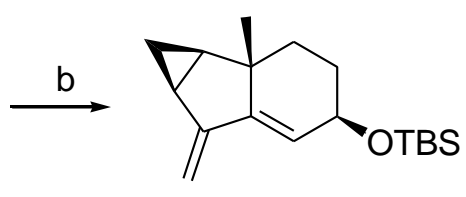

21

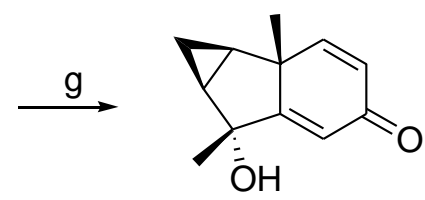

26

Reagents and conditions: a) MeLi, THF, $-100{ }^{\circ} \mathrm{C}, 89 \%$; b) Martin's sulfurane, $\mathrm{CH}_{2} \mathrm{Cl}_{2}, 0{ }^{\circ} \mathrm{C}, 96 \%$; c) (1) $\mathrm{NaBH}_{4}, \mathrm{CeCl}_{3} \cdot 7 \mathrm{H}_{2} \mathrm{O}, \mathrm{MeOH} 0$ ${ }^{\circ} \mathrm{C}$; (2) $\mathrm{Ac}_{2} \mathrm{O}$, Pyridine, DMAP, $\mathrm{CH}_{2} \mathrm{Cl}_{2}, 20{ }^{\circ} \mathrm{C}, 95 \%$; d) (1) $n$ - $\mathrm{Bu}_{4} \mathrm{NF}$, THF, $20{ }^{\circ} \mathrm{C}$; (2) Dess-Martin periodinane, $\mathrm{NaHCO}_{3}, \mathrm{CH}_{2} \mathrm{Cl}_{2}, 20{ }^{\circ} \mathrm{C}$, $91 \%$; e) (1) $\mathrm{K}_{2} \mathrm{CO}_{3}, \mathrm{MeOH}, 20^{\circ} \mathrm{C}$; (2) $t$ - $\mathrm{BuMe}_{2} \mathrm{SiOTf}_{3} \mathrm{Et}_{3} \mathrm{~N}, \mathrm{CH}_{2} \mathrm{Cl}_{2},-78{ }^{\circ} \mathrm{C}$; (3) $\mathrm{Pd}(\mathrm{OAc})_{2}, \mathrm{CH}_{3} \mathrm{CN}, 20{ }^{\circ} \mathrm{C}, 73 \%$; f) (1) $n$ - $\mathrm{Bu} 4 \mathrm{NF}, \mathrm{THF}$, $20{ }^{\circ} \mathrm{C}$; (2) Dess-Martin periodinane, $\mathrm{NaHCO}_{3}, \mathrm{CH}_{2} \mathrm{Cl}_{2}, 2{ }^{\circ} \mathrm{C}, 84 \%$; g) (1) $t$ - $\mathrm{BuMe}_{2} \mathrm{SiOTf}_{2} \mathrm{Et}_{3} \mathrm{~N}, \mathrm{CH}_{2} \mathrm{Cl}_{2},-78^{\circ} \mathrm{C}$; (2) $\mathrm{Pd}(\mathrm{OAc})_{2}, \mathrm{CH}_{3} \mathrm{CN}$, $20^{\circ} \mathrm{C}, 78 \%$. Martin's sulfurane $=$ bis[bis(trifluoromethyl)-phenylmethoxy]diphenylsulfurane, DMAP = 4-dimethylaminopyridine. 
Preparation of allylic alcohol 20

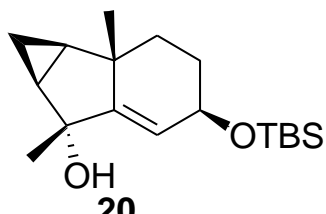

20

To a solution of cyclopropyl enone $19(58.8 \mathrm{mg}, 0.20 \mathrm{mmol})$ in dry THF $(2.5 \mathrm{~mL})$ was added $\operatorname{MeLi}\left(0.1 \mathrm{~mL}, 0.30 \mathrm{mmol}, 3 \mathrm{M}\right.$ in diethoxymethane) slowly at $-100{ }^{\circ} \mathrm{C}$ under argon atmosphere. The reaction was complete monitored by TLC (Hexane/EtOAc 8:1) after stirring at this temperature for about $30 \mathrm{~min}$. The reaction was quenched with saturated aqueous $\mathrm{NH}_{4} \mathrm{Cl}(5 \mathrm{~mL})$, diluted with EtOAc $(50 \mathrm{~mL})$, and washed with water $(10 \mathrm{~mL} \times 2)$ and then brine $(10 \mathrm{~mL})$. The organic layer was dried over $\mathrm{Na}_{2} \mathrm{SO}_{4}$, filtered and concentrated. The residue was purified by column chromatography on silica gel (Hexanes/EtOAc 12:1) to give allylic alcohol 20 (55.2 mg, 89\%) as white solid: $R_{\mathrm{f}}=0.40$ (Hexanes/EtOAc 8:1); m.p.: 109.5-110.0 ${ }^{\circ} \mathrm{C}$; IR (film): $v=3294$, 2956, 2930, 2856, 1252, 1085, 1074, 862, 835, $776 \mathrm{~cm}^{-1} ;{ }^{1} \mathrm{H}$ NMR $\left(400 \mathrm{MHz}, \mathrm{CDCl}_{3}\right) \delta 5.40(\mathrm{~d}, J$ $=3.6 \mathrm{~Hz}, 1 \mathrm{H}), 4.33(\mathrm{td}, J=4.0,8.0 \mathrm{~Hz}, 1 \mathrm{H}), 1.94(\mathrm{tt}, J=3.2,10.0 \mathrm{~Hz}, 1 \mathrm{H}), 1.85-1.75(\mathrm{~m}, 3 \mathrm{H})$, $1.71-1.62(\mathrm{~m}, 1 \mathrm{H}), 1.44(\mathrm{ddd}, J=4.0,7.6,8.4 \mathrm{~Hz}, 1 \mathrm{H}), 1.30(\mathrm{~s}, 3 \mathrm{H}), 1.23(\mathrm{td}, J=4.0,8.0 \mathrm{~Hz}, 1 \mathrm{H})$, 1.04 (s, 3H), 0.89 (s, 9H), 0.79-0.71 (m, 2H), $0.07 \mathrm{ppm}(\mathrm{s}, 6 \mathrm{H}) ;{ }^{13} \mathrm{C} \mathrm{NMR}\left(100 \mathrm{MHz}, \mathrm{CDCl}_{3}\right) \delta$ $164.1,118.4,78.5,68.2,39.0,38.8,30.3,30.3,28.3,26.5,26.0,24.0,18.3,13.2,-4.4,-4.4$ ppm; HRMS (EI) $m / z$ calcd for $\mathrm{C}_{18} \mathrm{H}_{32} \mathrm{O}_{2} \mathrm{Si}[\mathrm{M}]^{+}$308.2166, found 308.2174.

\section{Preparation of diene 21}

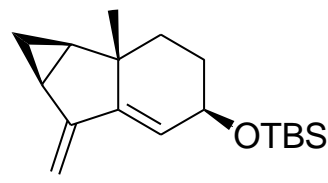

21

To a solution of allylic alcohol 20 (244 mg, $0.79 \mathrm{mmol})$ in dry $\mathrm{CH}_{2} \mathrm{Cl}_{2}(10 \mathrm{~mL})$ was added slowly a solution of Martin's sulfurane dehydrating reagent $(1.07 \mathrm{~g}, 1.58 \mathrm{mmol})$ in $\operatorname{dry} \mathrm{CH}_{2} \mathrm{Cl}_{2}(7 \mathrm{~mL})$ at $0{ }^{\circ} \mathrm{C}$ under argon atmosphere. After stirring at this temperature for about 30 min the reaction was complete monitored by TLC (Hexanes/EtOAc8:1). The reaction was quenched with saturated aqueous $\mathrm{NaHCO}_{3}(10 \mathrm{~mL})$, diluted with EtOAc $(100 \mathrm{~mL})$, and washed with water $(20 \mathrm{~mL} \times 2)$ and then brine $(20 \mathrm{~mL})$. The organic layer was dried over $\mathrm{Na}_{2} \mathrm{SO}_{4}$, filtered and concentrated. The 
residue was purified by column chromatography on silica gel (Hexanes/EtOAc 30:1) to give diene 21 (221 mg, 96\%) as colorless oil: $R_{\mathrm{f}}=0.80$ (Hexanes/EtOAc 8:1); IR (film): $v=3076$, 2954, 2929, 1633, 1472, 1462, 1255, 1078, 1028, 876, 856, 836, $774 \mathrm{~cm}^{-1} ;{ }^{1} \mathrm{H}$ NMR (400 MHz, $\left.\mathrm{C}_{6} \mathrm{D}_{6}\right) \delta 5.63(\mathrm{~d}, J=4.8 \mathrm{~Hz}, 1 \mathrm{H}), 5.30(\mathrm{~s}, 1 \mathrm{H}), 4.99(\mathrm{~s}, 1 \mathrm{H}), 4.36(\mathrm{td}, J=4.8,7.6 \mathrm{~Hz}, 1 \mathrm{H})$, 2.00-1.81 (m, 3H), $1.68(\mathrm{ddd}, J=3.2,4.4,12.8 \mathrm{~Hz}, 1 \mathrm{H}), 1.60(\mathrm{td}, J=5.2,12.8 \mathrm{~Hz}, 1 \mathrm{H}), 1.17(\mathrm{td}, J$ $=4.0,8.0 \mathrm{~Hz}, 1 \mathrm{H}), 1.06(\mathrm{~s}, 3 \mathrm{H}), 0.99(\mathrm{~s}, 9 \mathrm{H}), 0.78-0.74(\mathrm{~m}, 1 \mathrm{H}), 0.71(\mathrm{td}, J=4.8,8.0 \mathrm{~Hz}, 1 \mathrm{H})$, 0.09 ppm (s, 6H); ${ }^{13} \mathrm{C}$ NMR (100 MHz, $\left.\mathrm{C}_{6} \mathrm{D}_{6}\right) \delta$ 155.5, 150.9, 119.8, 104.3, 67.9, 39.9, 38.2, 30.6, 29.8, 26.2, 23.7, 18.4, 16.9, 1.4, -4.1, $-4.3 \mathrm{ppm}$; HRMS (EI) $\mathrm{m} / \mathrm{z}$ calcd for $\mathrm{C}_{18} \mathrm{H}_{30} \mathrm{OSi}[\mathrm{M}]^{+}$ 290.2060, found 290.2061 .

\section{Preparation of compound 22}

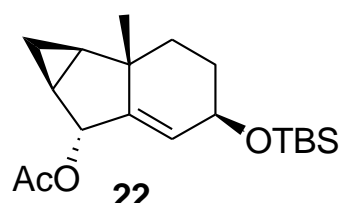

To a solution of cyclopropyl 19 (190 mg, $0.65 \mathrm{mmol})$ and $\mathrm{CeCl}_{3} \cdot 7 \mathrm{H}_{2} \mathrm{O}(291 \mathrm{mg}, 0.78 \mathrm{mmol})$ in $\mathrm{MeOH}(5 \mathrm{~mL})$ was added $\mathrm{NaBH}_{4}(30 \mathrm{mg}, 0.78 \mathrm{mmol})$ at $0{ }^{\circ} \mathrm{C}$. The reaction was stirred at this temperature for about $30 \mathrm{~min}$, quenched with saturated aqueous $\mathrm{NH}_{4} \mathrm{Cl}(10 \mathrm{~mL})$, and evaporated in vacuo. The residue was diluted with EtOAc $(100 \mathrm{~mL})$, washed with water $(30 \mathrm{~mL} \times 2)$ and then brine $(30 \mathrm{~mL})$. The organic layer was dried over $\mathrm{Na}_{2} \mathrm{SO}_{4}$, filtered and concentrated. To a solution of the crude product in dry $\mathrm{CH}_{2} \mathrm{Cl}_{2}(3 \mathrm{~mL})$ and pyridine $(1 \mathrm{~mL})$ was added $\mathrm{Ac}_{2} \mathrm{O}(92 \mu \mathrm{L}, 0.98$ mmol) and DMAP (16 mg, $0.13 \mathrm{mmol})$ at $0{ }^{\circ} \mathrm{C}$ under argon atmosphere. The reaction was stirred for about $1.5 \mathrm{~h}$ at $20{ }^{\circ} \mathrm{C}$, quenched with ice, diluted with EtOAc $(100 \mathrm{~mL})$, and washed with saturated aqueous $\mathrm{NH}_{4} \mathrm{Cl}(20 \mathrm{~mL} \times 2)$, water $(20 \mathrm{~mL})$ and then brine $(20 \mathrm{~mL})$. The organic layer was dried over $\mathrm{Na}_{2} \mathrm{SO}_{4}$, filtered and concentrated. The residue was purified by column chromatography on silica gel (Hexanes/EtOAc 12:1) to give compound 22 (207 $\mathrm{mg}, 95 \%$ ) as colorless oil: $R_{\mathrm{f}}=0.80$ (Hexanes/EtOAc 3:1); IR (film): $v=2957,2929,2856,1740,1463,1456$, 1259, 1237, 1082, 873, $798 \mathrm{~cm}^{-1} ;{ }^{1} \mathrm{H}$ NMR (400 MHz, $\left.\mathrm{CDCl}_{3}\right) \delta 5.17(\mathrm{~s}, 1 \mathrm{H}), 5.08(\mathrm{~d}, J=1.6 \mathrm{~Hz}$, 1H), 4.37-4.35 (m, 1H), $2.14(\mathrm{~s}, 3 \mathrm{H}), 1.98-1.93(\mathrm{~m}, 1 \mathrm{H}), 1.86-1.69(\mathrm{~m}, 3 \mathrm{H}), 1.35-1.30(\mathrm{~m}, 1 \mathrm{H})$, $1.24(\mathrm{td}, J=4.0,8.0 \mathrm{~Hz}, 1 \mathrm{H}), 0.98(\mathrm{~s}, 3 \mathrm{H}), 0.91-0.87(\mathrm{~m}, 1 \mathrm{H}), 0.89(\mathrm{~s}, 9 \mathrm{H}), 0.81-0.78(\mathrm{~m}, 1 \mathrm{H})$,

0.07 ppm (s, 6H); ${ }^{13} \mathrm{C}$ NMR (100 MHz, $\left.\mathrm{CDCl}_{3}\right) \delta 170.4,153.9,118.4,75.3,68.2,37.6,37.3,30.3$, 
29.0, 26.0, 22.6, 22.5, 21.1, 18.2, 14.6, -4.4, -4.4 ppm; HRMS (ESI) $\mathrm{m} / z$ calcd for $\mathrm{C}_{19} \mathrm{H}_{32} \mathrm{O}_{3} \mathrm{SiNa}$ $[\mathrm{M}+\mathrm{Na}]^{+}$359.2013, found 359.2029.

\section{Preparation of enone 23}

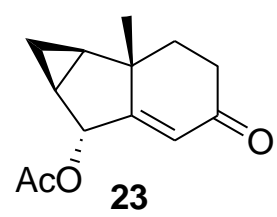

To a solution of compound $22(190 \mathrm{mg}, 0.57 \mathrm{mmol})$ in THF $(3.0 \mathrm{~mL})$ was added TBAF $(0.5 \mathrm{~mL}, 1$ $\mathrm{M}$ in THF) at $20{ }^{\circ} \mathrm{C}$. The reaction was stirred overnight, diluted with EtOAc $(100 \mathrm{~mL})$, washed with water $(20 \mathrm{~mL} \times 2)$, and then brine $(20 \mathrm{~mL})$. The organic layer was dried over $\mathrm{Na}_{2} \mathrm{SO}_{4}$, filtered and concentrated. To a solution of the crude product and $\mathrm{NaHCO}_{3}(240 \mathrm{mg}, 2.83 \mathrm{mmol})$ in dry $\mathrm{CH}_{2} \mathrm{Cl}_{2}(12 \mathrm{~mL})$ was added DMP $(360 \mathrm{mg}, 0.85 \mathrm{mmol})$ at $0{ }^{\circ} \mathrm{C}$ under argon atmosphere. The reaction was kept stirring at $20{ }^{\circ} \mathrm{C}$ for about $0.5 \mathrm{~h}$, cooled to $0{ }^{\circ} \mathrm{C}$, and quenched by saturated aqueous $\mathrm{Na}_{2} \mathrm{~S}_{2} \mathrm{O}_{3}(10 \mathrm{~mL})$. The mixture was diluted with $\mathrm{CH}_{2} \mathrm{Cl}_{2}(100 \mathrm{~mL})$, washed with water $(20 \mathrm{~mL} \times 2)$ and then brine $(20 \mathrm{~mL})$. The organic layer was dried over $\mathrm{Na}_{2} \mathrm{SO}_{4}$, filtered and concentrated. The residue was purified by column chromatography on silica gel (Hexanes/EtOAc 5:1) to give enone $\mathbf{2 3}(113 \mathrm{mg}, 91 \%)$ as colorless oil: $R_{\mathrm{f}}=0.30$ (Hexanes/EtOAc 3:1); IR (film): $v=2929,2865,1743,1676,1666,1464,1456,1233,1046,873,800 \mathrm{~cm}^{-1} ;{ }^{1} \mathrm{H}$ NMR $(400 \mathrm{MHz}$, $\left.\mathrm{CDCl}_{3}\right) \delta 5.61(\mathrm{~d}, J=1.6 \mathrm{~Hz}, 1 \mathrm{H}), 5.37(\mathrm{~s}, 1 \mathrm{H}), 2.61(\mathrm{dq}, J=6.4,18.8 \mathrm{~Hz}, 1 \mathrm{H}), 2.47-2.41(\mathrm{~m}, 1 \mathrm{H})$, 2.23-2.15 (m, 2H), $2.14(\mathrm{~s}, 3 \mathrm{H}), 1.57-1.52(\mathrm{~m}, 1 \mathrm{H}), 1.43(\mathrm{td}, J=4.0,8.0 \mathrm{~Hz}, 1 \mathrm{H}), 1.12(\mathrm{~s}, 3 \mathrm{H})$, $1.03(\mathrm{td}, J=6.0,8.8 \mathrm{~Hz}, 1 \mathrm{H}), 0.83 \mathrm{ppm}(\mathrm{dt}, J=4.0,6.0 \mathrm{~Hz}, 1 \mathrm{H}) ;{ }^{13} \mathrm{C} \mathrm{NMR}\left(100 \mathrm{MHz}, \mathrm{CDCl}_{3}\right) \delta$ 198.5, 177.4, 170.2, 118.9, 75.3, 39.3, 37.5, 34.1, 28.9, 22.2, 21.1, 20.9, 14.2 ppm; HRMS (ESI) $m / z$ calcd for $\mathrm{C}_{13} \mathrm{H}_{17} \mathrm{O}_{3}[\mathrm{M}+\mathrm{H}]^{+}$221.1172, found 221.1169.

\section{Preparation of dienophile 24}

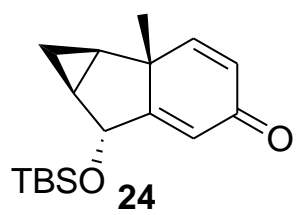

To a solution enone $23(134 \mathrm{mg}, 0.61 \mathrm{mmol})$ in $\mathrm{MeOH}(9 \mathrm{~mL})$ was added $\mathrm{K}_{2} \mathrm{CO}_{3}(126 \mathrm{mg}, 0.91$ mmol) at $0{ }^{\circ} \mathrm{C}$. The reaction was raised to $20^{\circ} \mathrm{C}$ and stirred at this temperature for about $1 \mathrm{~h}$. The 
reaction was complete monitored by TLC (Hexanes/EtOAc 2:1). Quench the reaction with saturated aqueous $\mathrm{NH}_{4} \mathrm{Cl}(10 \mathrm{~mL})$, and evaporate $\mathrm{MeOH}$ out in vacuo. The residue was diluted with EtOAc $(100 \mathrm{~mL})$, washed with water $(20 \mathrm{~mL} \times 2)$ and then brine $(20 \mathrm{~mL})$. The organic layer was dried over $\mathrm{Na}_{2} \mathrm{SO}_{4}$, filtered and concentrated. To a solution of the crude product in dry $\mathrm{CH}_{2} \mathrm{Cl}_{2}(12 \mathrm{~mL})$ was added $\mathrm{Et}_{3} \mathrm{~N}(320 \mu \mathrm{L}, 2.44 \mathrm{mmol})$ and TBSOTf ( $\left.330 \mu \mathrm{L}, 1.53 \mathrm{mmol}\right)$ at -78 ${ }^{\circ} \mathrm{C}$ under argon atmosphere. The temperature was raised slowly and the reaction was complete at $-30{ }^{\circ} \mathrm{C}$ monitored by TLC (Hexanes/EtOAc 2:1). The reaction was quenched with saturated aqueous $\mathrm{NaHCO}_{3}(10 \mathrm{~mL})$, diluted with with EtOAc $(100 \mathrm{~mL})$, washed with water $(20 \mathrm{~mL} \times 2)$ and then brine $(20 \mathrm{~mL})$. The organic layer was dried over $\mathrm{Na}_{2} \mathrm{SO}_{4}$, filtered and concentrated. To a solution of the crude product in $\mathrm{CH}_{3} \mathrm{CN}(10 \mathrm{~mL})$ was added $\mathrm{Pd}(\mathrm{OAc})_{2}(205 \mathrm{mg}, 0.91 \mathrm{mmol})$ at 20 ${ }^{\circ} \mathrm{C}$. The reaction was kept stirring at this temperature overnight, cooled to $0{ }^{\circ} \mathrm{C}$ and quenched with saturated aqueous $\mathrm{Na}_{2} \mathrm{~S}_{2} \mathrm{O}_{3}(10 \mathrm{~mL})$. The reaction was diluted with EtOAc $(100 \mathrm{~mL})$, washed with saturated aqueous $\mathrm{Na}_{2} \mathrm{~S}_{2} \mathrm{O}_{3}(20 \mathrm{~mL} \times 2)$, water $(20 \mathrm{~mL})$ and brine $(20 \mathrm{~mL})$. The organic layer was dried over $\mathrm{Na}_{2} \mathrm{SO}_{4}$, filtered and concentrated. The residue was purified by column chromatography on silica gel (Hexane/EtOAc10:1) to give dienophile 24 (129 mg, 73\%) as colorless oil: $R_{\mathrm{f}}=0.55$ (Hexanes/EtOAc 3:1); IR (film): $v=3041,3001,2955,2930,2886,2858$, 2360, 1670, 1641, 1472, 1464, 1380, 1260, 1146, 856, 839, 777, 702, $669 \mathrm{~cm}^{-1} ;{ }^{1} \mathrm{H}$ NMR (400 $\left.\mathrm{MHz}, \mathrm{CDCl}_{3}\right) \delta 7.10(\mathrm{~d}, J=1.6 \mathrm{~Hz}, 1 \mathrm{H}), 6.15(\mathrm{dd}, J=1.6,9.6 \mathrm{~Hz}, 1 \mathrm{H}), 5.95(\mathrm{t}, J=1.6 \mathrm{~Hz}, 1 \mathrm{H})$, 4.39 (t, $J=1.6 \mathrm{~Hz}, 1 \mathrm{H}), 1.60$ (tdd, $J=1.6,4.0,8.4 \mathrm{~Hz}, 1 \mathrm{H}), 1.47$ (td, $J=4.0,8.0 \mathrm{~Hz}, 1 \mathrm{H}), 1.10$ (s, $3 \mathrm{H}), 1.03(\mathrm{td}, J=6.0,8.4 \mathrm{~Hz}, 1 \mathrm{H}), 0.95(\mathrm{~s}, 9 \mathrm{H}), 0.90(\mathrm{dt}, J=4.0,6.0 \mathrm{~Hz}, 1 \mathrm{H}), 0.15 \mathrm{ppm}(\mathrm{s}, 6 \mathrm{H})$;

${ }^{13} \mathrm{C} \mathrm{NMR}\left(100 \mathrm{MHz}, \mathrm{CDCl}_{3}\right) \delta 186.8,179.5,154.0,127.6,116.2,74.6,41.5,26.1,25.8,25.3,22.5$, 18.3, 14.8, -4.9, -5.0 ppm; HRMS (ESI) $\mathrm{m} / 2$ calcd for $\mathrm{C}_{17} \mathrm{H}_{27} \mathrm{O}_{2} \mathrm{Si}[\mathrm{M}+\mathrm{H}]^{+} 291.1775$, found 291.1766.

\section{Preparation of enone 25}

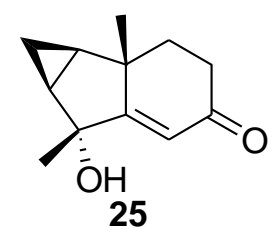

To a solution of compound $\mathbf{2 0}(40 \mathrm{mg}, 0.13 \mathrm{mmol})$ in THF $(1.0 \mathrm{~mL})$ was added TBAF $(0.2 \mathrm{~mL}, 1$ 
$M$ in THF) at $20^{\circ} \mathrm{C}$. The reaction was stirred overnight, diluted with EtOAc $(50 \mathrm{~mL})$, washed with water $(10 \mathrm{~mL} \times 2)$, and then brine $(10 \mathrm{~mL})$. The organic layer was dried over $\mathrm{Na}_{2} \mathrm{SO}_{4}$, filtered and concentrated. To a solution of the crude product and $\mathrm{NaHCO}_{3}(55 \mathrm{mg}, 0.65 \mathrm{mmol})$ in dry $\mathrm{CH}_{2} \mathrm{Cl}_{2}$ $(5 \mathrm{~mL})$ was added DMP $(85 \mathrm{mg}, 0.20 \mathrm{mmol})$ at $0{ }^{\circ} \mathrm{C}$ under argon atmosphere. The reaction was kept stirring at $20{ }^{\circ} \mathrm{C}$ for about $0.5 \mathrm{~h}$, cooled to $0{ }^{\circ} \mathrm{C}$, and quenched by saturated aqueous $\mathrm{Na}_{2} \mathrm{~S}_{2} \mathrm{O}_{3}$ (5 mL). The mixture was diluted with $\mathrm{CH}_{2} \mathrm{Cl}_{2}(50 \mathrm{~mL})$, washed with water $(10 \mathrm{~mL} \times 2)$ and then brine $(10 \mathrm{~mL})$. The organic layer was dried over $\mathrm{Na}_{2} \mathrm{SO}_{4}$, filtered and concentrated. The residue was purified by column chromatography on silica gel (Hexanes/EtOAc 1:1) to give enone 25 (21 $\mathrm{mg}, 84 \%)$ as white solid : $R_{\mathrm{f}}=0.40\left(\right.$ Hexanes/EtOAc 2:3); ${ }^{1} \mathrm{H}$ NMR $\left(400 \mathrm{MHz}, \mathrm{CDCl}_{3}\right) \delta 5.80(\mathrm{~s}$, $1 \mathrm{H}), 2.61-2.52(\mathrm{~m}, 2 \mathrm{H}), 2.41-2.35(\mathrm{~m}, 1 \mathrm{H}), 2.15-2.07(\mathrm{~m}, 2 \mathrm{H}), 1.64(\mathrm{ddd}, J=4.0,7.2,8.8 \mathrm{~Hz}, 1 \mathrm{H})$, $1.40(\mathrm{td}, J=4.0,7.8 \mathrm{~Hz}, 1 \mathrm{H}), 1.35(\mathrm{~s}, 3 \mathrm{H}), 1.11(\mathrm{~s}, 3 \mathrm{H}), 0.89-0.81(\mathrm{~m}, 2 \mathrm{H}) \mathrm{ppm} ;{ }^{13} \mathrm{C}$ NMR $(100$ $\left.\mathrm{MHz}, \mathrm{CDCl}_{3}\right) \delta 199.7,187.5,118.6,79.1,40.5,37.9,34.2,30.0,28.0,26.3,22.4,12.8 \mathrm{ppm} ;$ HRMS (ESI) $m / z$ calcd for $\mathrm{C}_{12} \mathrm{H}_{17} \mathrm{O}_{2}[\mathrm{M}+\mathrm{H}]^{+} 193.1223$, found 193.1215 .

\section{Preparation of dienophile 26}

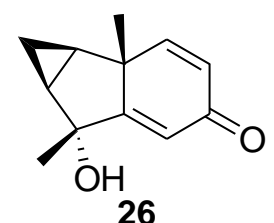

To a solution of enone $25(21 \mathrm{mg}, 0.11 \mathrm{mmol})$ in dry $\mathrm{CH}_{2} \mathrm{Cl}_{2}(2.0 \mathrm{~mL})$ was added $\mathrm{Et}_{3} \mathrm{~N}(38 \mu \mathrm{L}$, $0.27 \mathrm{mmol})$ and TBSOTf $(28 \mu \mathrm{L}, 0.13 \mathrm{mmol})$ at $-78{ }^{\circ} \mathrm{C}$ under argon atmosphere. The temperature was raised slowly and the reaction was complete monitored by TLC (Hexanes/EtOAc 2:3). The reaction was quenched with saturated aqueous $\mathrm{NaHCO}_{3}(5 \mathrm{~mL})$, diluted with with EtOAc $(50 \mathrm{~mL})$, washed with water $(10 \mathrm{~mL} \times 2)$ and then brine $(10 \mathrm{~mL})$. The organic layer was dried over $\mathrm{Na}_{2} \mathrm{SO}_{4}$, filtered and concentrated. To a solution of the crude product in $\mathrm{CH}_{3} \mathrm{CN}(2 \mathrm{~mL})$ was added $\mathrm{Pd}(\mathrm{OAc})_{2}(37 \mathrm{mg}, 0.16 \mathrm{mmol})$ at $20{ }^{\circ} \mathrm{C}$. The reaction was kept stirring at this temperature overnight, cooled to $0{ }^{\circ} \mathrm{C}$ and quenched with saturated aqueous $\mathrm{Na}_{2} \mathrm{~S}_{2} \mathrm{O}_{3}(5 \mathrm{~mL})$. The reaction was diluted with EtOAc $(50 \mathrm{~mL})$, washed with saturated aqueous $\mathrm{Na}_{2} \mathrm{~S}_{2} \mathrm{O}_{3}(10 \mathrm{~mL} \times 2)$, water $(10 \mathrm{~mL})$ and brine $(10 \mathrm{~mL})$. The organic layer was dried over $\mathrm{Na}_{2} \mathrm{SO}_{4}$, filtered and concentrated. The residue was purified by column chromatography on silica gel (Hexanes/EtOAc 1:1) to give 
dienophile 26 (16 mg, 78\%) as white solid : $R_{\mathrm{f}}=0.50$ (Hexanes/EtOAc 2:3); ${ }^{1} \mathrm{H}$ NMR (400 MHz, MeOD) $\delta 7.36(\mathrm{~d}, J=9.6 \mathrm{~Hz}, 1 \mathrm{H}), 6.09(\mathrm{dd}, J=1.6,9.6 \mathrm{~Hz}, 1 \mathrm{H}), 5.99(\mathrm{~d}, J=1.6 \mathrm{~Hz}, 1 \mathrm{H})$, 1.72-1.67 (m, 1H), $1.64(\mathrm{td}, J=3.6,7.8 \mathrm{~Hz}, 1 \mathrm{H}), 1.43(\mathrm{~s}, 3 \mathrm{H}), 1.22(\mathrm{~s}, 3 \mathrm{H}), 1.11(\mathrm{dt}, J=4.0,6.4$ $\mathrm{Hz}, 1 \mathrm{H}), 0.96(\mathrm{td}, J=6.8,8.8 \mathrm{~Hz}, 1 \mathrm{H}) \mathrm{ppm} ;{ }^{13} \mathrm{C} \mathrm{NMR}(100 \mathrm{MHz}, \mathrm{MeOD}) \delta 189.4,187.7,158.5$, 127.2, 118.5, 78.6, 45.7, 32.2, 28.3, 25.7, 22.6, $13.3 \mathrm{ppm}$; HRMS (ESI) $\mathrm{m} / \mathrm{z}$ calcd for $\mathrm{C}_{12} \mathrm{H}_{15} \mathrm{O}_{2}$ $[\mathrm{M}+\mathrm{H}]^{+}$191.1067, found 191.1065.

Synthesis of the Heptacyclic Cores 27 and 28 via endo-Diels-Alder Cycloaddition (Revised)

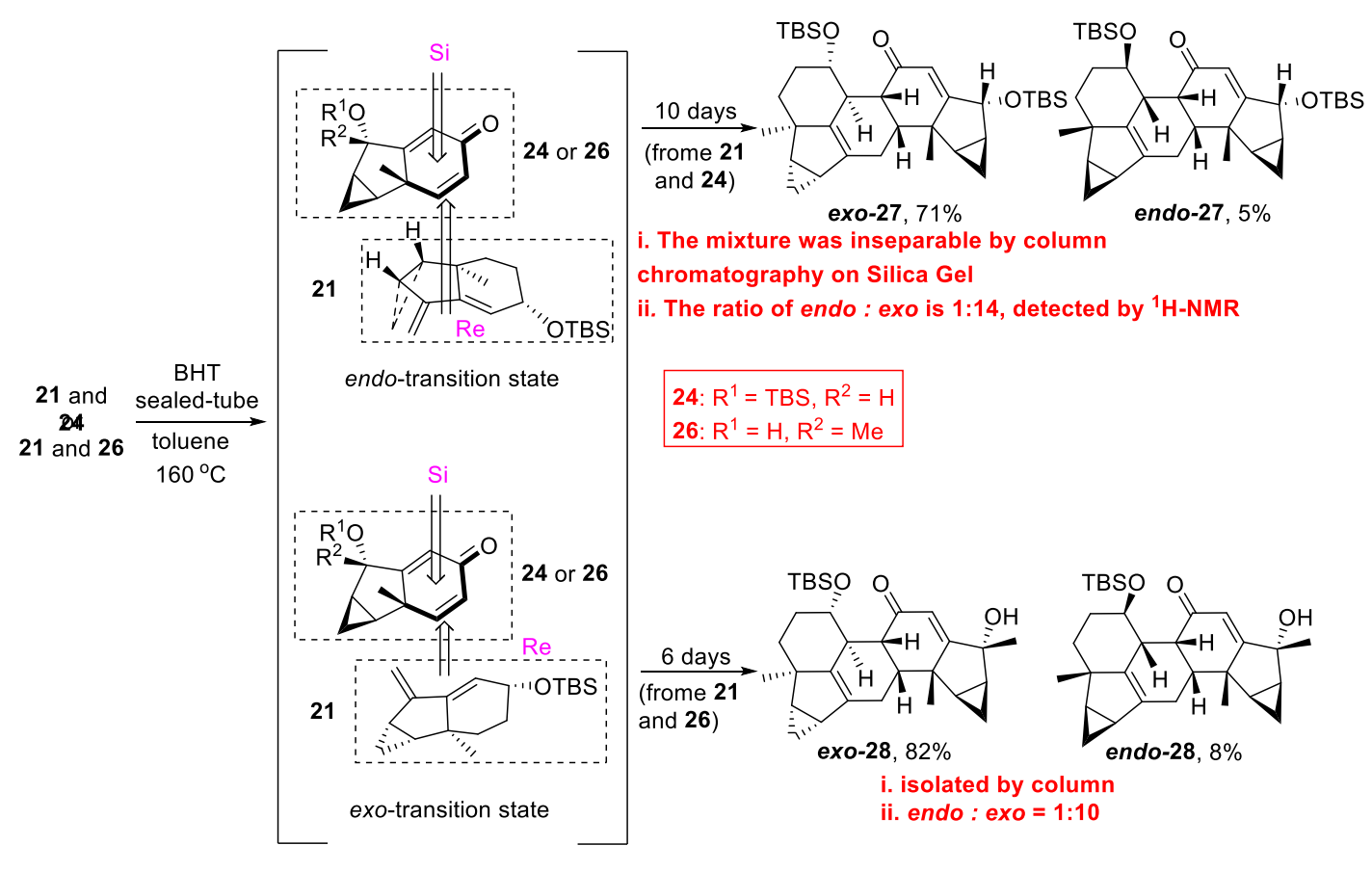

Reagents and conditions: a) BHT, toluene, $160^{\circ} \mathrm{C}$, sealed-tube, $10 \mathrm{~d}, 76 \%$ (92\% BRSM, $d r=14: 1$ ); b) BHT, toluene, $160^{\circ} \mathrm{C}$, sealed-tube, $6 \mathrm{~d}, 90 \%(d r=10: 1) \mathrm{BHT}=$ butylated hydroxy-toluene. 


\section{Preparation of the inseparable heptacyclic key cores exo-27 and endo-27}

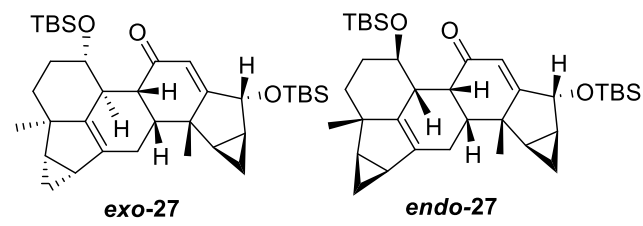

Inseparable mixture with the endo/exo ratio of 1:14
A solution of diene 21 (29.5mg, $0.102 \mathrm{mmol})$, dienophile 24 (13.2 $\mathrm{mg}, 0.0455 \mathrm{mmol})$ and BHT (22.5 $\mathrm{mg}, 1.02 \mathrm{mmol})$ in toluene $(1.5 \mathrm{~mL})$ under argon atmosphere was heated to $160{ }^{\circ} \mathrm{C}$ in a

sealed-tube for 10 day. The reaction mixture was purified by column chromatography on silica gel (Hexanes/EtOAc 30:1) to give the inseparable heptacyclic key cores endo- 27 and exo-27 (20.3 mg, 76\%, 92\% BRSM, $d r=14: 1$ (exo:endo) detected from ${ }^{1} \mathrm{H}-\mathrm{NMR}$ ) as a yellow solid: $R_{\mathrm{f}}=0.60$ (Hexanes/EtOAc 8:1); IR (film): $v=2957,2931,2858,2372,2346,1664,1461,1259,1135$, 1084, 856, 836, $778 \mathrm{~cm}^{-1} ;{ }^{1} \mathrm{H}$ NMR $\left(400 \mathrm{MHz}, \mathrm{C}_{6} \mathrm{D}_{6}\right) \delta 6.11(\mathrm{~d}, J=2.0 \mathrm{~Hz}, 1 \mathrm{H}), 4.23(\mathrm{~s}, 1 \mathrm{H})$, 3.47-3.39 (m, 2H), $3.33(\mathrm{~d}, J=4.0 \mathrm{~Hz}, 1 \mathrm{H}), 2.37(\mathrm{dd}, J=7.2,16.4 \mathrm{~Hz}, 1 \mathrm{H}), 2.26-2.21(\mathrm{~m}, 1 \mathrm{H})$, $2.09(\mathrm{dd}, J=5.2,16.4 \mathrm{~Hz}, 1 \mathrm{H}), 1.97-1.84(\mathrm{~m}, 2 \mathrm{H}), 1.52-1.46(\mathrm{~m}, 1 \mathrm{H}), 1.43-1.34(\mathrm{~m}, 2 \mathrm{H})$, $1.33-1.27(\mathrm{~m}, 2 \mathrm{H}), 1.22-1.18(\mathrm{~m}, 1 \mathrm{H}), 1.16(\mathrm{~s}, 3 \mathrm{H}), 1.00(\mathrm{~s}, 9 \mathrm{~h}), 0.93(\mathrm{~s}, 9 \mathrm{H}), 0.65(\mathrm{td}, J=6.0,8.4$ $\mathrm{Hz}, 1 \mathrm{H}), 0.52(\mathrm{td}, J=4.0,7.6 \mathrm{~Hz}, 1 \mathrm{H}), 0.39(\mathrm{dd}, J=4.0,9.2 \mathrm{~Hz}), 0.14(\mathrm{~s}, 3 \mathrm{H}), 0.10(\mathrm{~s}, 3 \mathrm{H}), 0.08$ (s, 3H), 0.04 (s, 3H), 0.04-0.02 (m, 1H); ${ }^{13} \mathrm{C}$ NMR (100 MHz, $\left.\mathrm{C}_{6} \mathrm{D}_{6}\right) \delta$ 197.2, 176.5, 139.6, 135.3, $119.9,76.6,75.9,46.9,43.2,42.9,42.5,39.8,39.1,33.2,28.8,26.5,26.2,26.0,25.0,24.9,24.6$, 23.3, 20.9, 18.5, 18.3, 15.3, 14.6, -3.1, -4.2, -4.7, -4.9; HRMS (EI) $\mathrm{m} / 2$ calcd for $\mathrm{C}_{35} \mathrm{H}_{56} \mathrm{O}_{3} \mathrm{Si}_{2}[\mathrm{M}]^{+}$ 580.3763 , found 580.3761 .

\section{Preparation of the heptacyclic key core exo-28 and endo-28}

A solution of diene 21 (62 mg, $0.213 \mathrm{mmol})$, dienophile 27 (16 mg, $0.085 \mathrm{mmol})$ and BHT (47 mg, $0.213 \mathrm{mmol})$ in toluene $(2.5 \mathrm{~mL})$ under argon atmosphere was heated at $160{ }^{\circ} \mathrm{C}$ in a sealed-tube for 6 day. The reaction mixture was purified by column chromatography on silica gel (Hexanes/EtOAc 10:1) to give the endo-down Diels-Alder cycloaddition product exo-28 (33 mg, $82 \%)$ as a white solid and the endo-28 (3 $\mathrm{mg}, 8 \%)$ as a white solid:

Exo-28: $R_{\mathrm{f}}=0.40\left(\right.$ Hexanes/EtOAc3:1); ${ }^{1} \mathrm{H}$ NMR $\left(400 \mathrm{MHz}, \mathrm{CDCl}_{3}\right) \delta 5.81(\mathrm{~s}, 1 \mathrm{H}), 3.32(\operatorname{td}, J=$ 4.8, $10.0 \mathrm{~Hz}, 1 \mathrm{H}), 3.10(\mathrm{~d}, J=4.0 \mathrm{~Hz}, 1 \mathrm{H}), 2.86(\mathrm{~d}, J=9.6 \mathrm{~Hz}, 1 \mathrm{H}), 2.38(\mathrm{dt}, J=5.2,10.4 \mathrm{~Hz}$, $1 \mathrm{H}), 2.29(\mathrm{dd}, J=5.6,17.2 \mathrm{~Hz}, 1 \mathrm{H}), 2.10-2.03(\mathrm{~m}, 2 \mathrm{H}), 1.84-1.70(\mathrm{~m}, 2 \mathrm{H}), 1.65-1.52(\mathrm{~m}, 3 \mathrm{H})$, $1.47(\mathrm{td}, J=2.8,6.6 \mathrm{~Hz}, 1 \mathrm{H}), 1.39-1.34(\mathrm{~m}, 1 \mathrm{H}), 1.36(\mathrm{~s}, 3 \mathrm{H}), 1.32-1.25(\mathrm{~m}, 1 \mathrm{H}), 1.28(\mathrm{~s}, 3 \mathrm{H})$, 


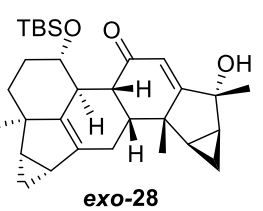

$1.09(\mathrm{~s}, 3 \mathrm{H}), 0.90-0.80(\mathrm{~m}, 3 \mathrm{H}), 0.85(\mathrm{~s}, 9 \mathrm{H}), 0.64(\mathrm{td}, J=4.0,7.6 \mathrm{~Hz}, 1 \mathrm{H})$, $0.06(\mathrm{~s}, 3 \mathrm{H}), 0.06-0.03(\mathrm{~m}, 1 \mathrm{H}), 0.03 \mathrm{ppm}(\mathrm{s}, 3 \mathrm{H}) ;{ }^{13} \mathrm{C}$ NMR $(100 \mathrm{MHz}$, $\left.\mathrm{CDCl}_{3}\right) \delta 199.3,182.4,139.3,134.8,119.6,79.2,75.4,46.6,44.8,42.3$, $42.2,39.4,38.6,32.6,30.2,28.3,26.5,25.8,25.5,24.6,24.4,24.3,20.6$,

17.9, 15.1, 12.6, -3.4, -4.5 ppm; HRMS (ESI) $\mathrm{m} / \mathrm{z}$ calcd for $\mathrm{C}_{30} \mathrm{H}_{44} \mathrm{O}_{3} \mathrm{SiNa}[\mathrm{M}+\mathrm{Na}]^{+}$503.2952, found 503.2978.

Endo-28: $R_{\mathrm{f}}=0.45\left(\right.$ Hexanes/EtOAc3:1); ${ }^{1} \mathrm{H}$ NMR $\left(400 \mathrm{MHz}, \mathrm{CDCl}_{3}\right) \delta 5.69(\mathrm{~s}, 1 \mathrm{H}), 5.10(\mathrm{dd}, \mathrm{J}$

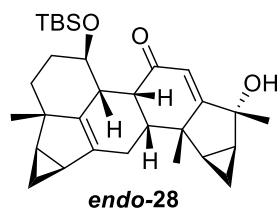
$=9.6,15.2 \mathrm{~Hz}, 1 \mathrm{H}), 3.25(\mathrm{~d}, \mathrm{~J}=5.6 \mathrm{~Hz}, 1 \mathrm{H}), 2.32-2.17(\mathrm{~m}, 3 \mathrm{H}), 2.02-1.98$ $(\mathrm{m}, 2 \mathrm{H}), 1.86-1.81(\mathrm{~m}, 2 \mathrm{H}), 1.71-1.56(\mathrm{~m}, 5 \mathrm{H}), 1.52-1.50(\mathrm{~m}, 3 \mathrm{H})$, 1.44-1.39 (m, 1H), $1.36(\mathrm{~s}, 3 \mathrm{H}), 1.30(\mathrm{~s}, 3 \mathrm{H}), 1.07(\mathrm{~s}, 3 \mathrm{H}), 0.89-0.85(\mathrm{~m}$, 2H), 0.85 (s, 9H), 0.67 (td, J = 4.4, 7.6 Hz, 1H), 0.42-0.41 (m, 1H), 0.10 (s, 3H), -0.10 ppm (s, 3H); ${ }^{13} \mathrm{C}$ NMR $\left(100 \mathrm{MHz}, \mathrm{CDCl}_{3}\right) \delta 200.4,179.2,142.7,133.8,120.3,78.6,71.8,50.8,45.4,45.2,44.3$, $42.2,35.1,32.6,30.1,29.2,26.3,26.0,25.6,25.0,24.4,24.3,23.5,18.1,14.6,13.2,-4.3,-4.6 \mathrm{ppm}$; HRMS (ESI) $m / z$ calcd for $\mathrm{C}_{30} \mathrm{H}_{44} \mathrm{O}_{3} \mathrm{SiNa}[\mathrm{M}+\mathrm{Na}]^{+} 503.2952$, found 503.2974. 


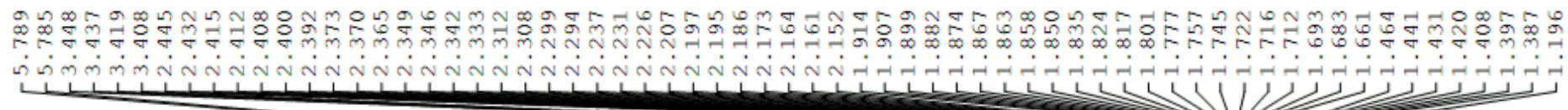

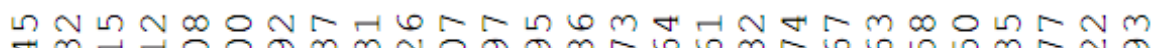

$\forall m$

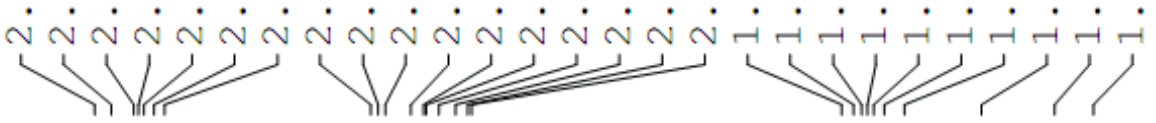<smiles>CC12CCC(=O)C=C1CC(O)CC2</smiles>

11a
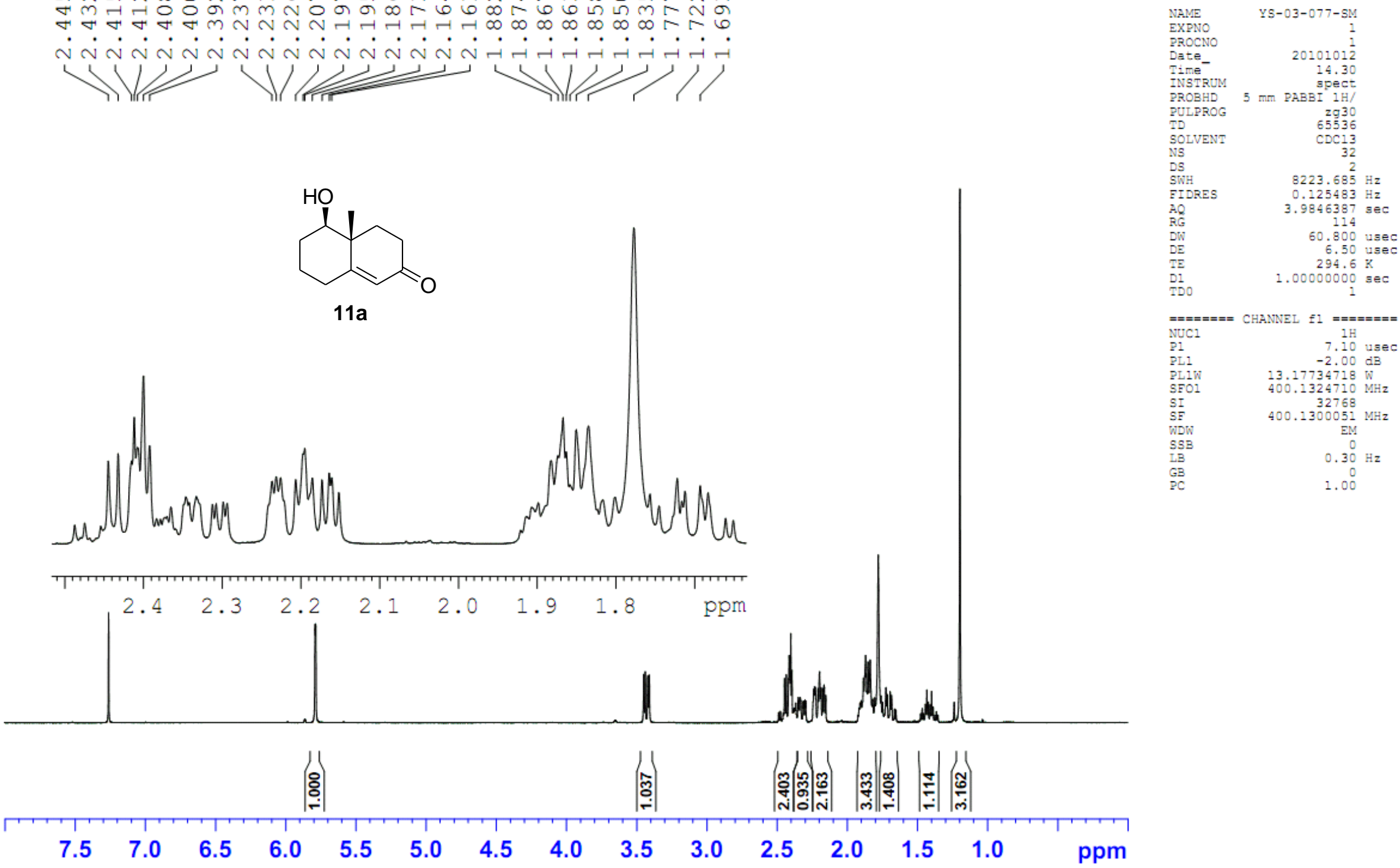


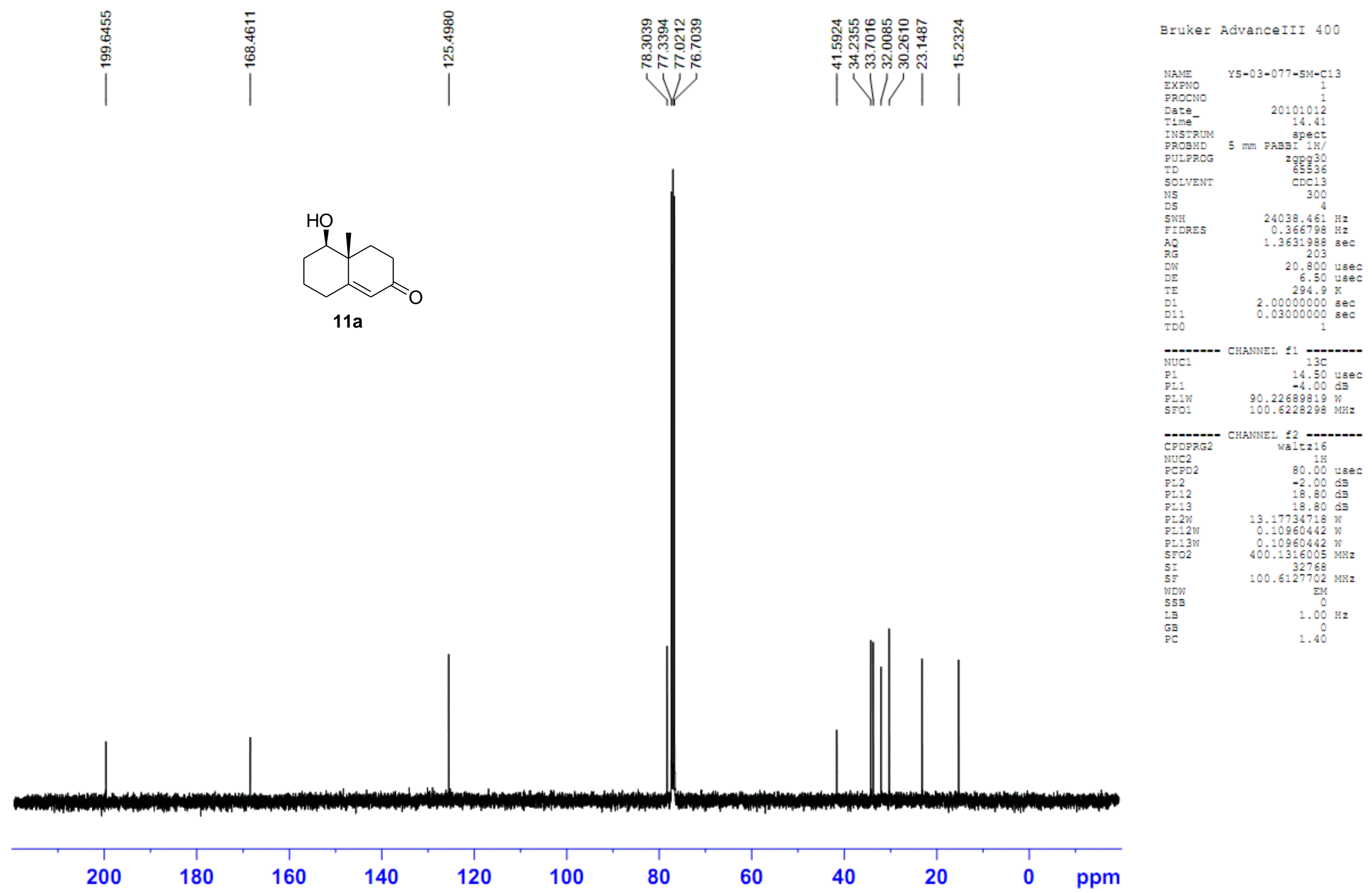




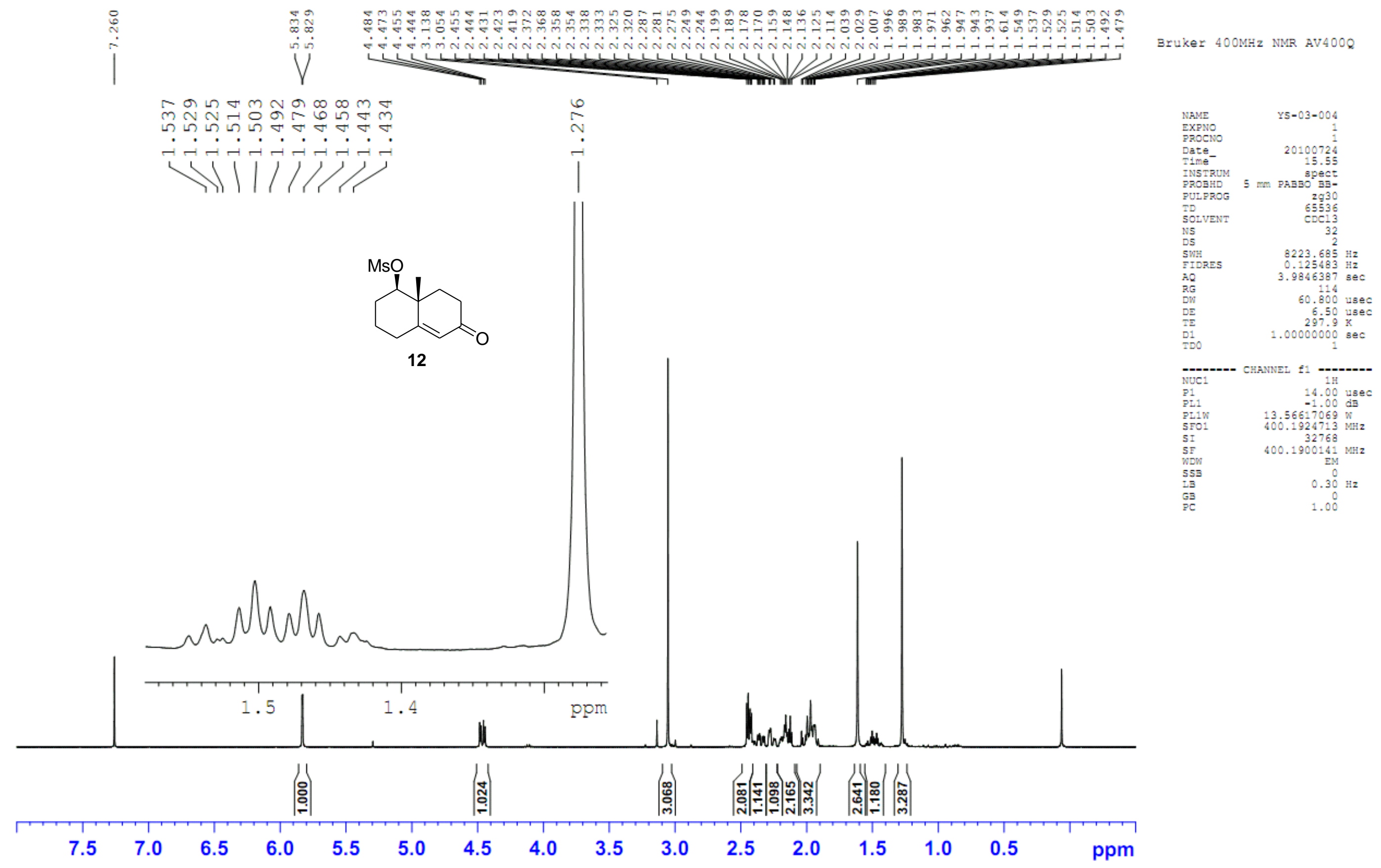




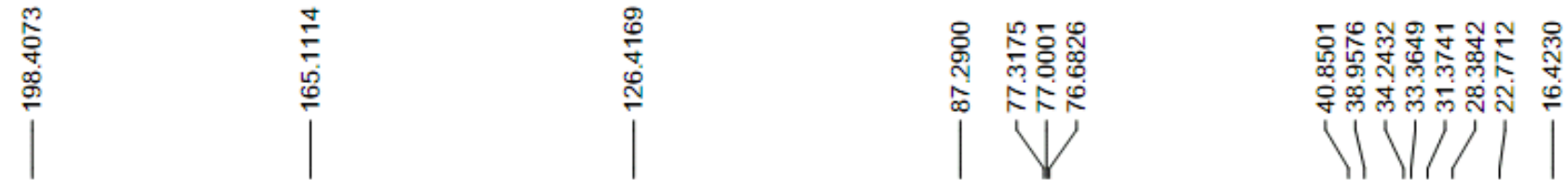

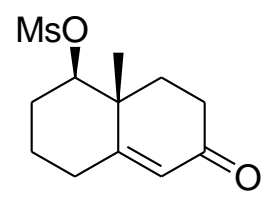

12

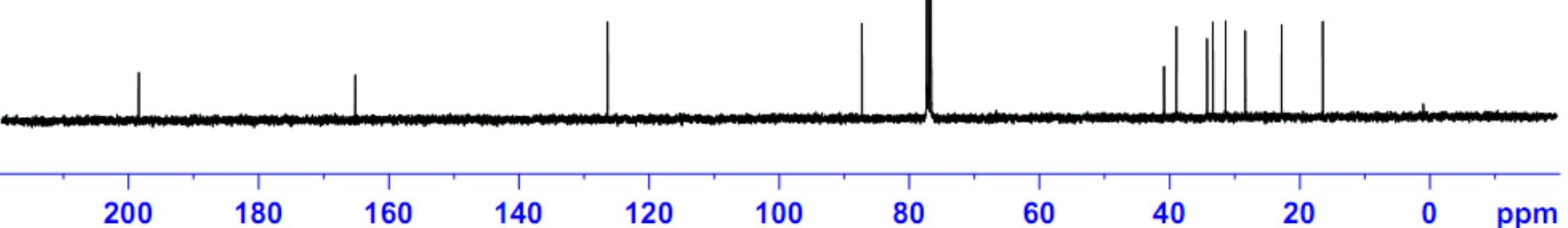




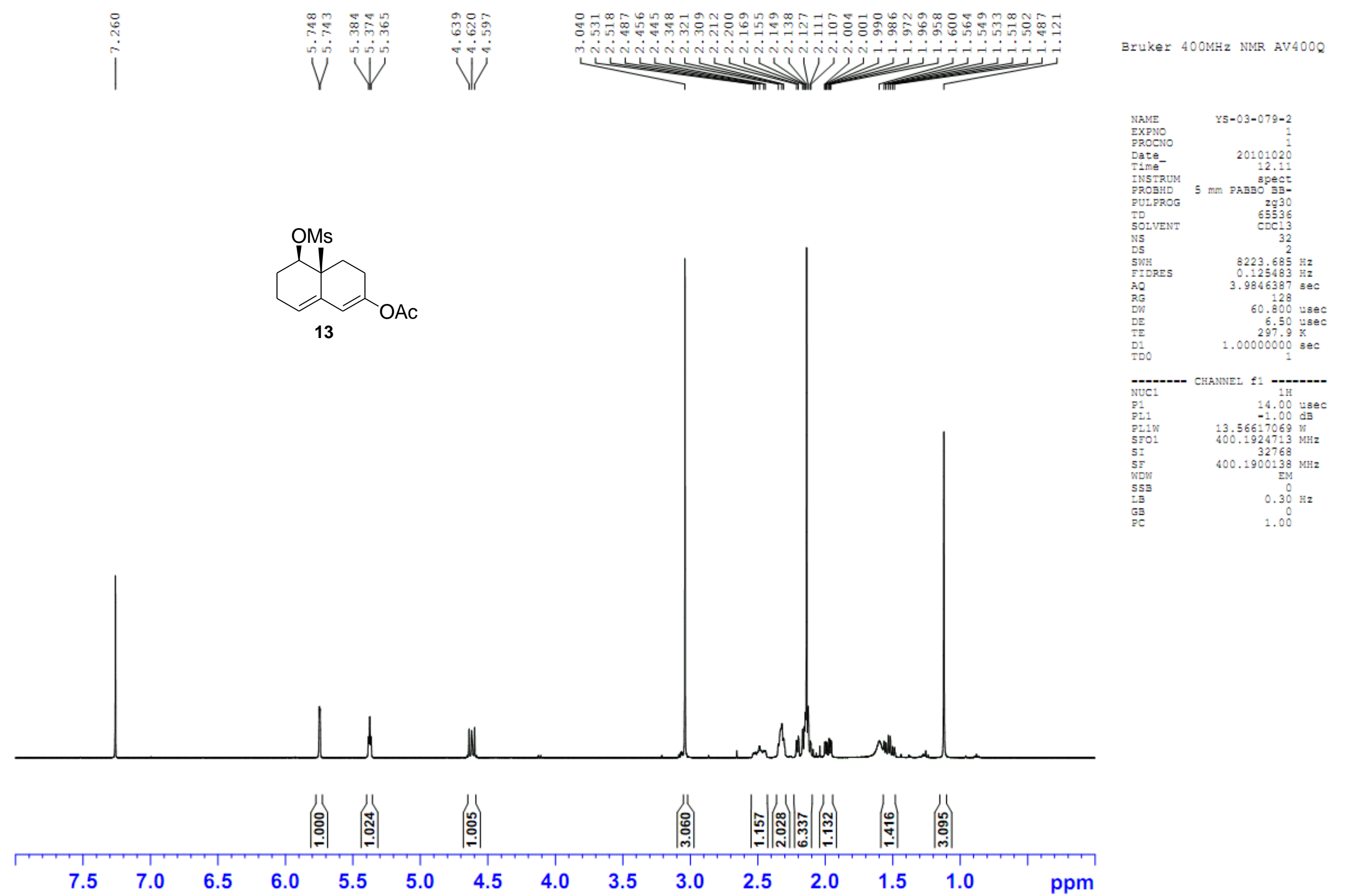




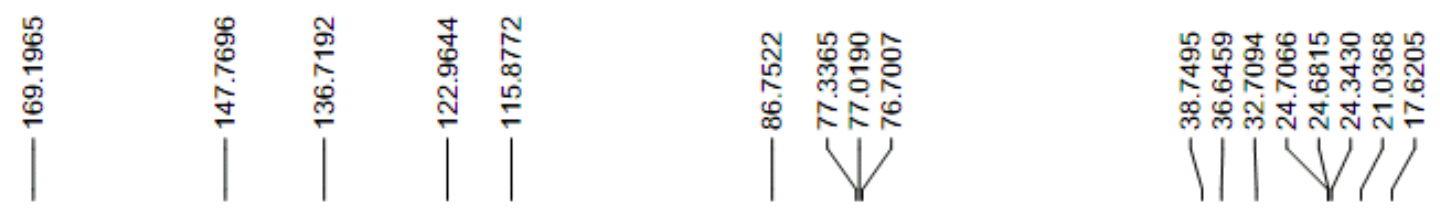
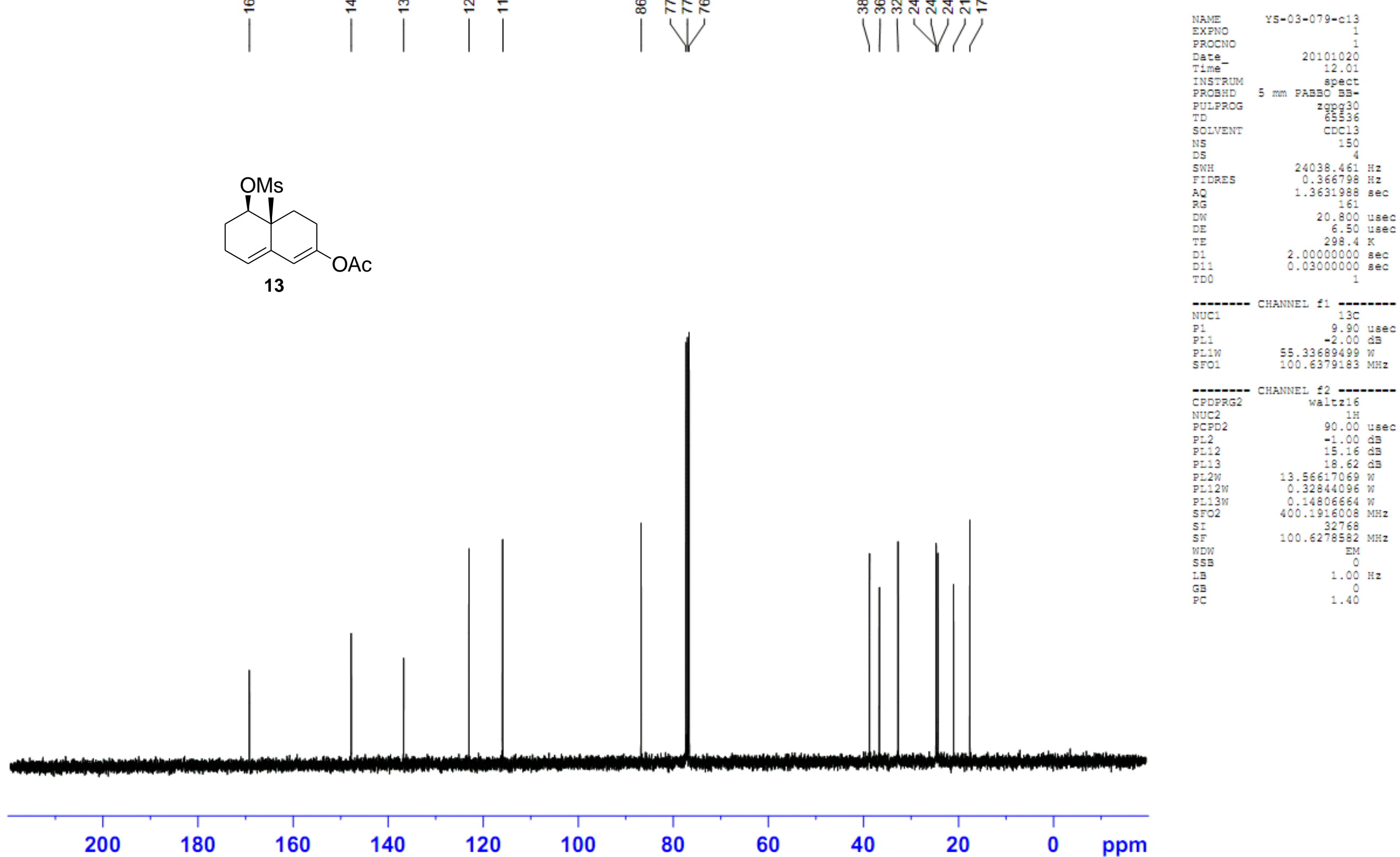


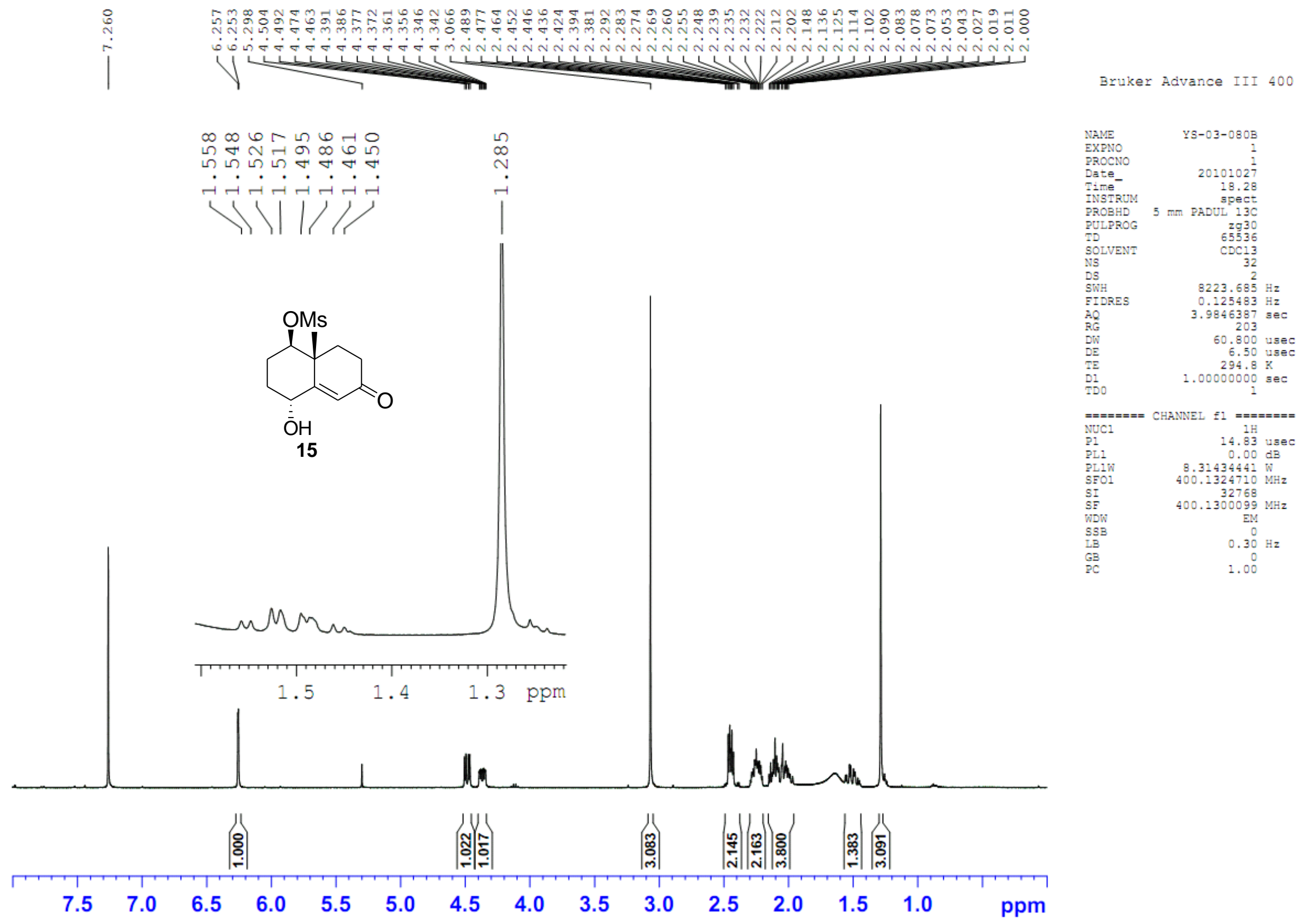




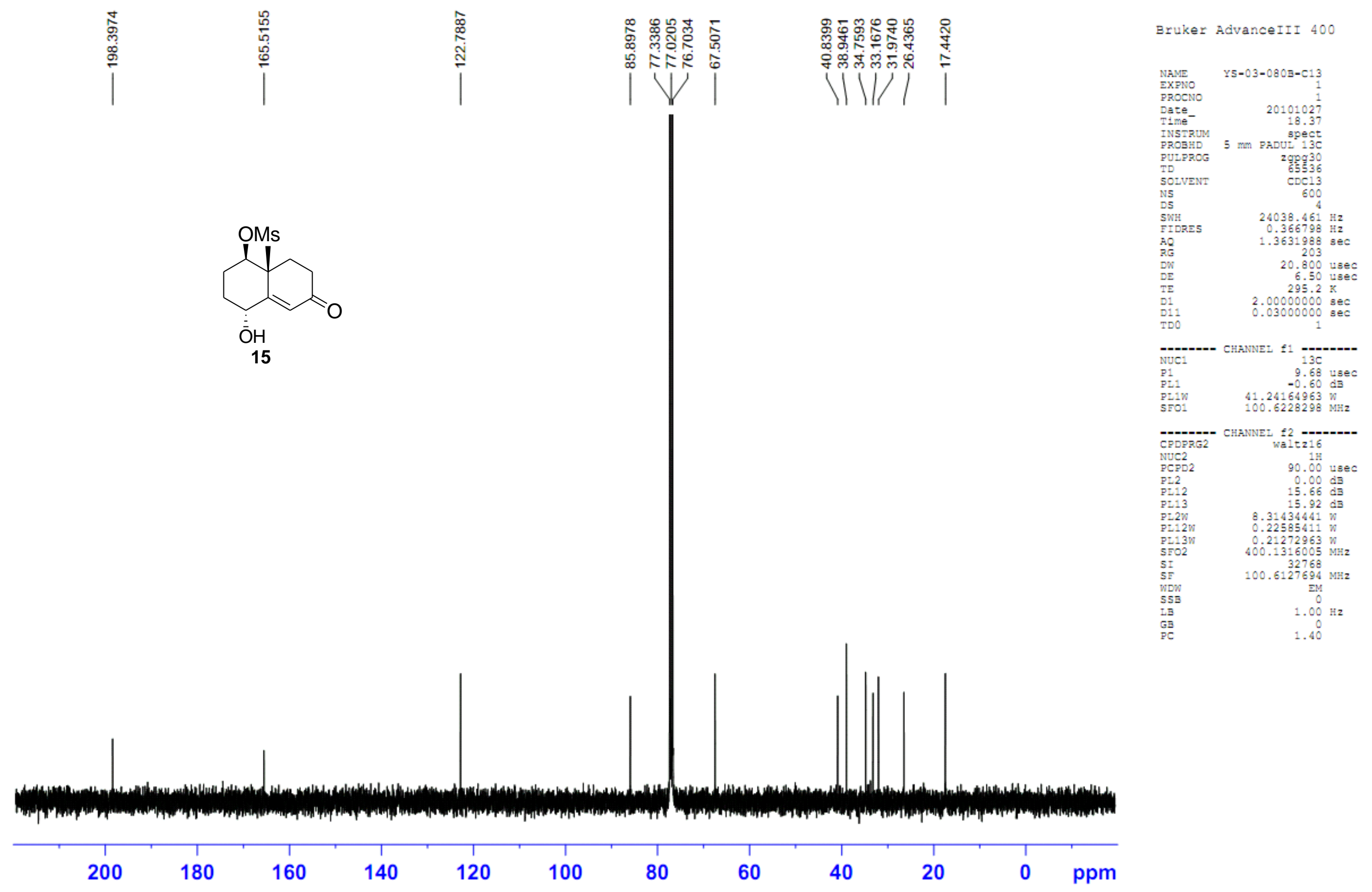




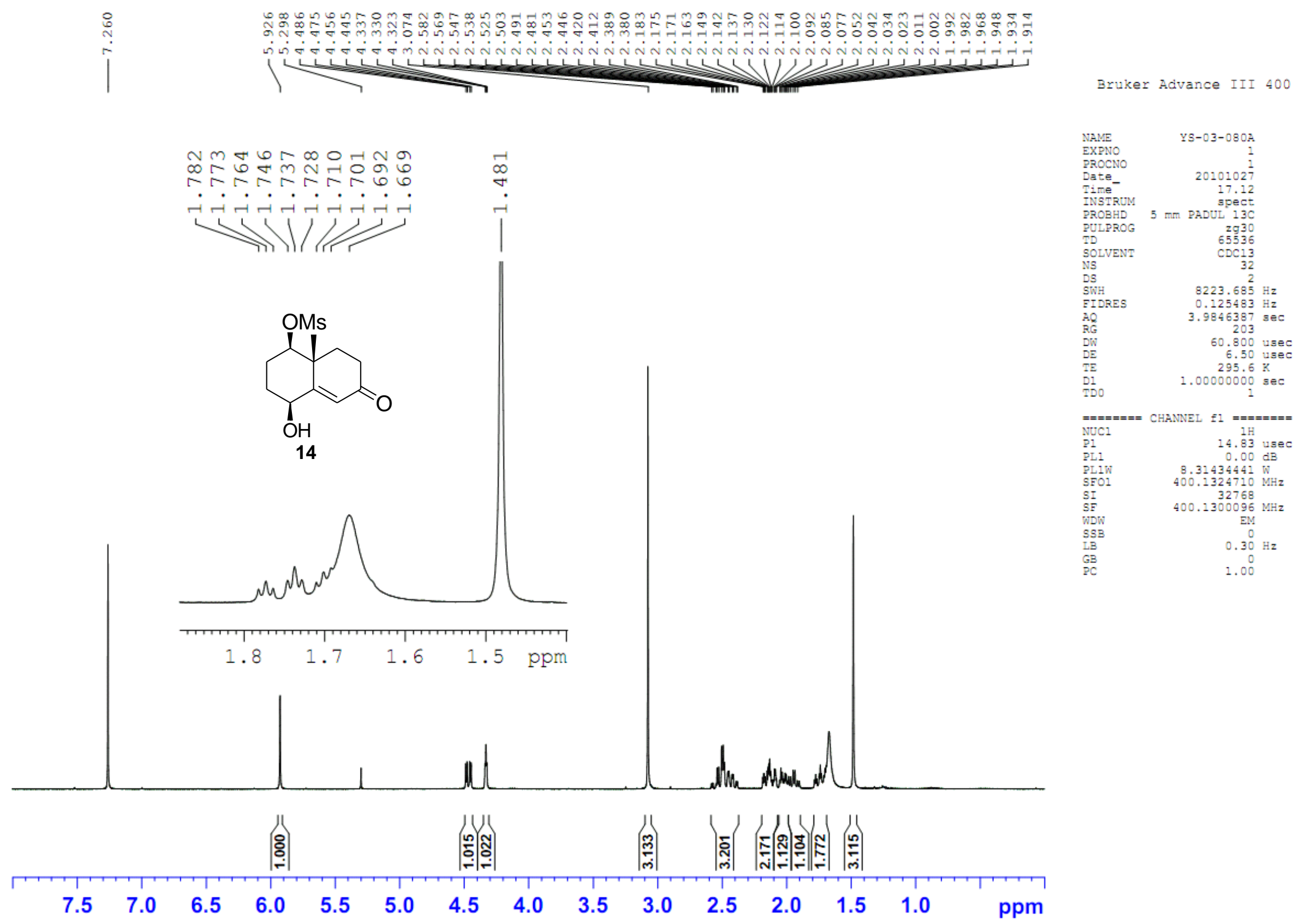




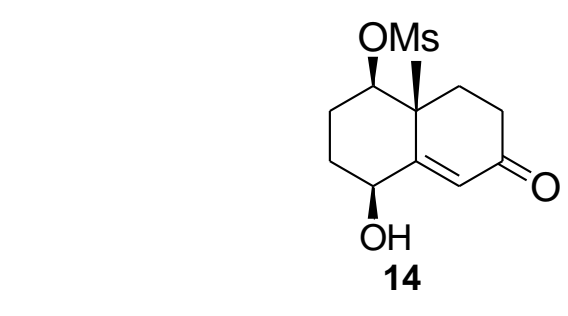

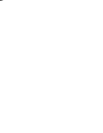
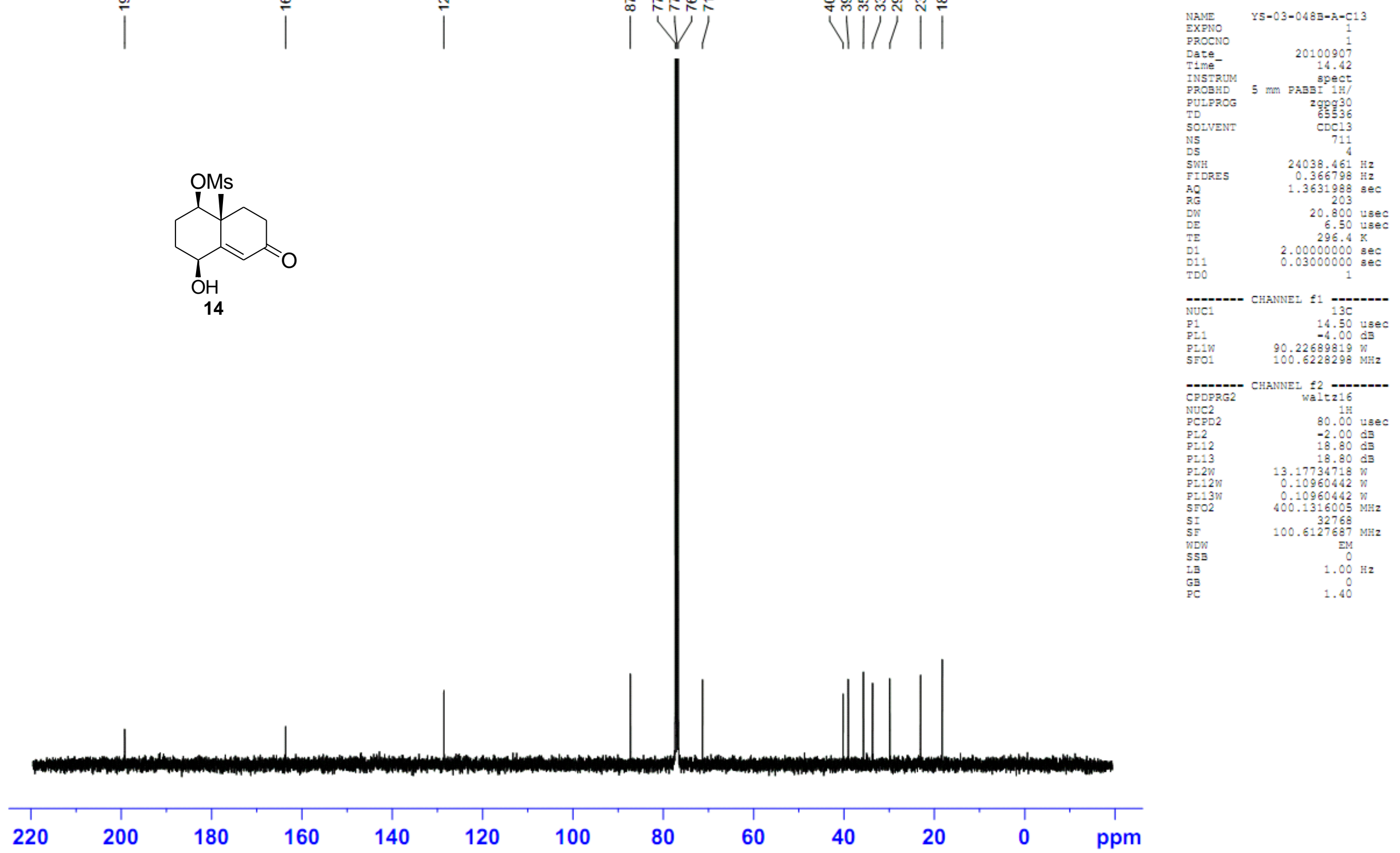


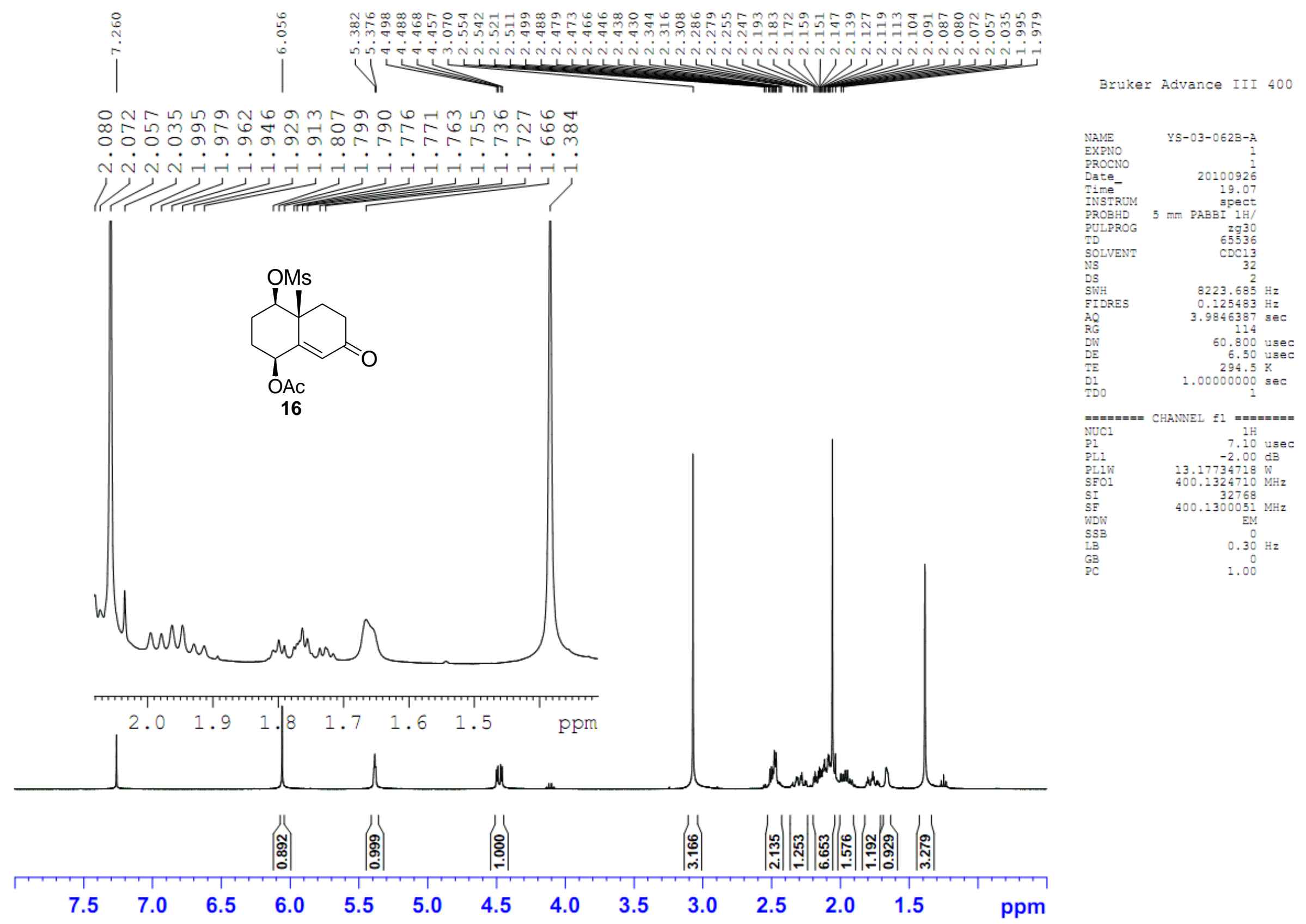




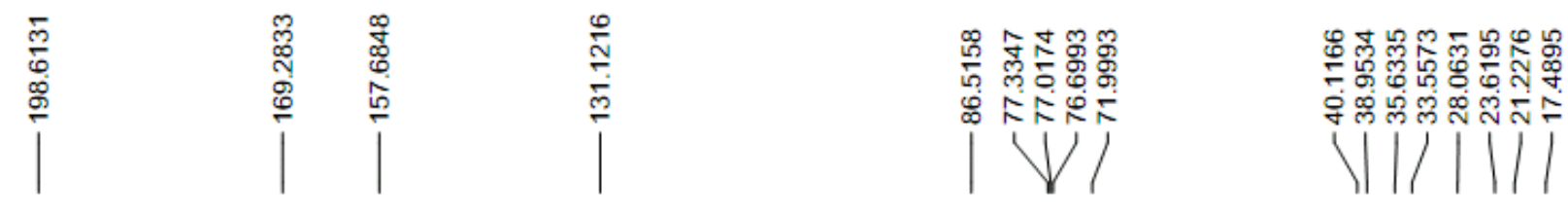
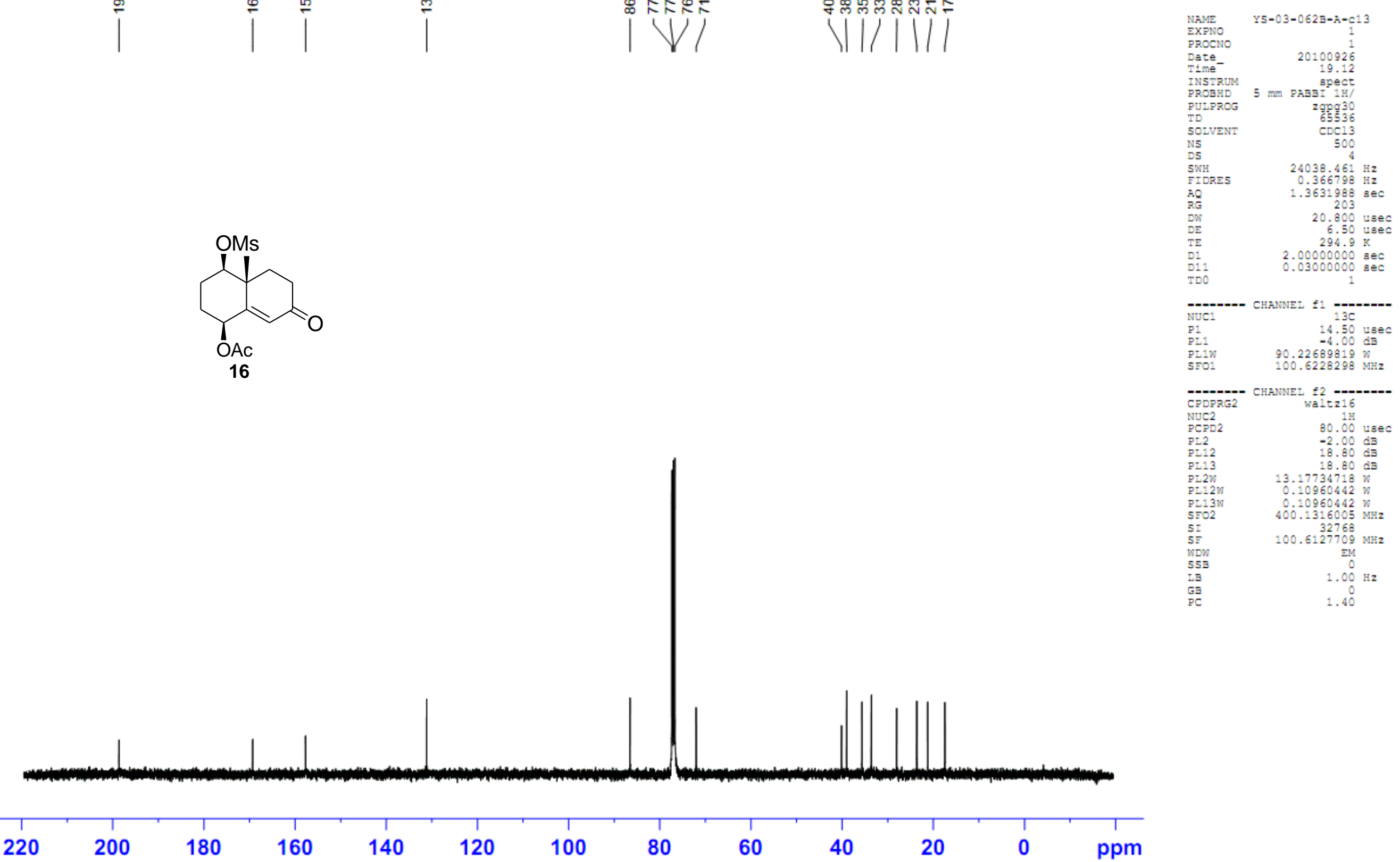
Bruker Advance III 400

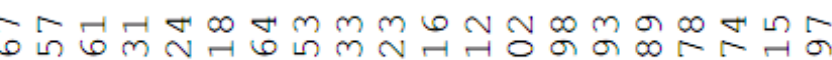

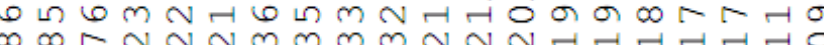

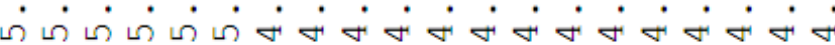

|
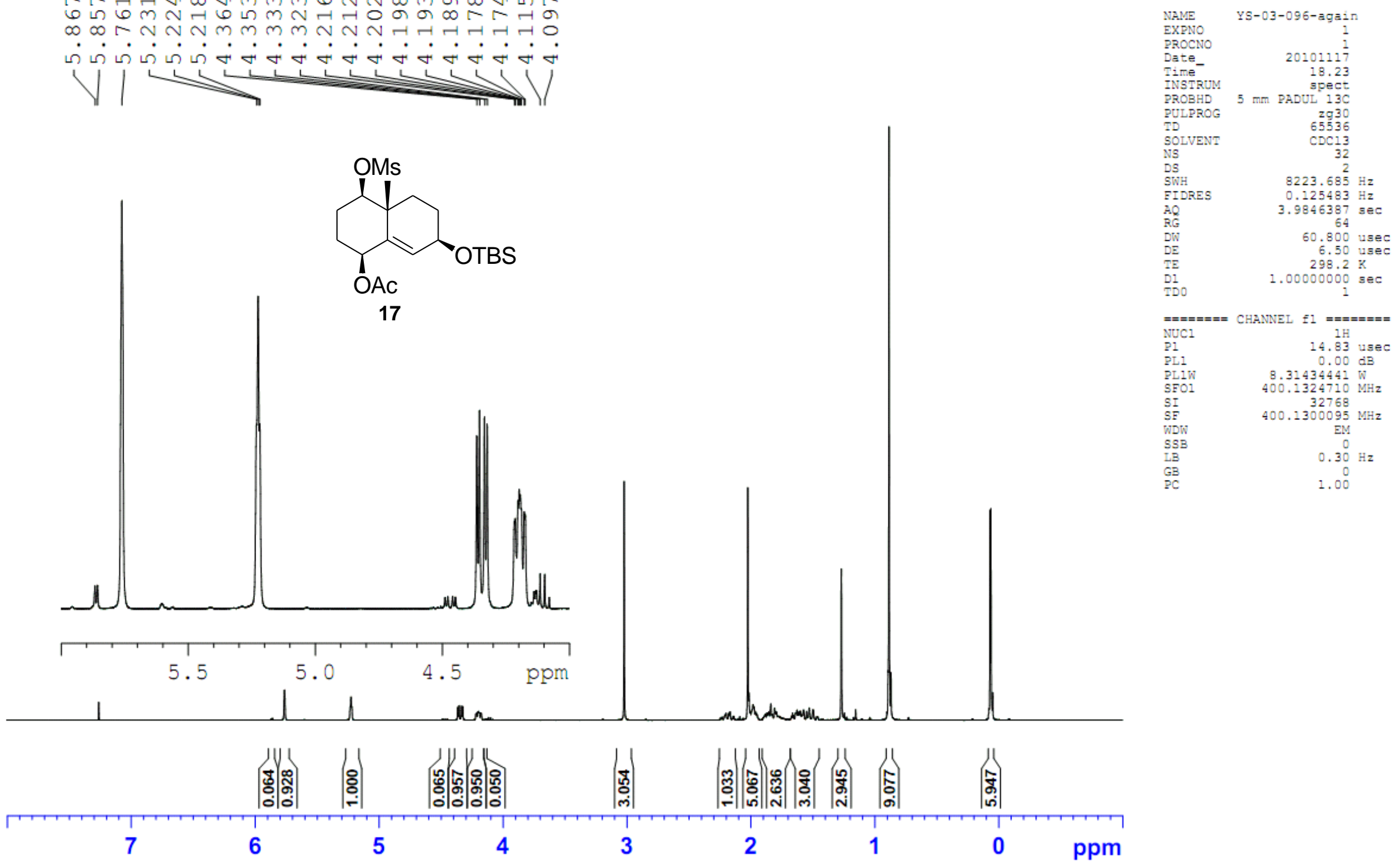

ppm 


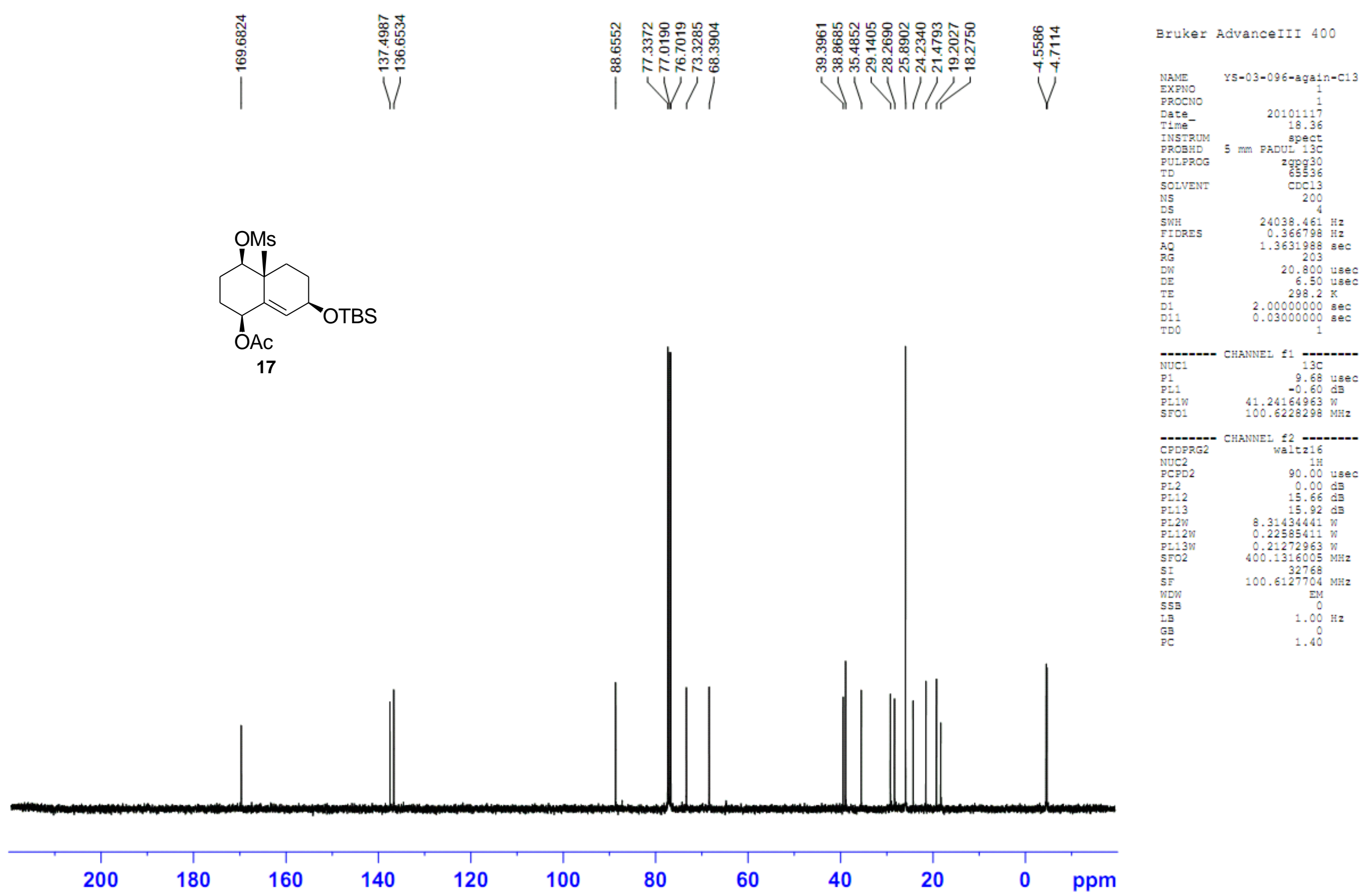




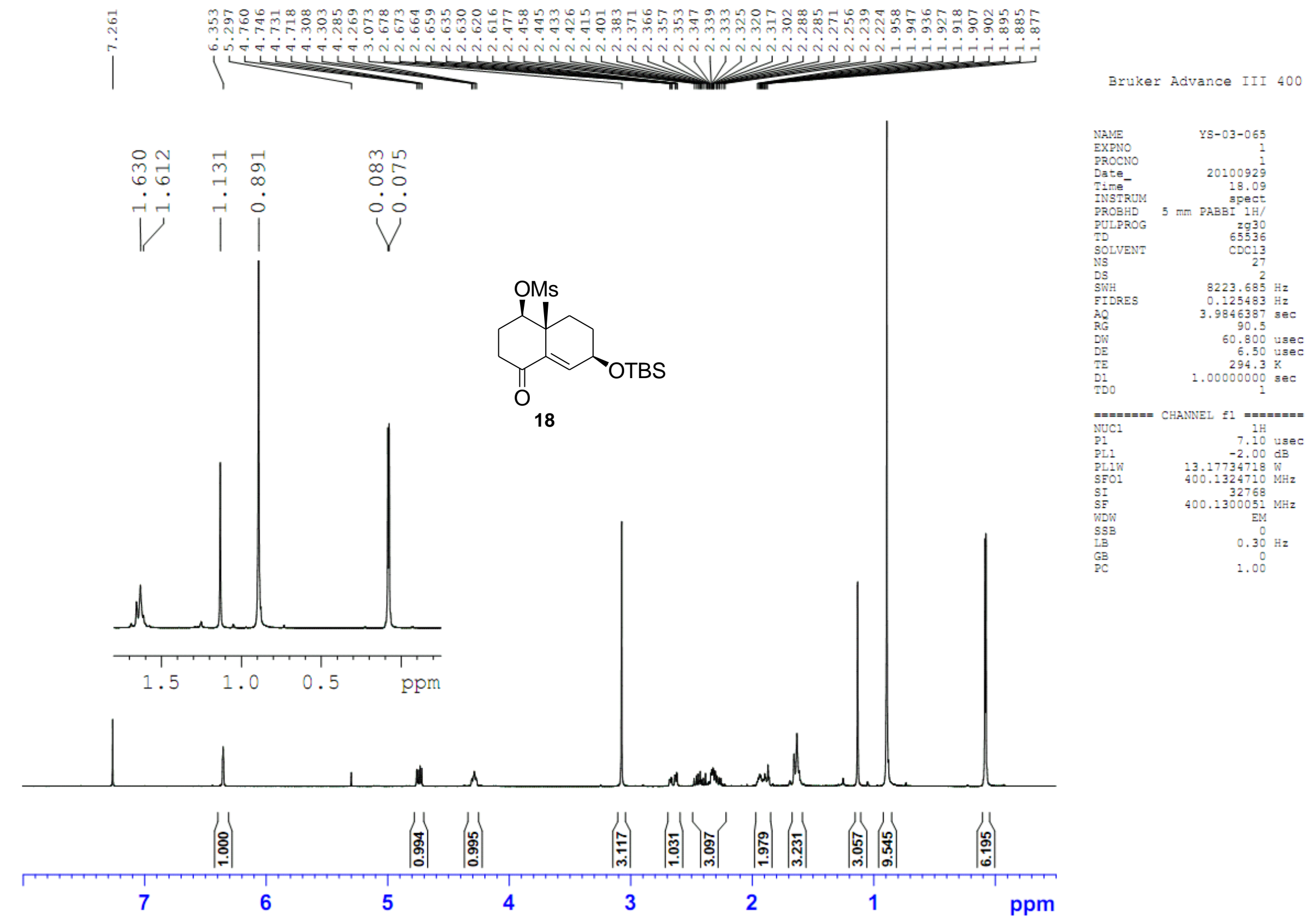
คR 


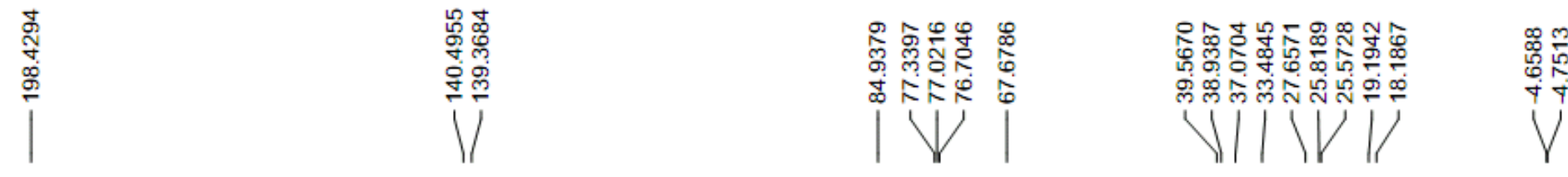

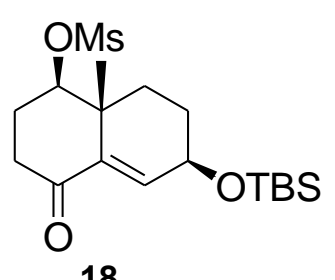

18
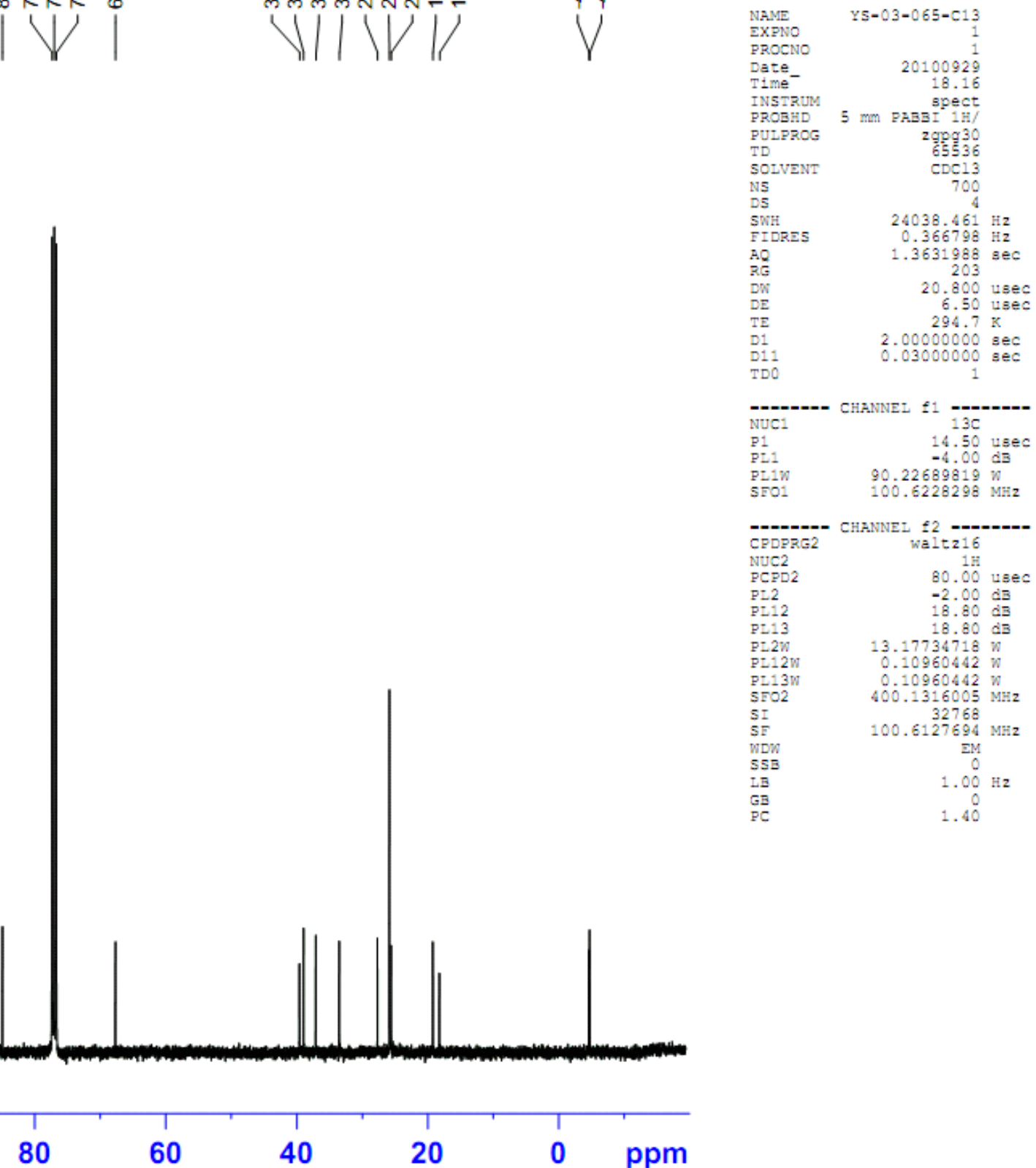


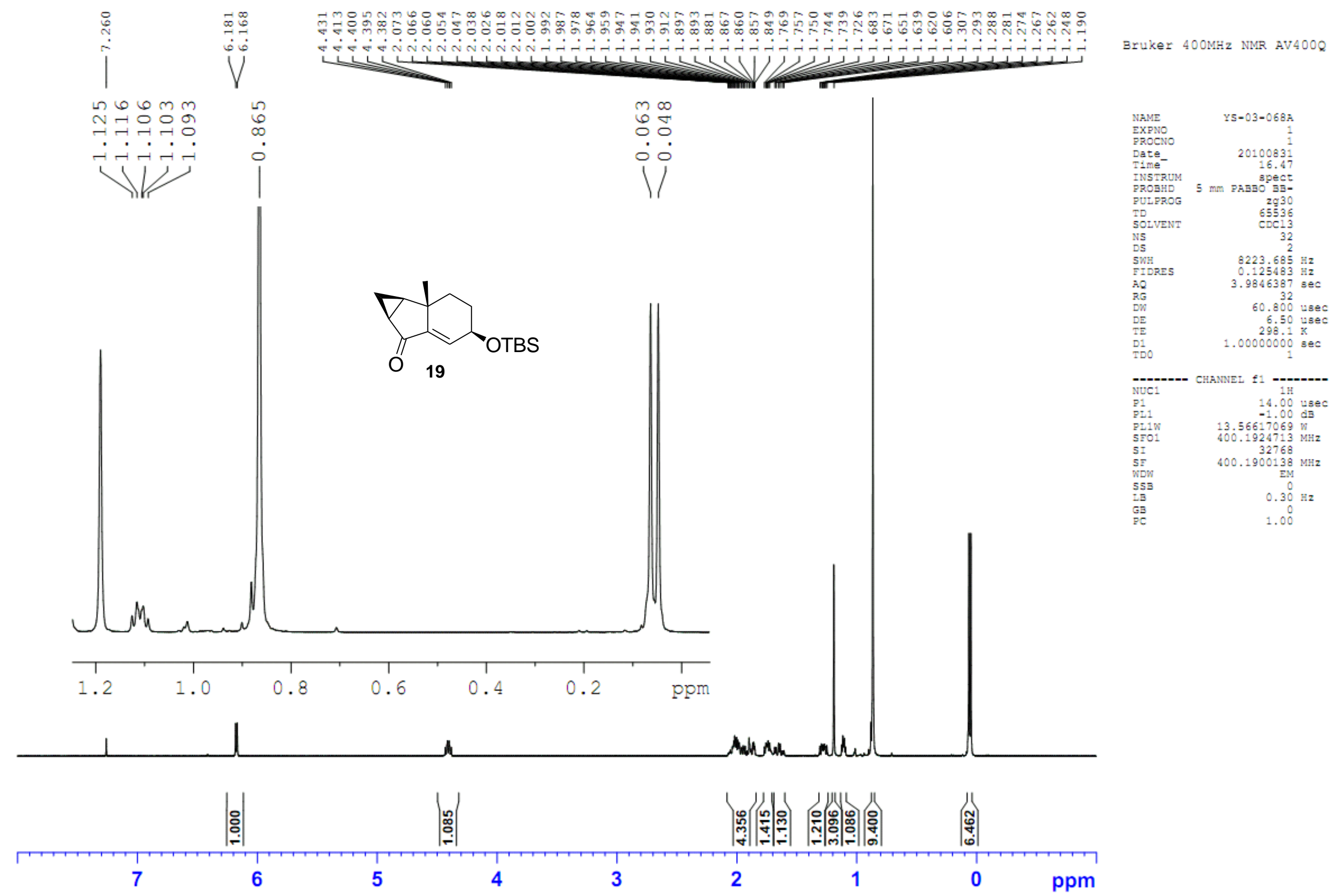




1
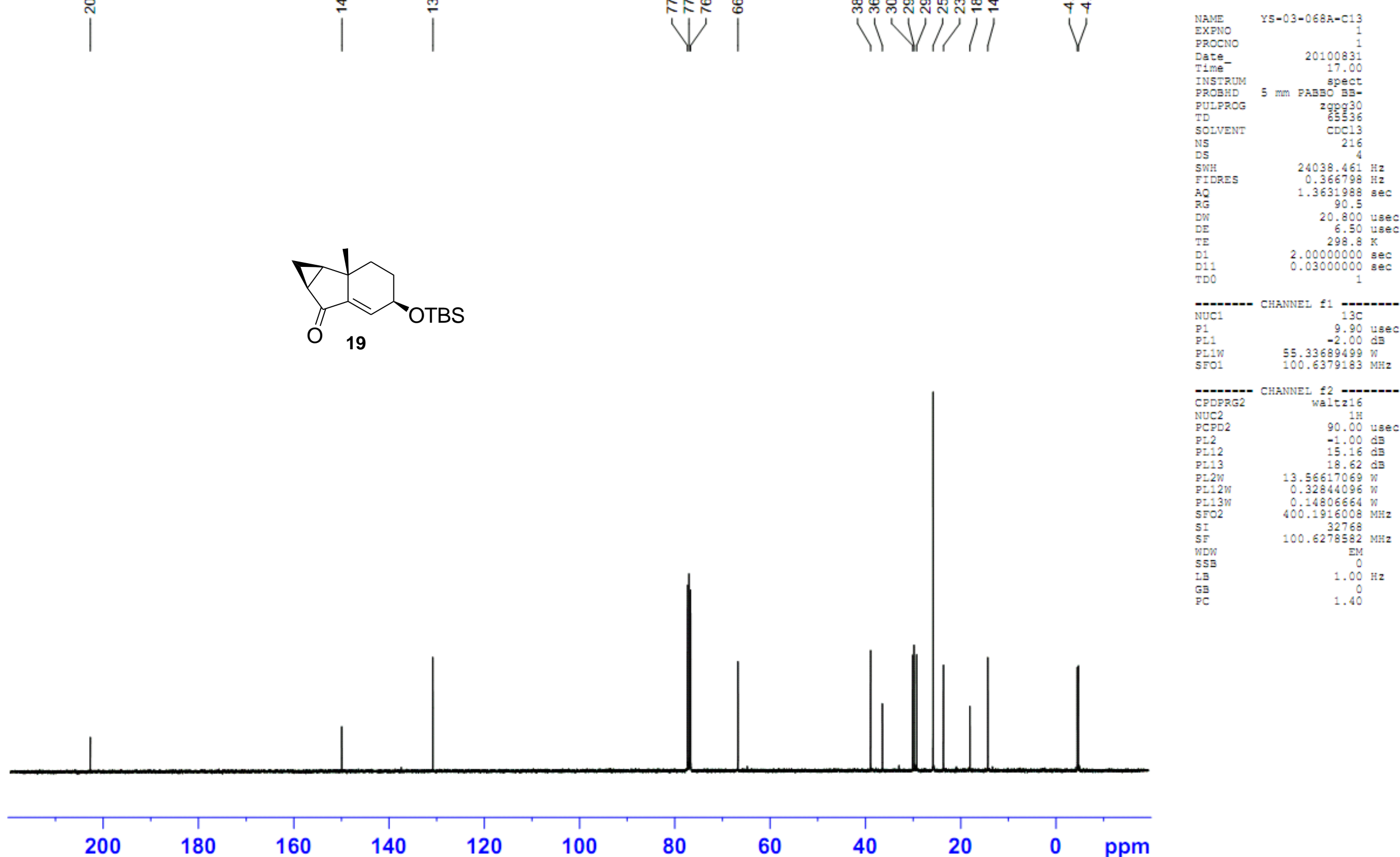


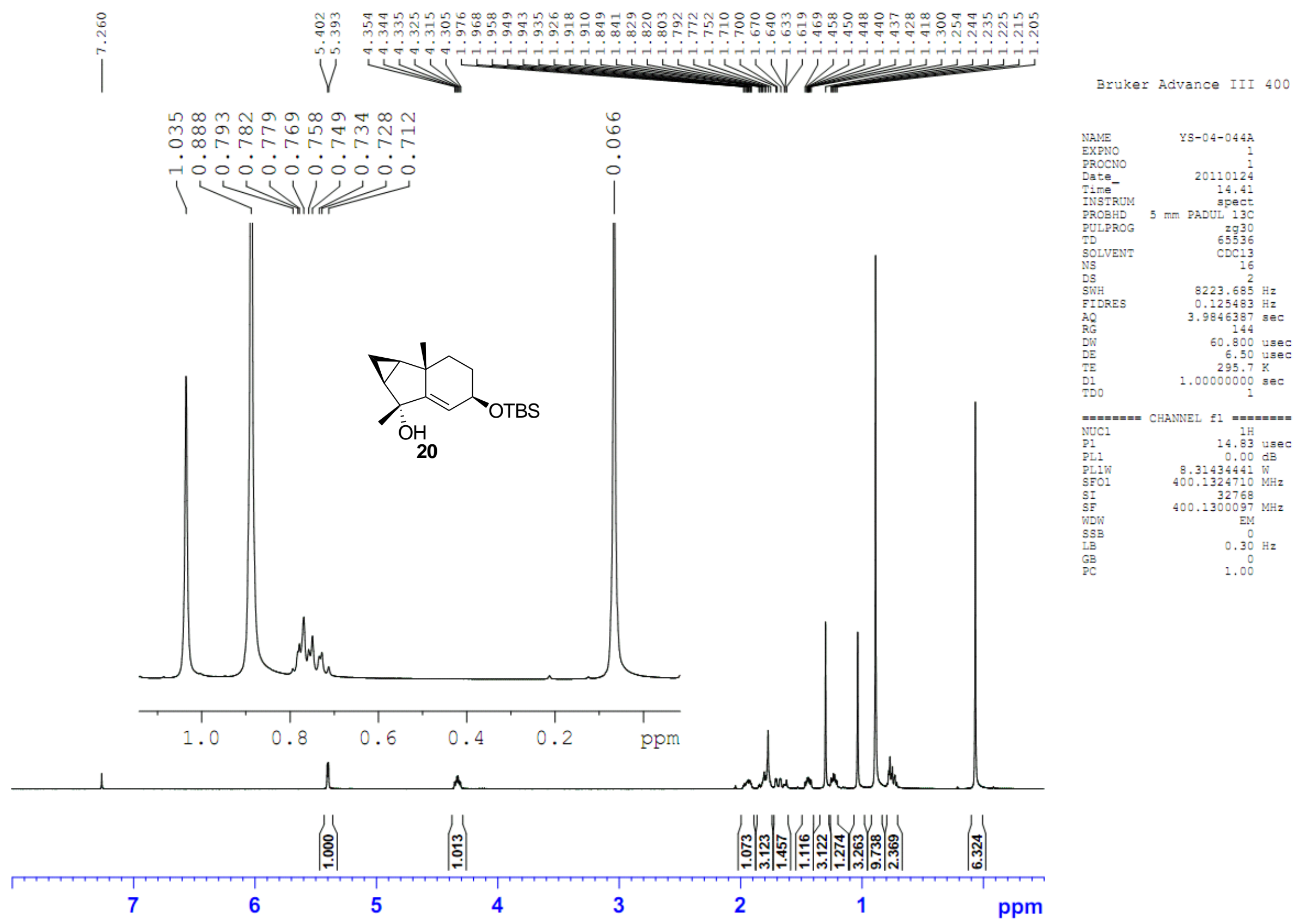




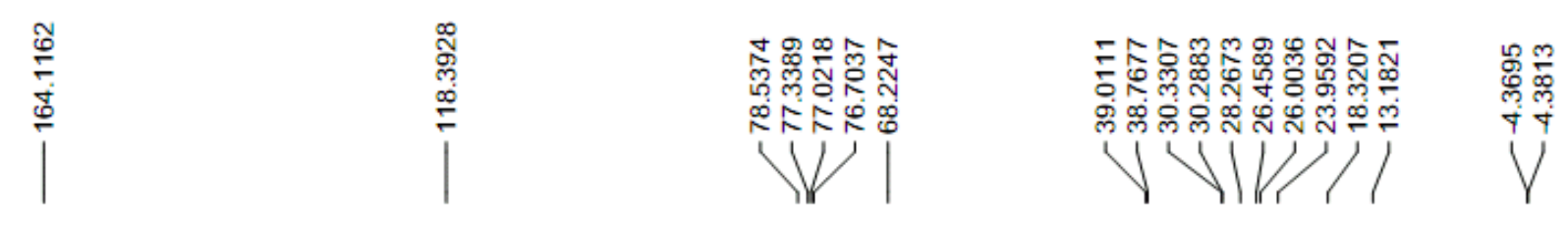

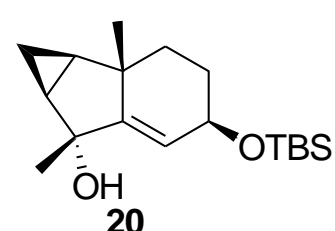

20

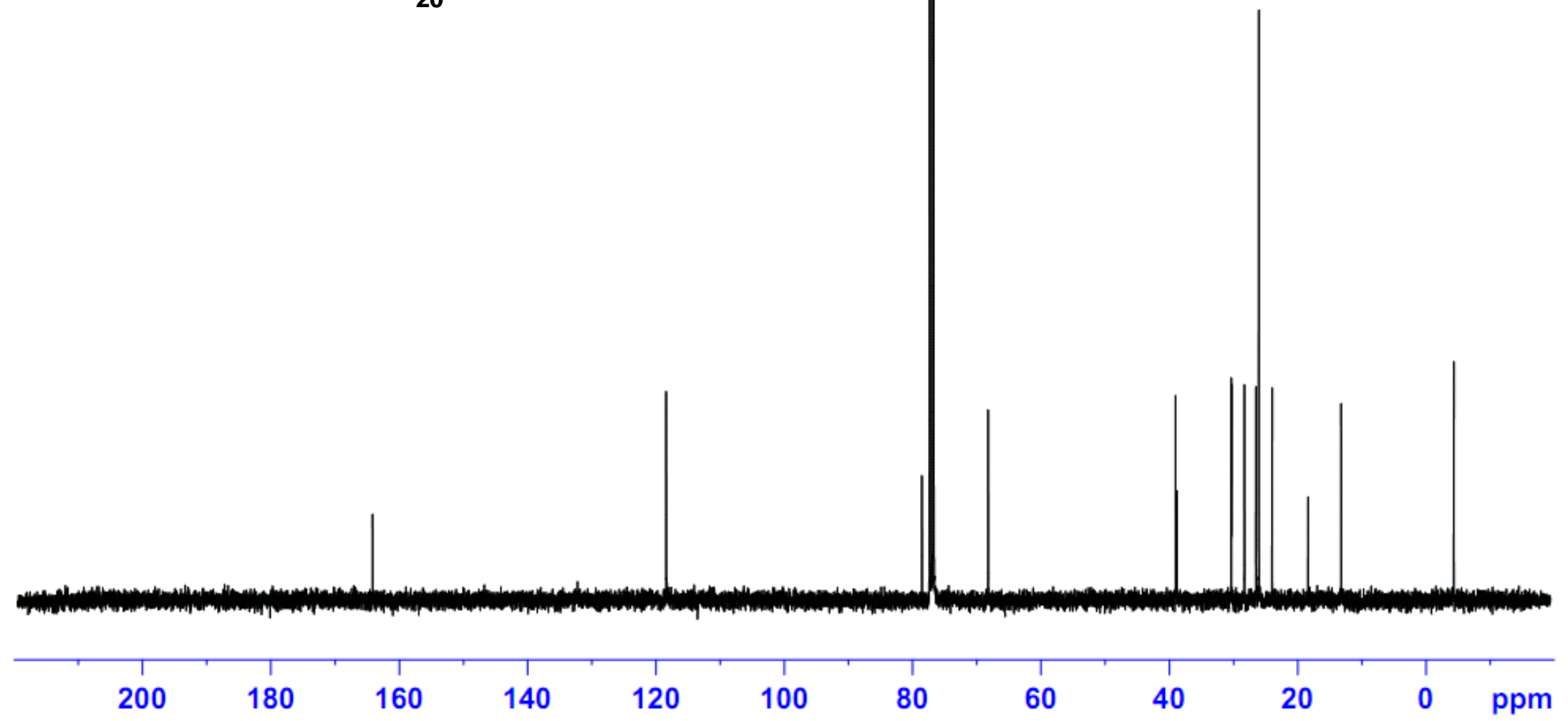



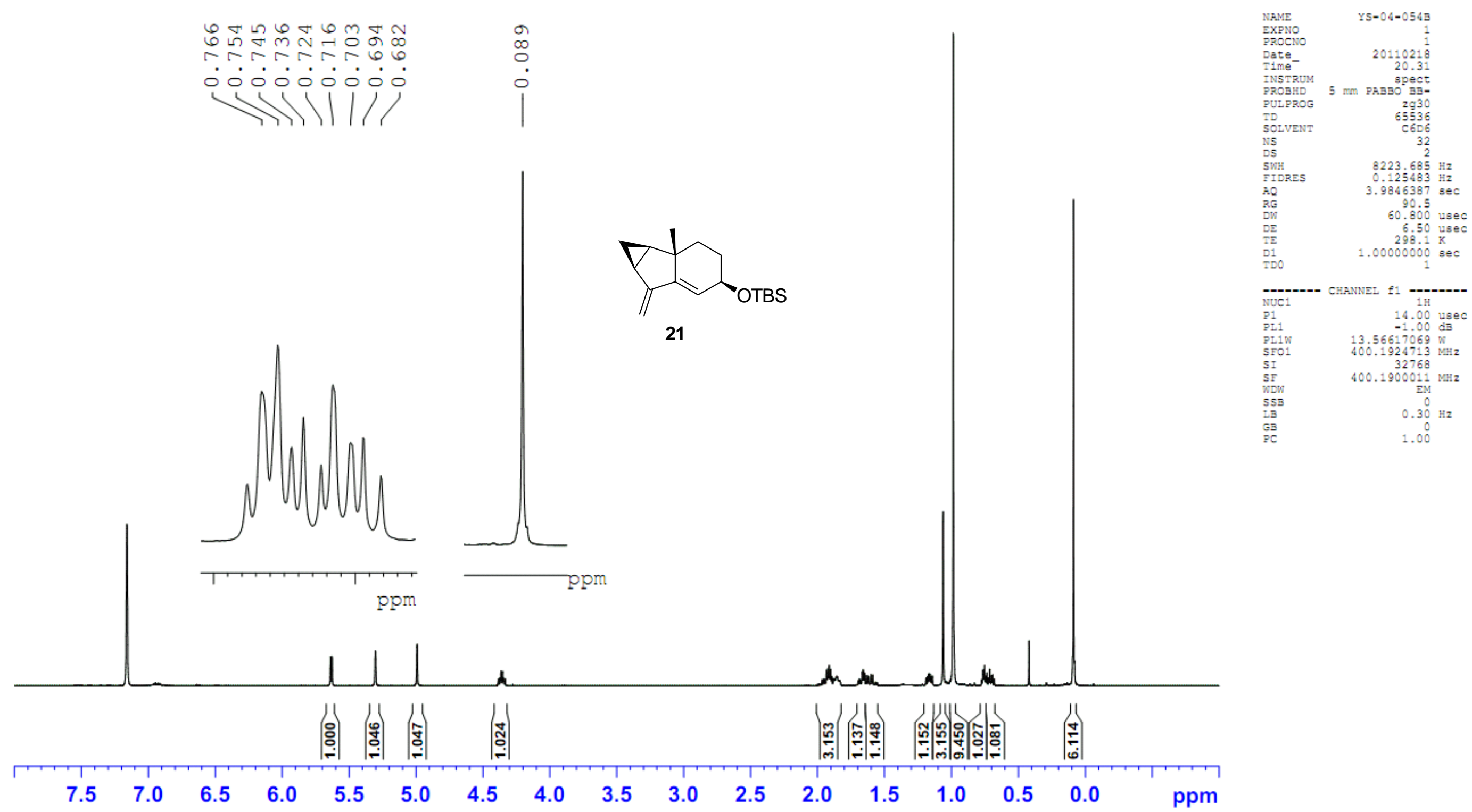


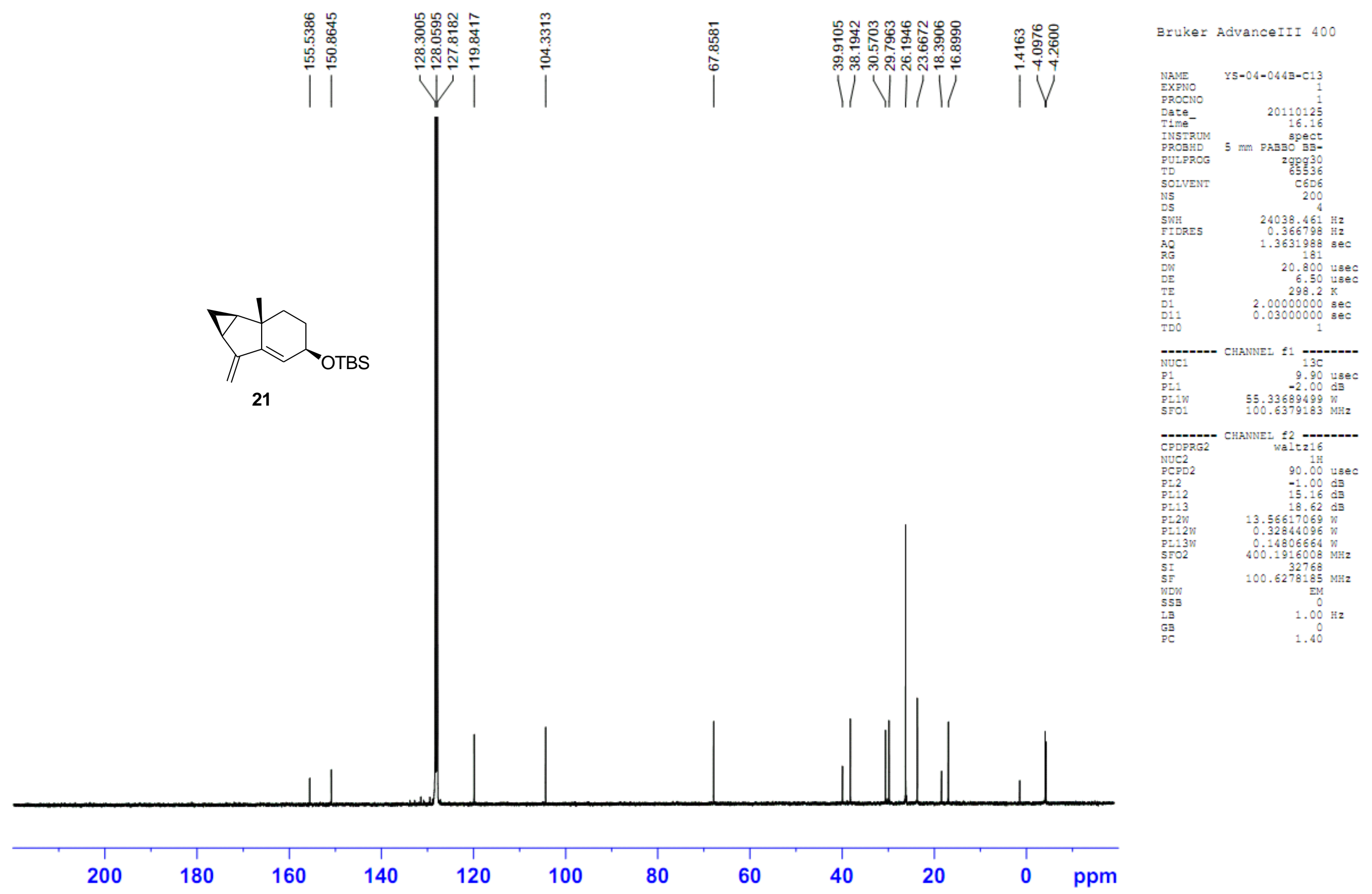




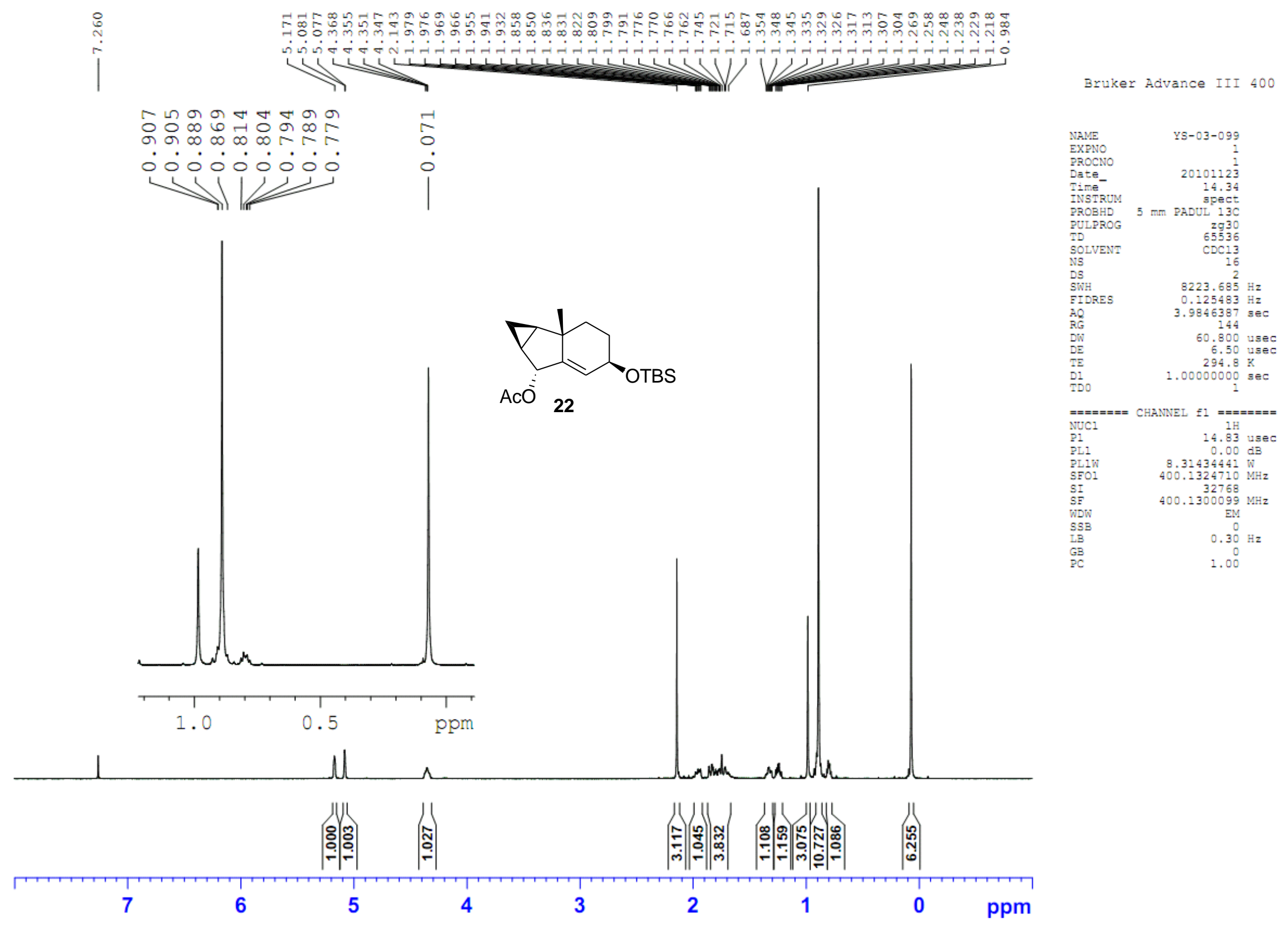




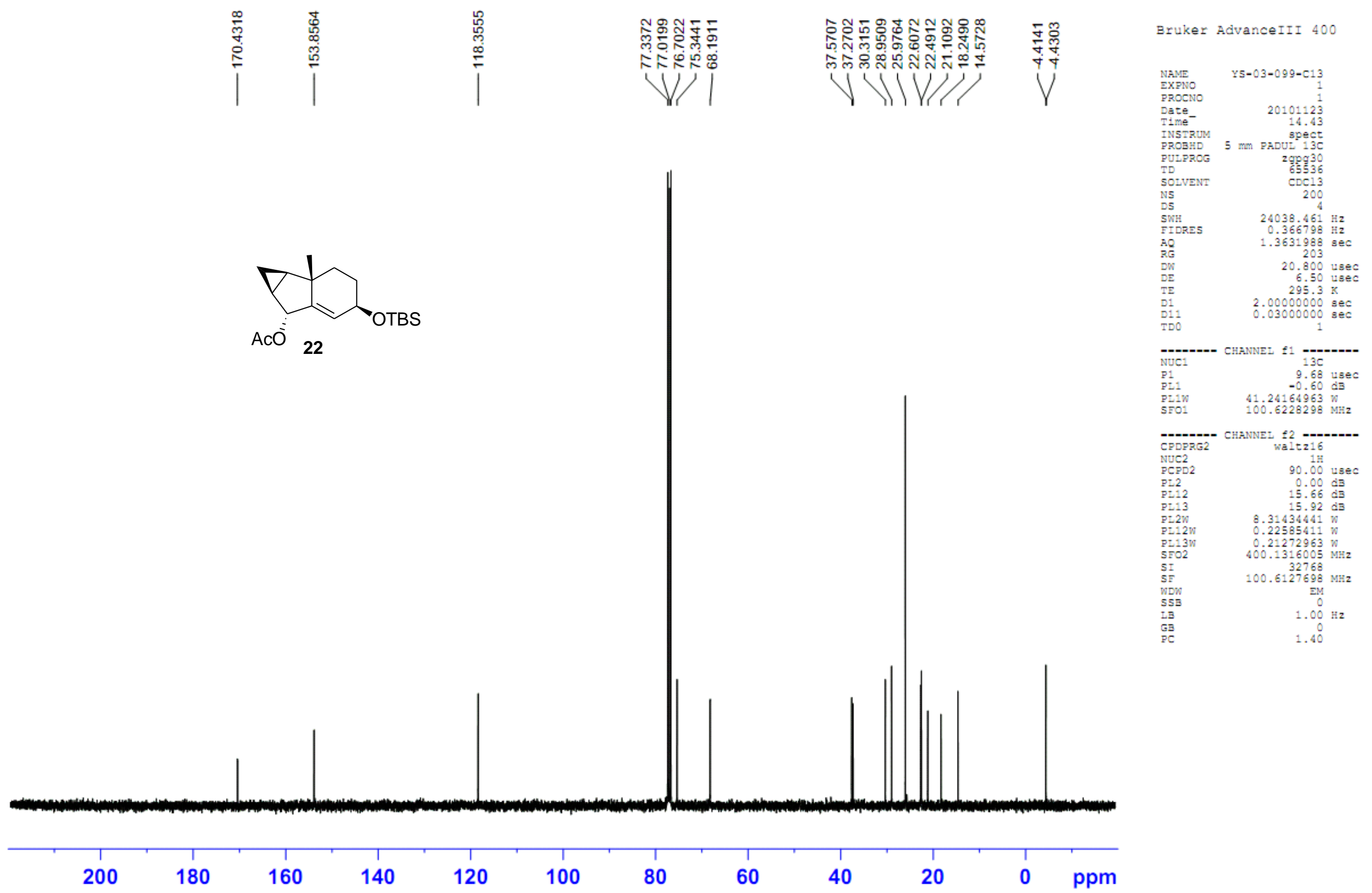




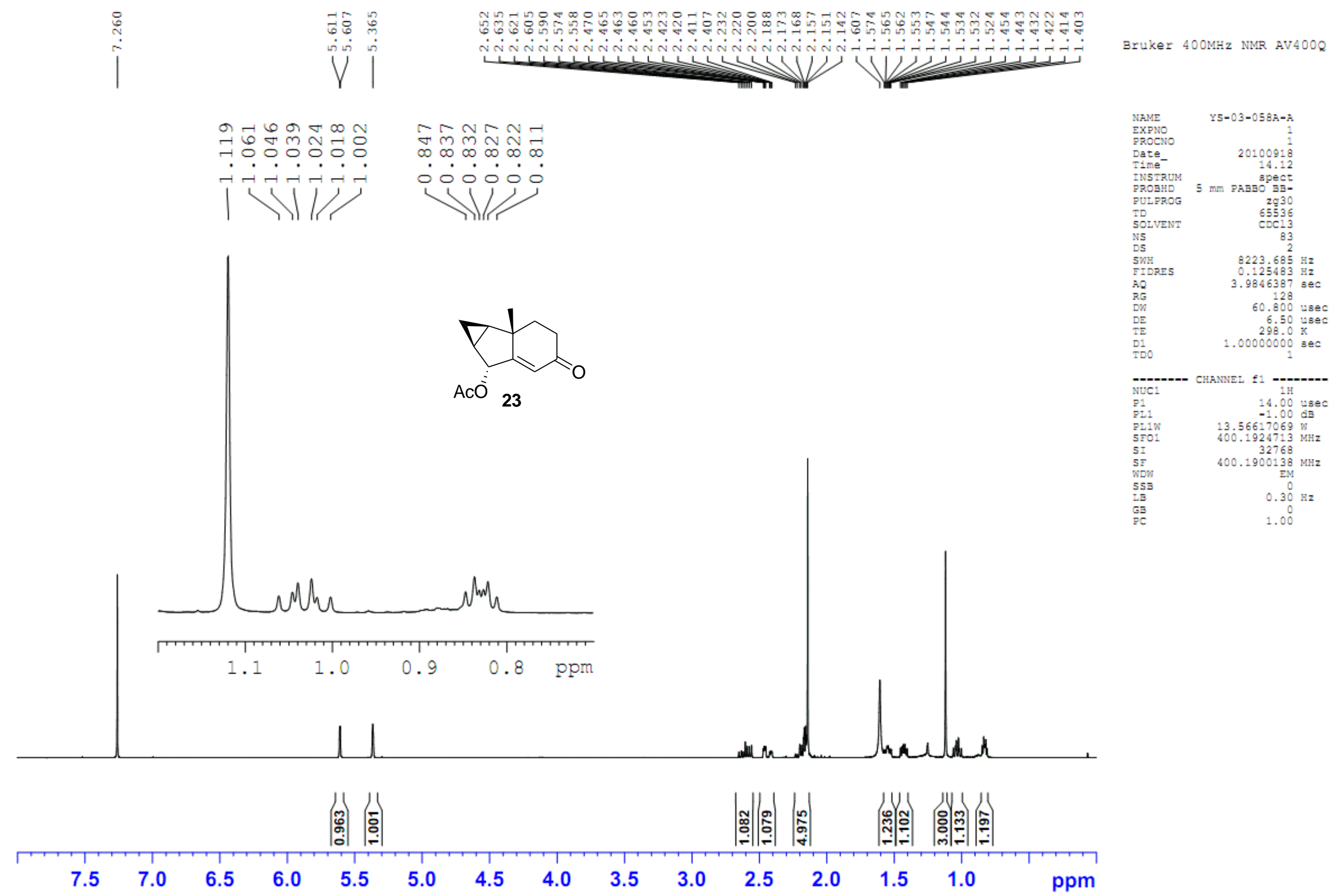



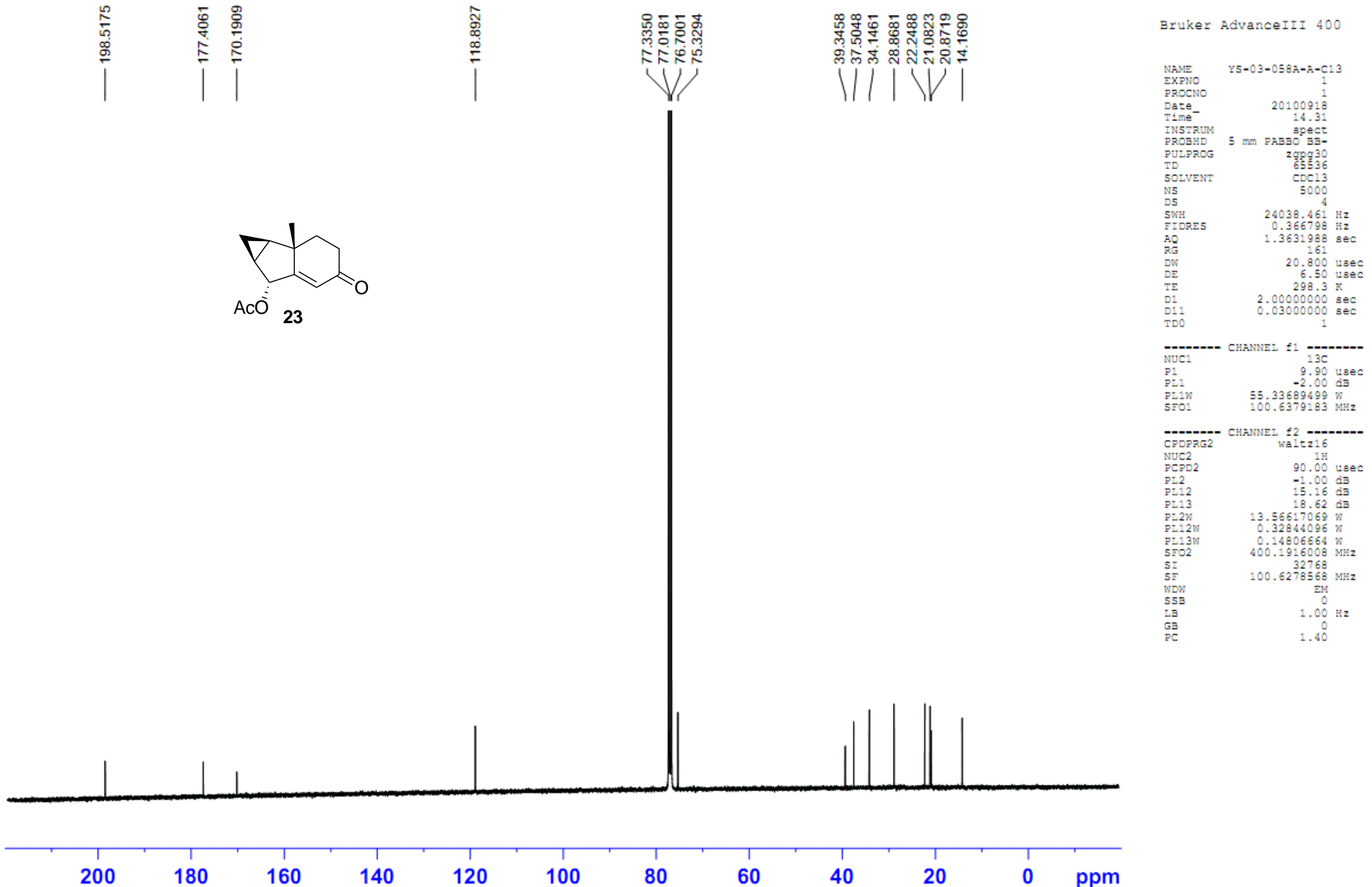


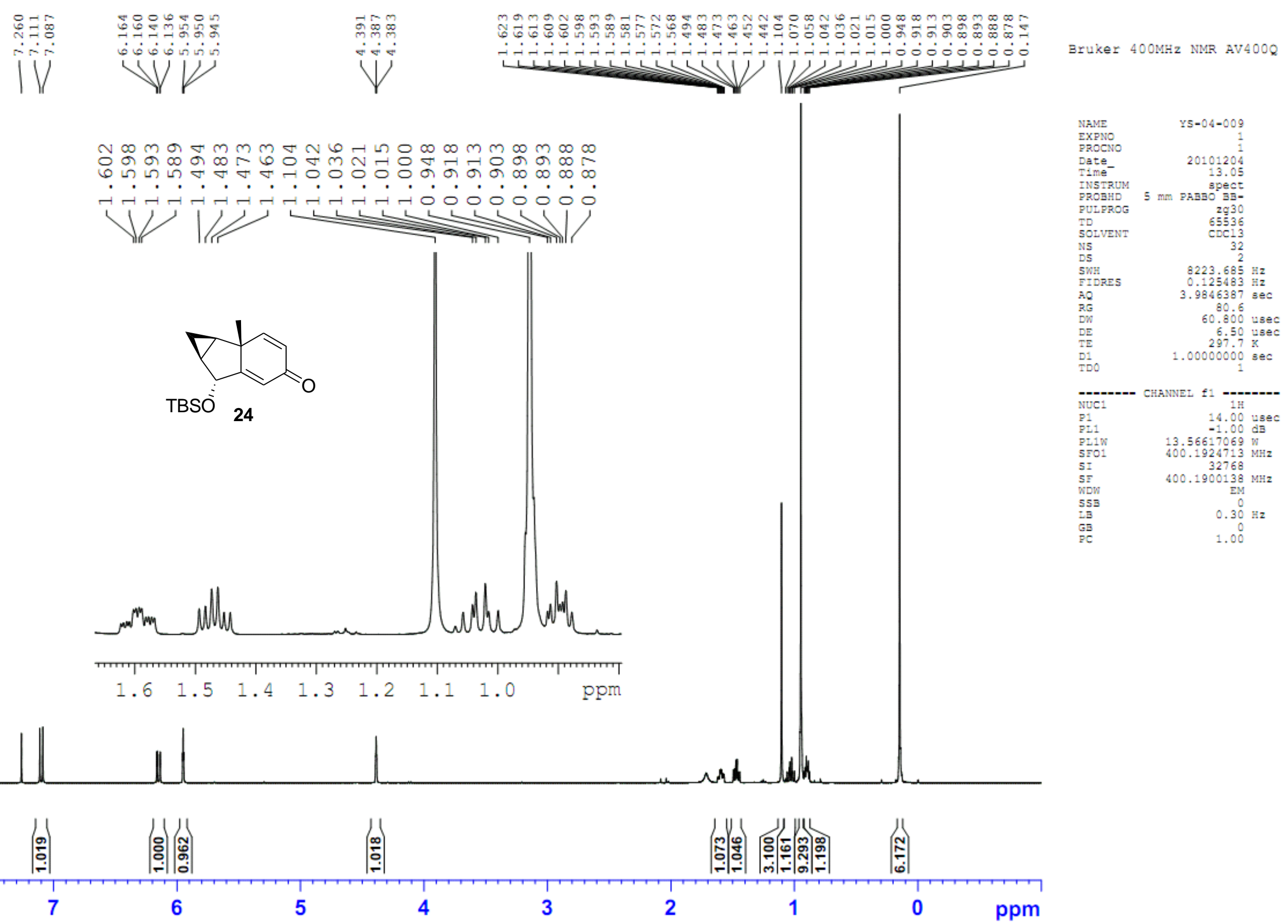




|
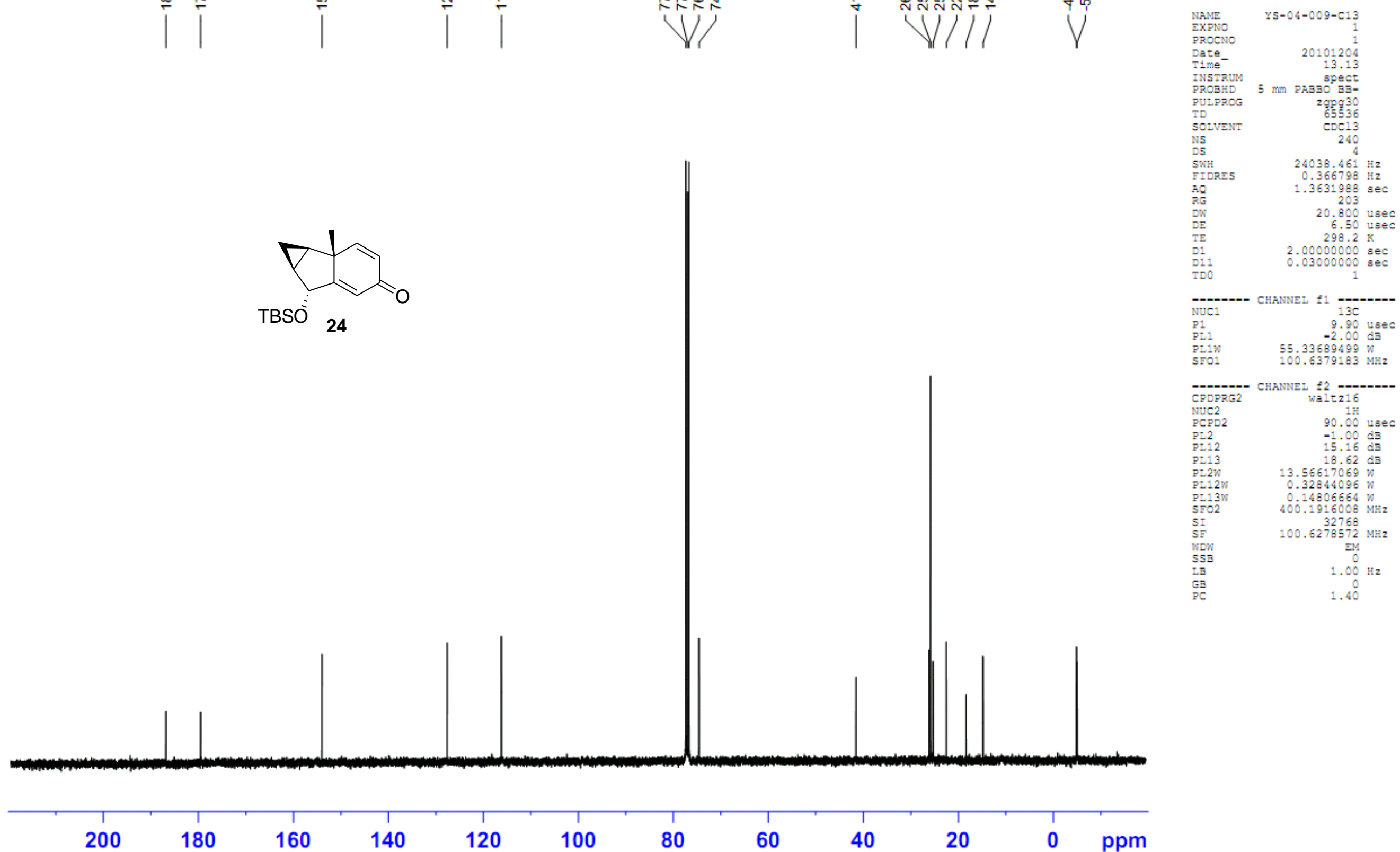

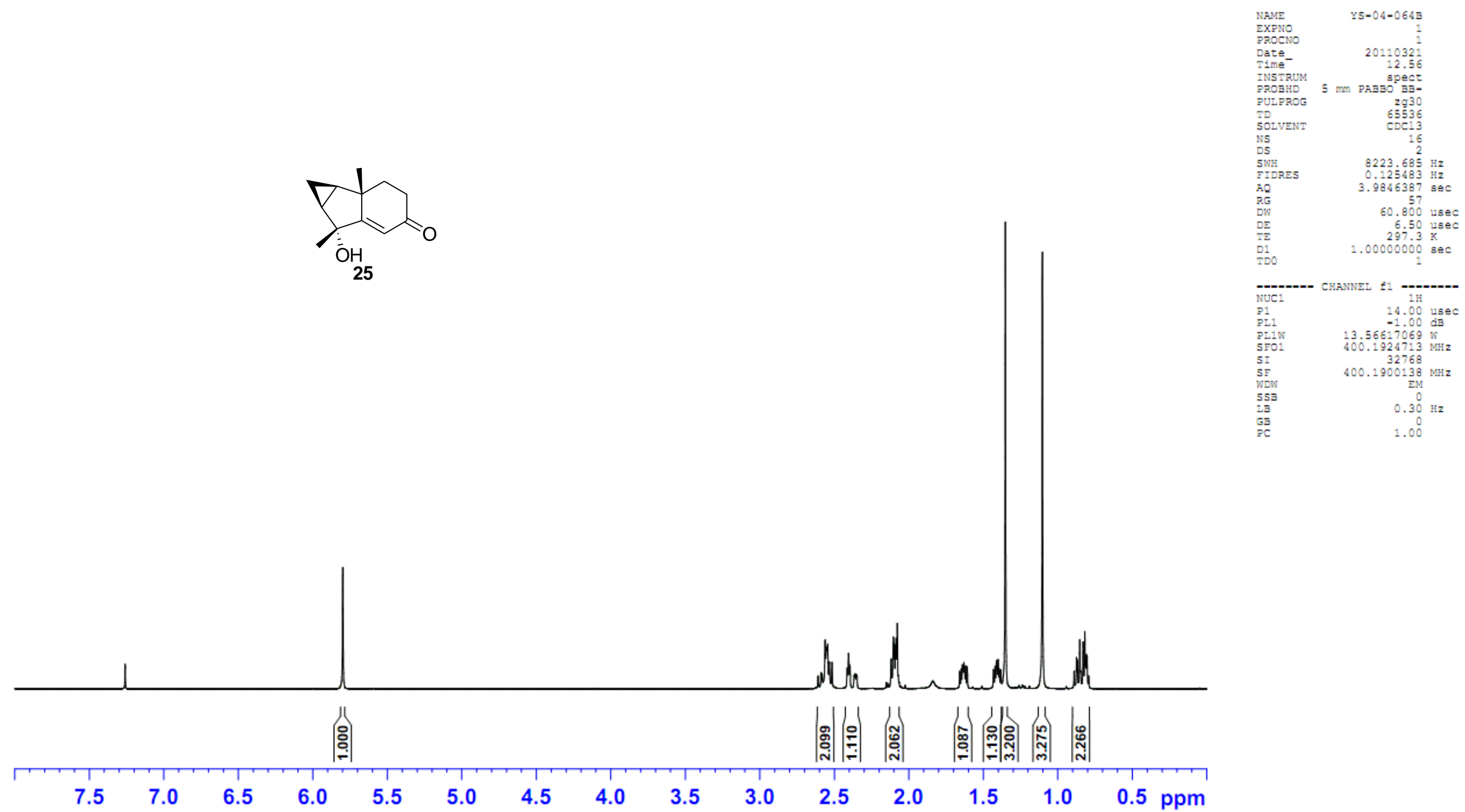


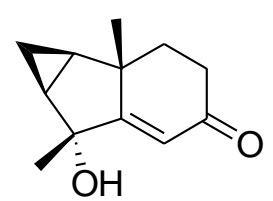

25
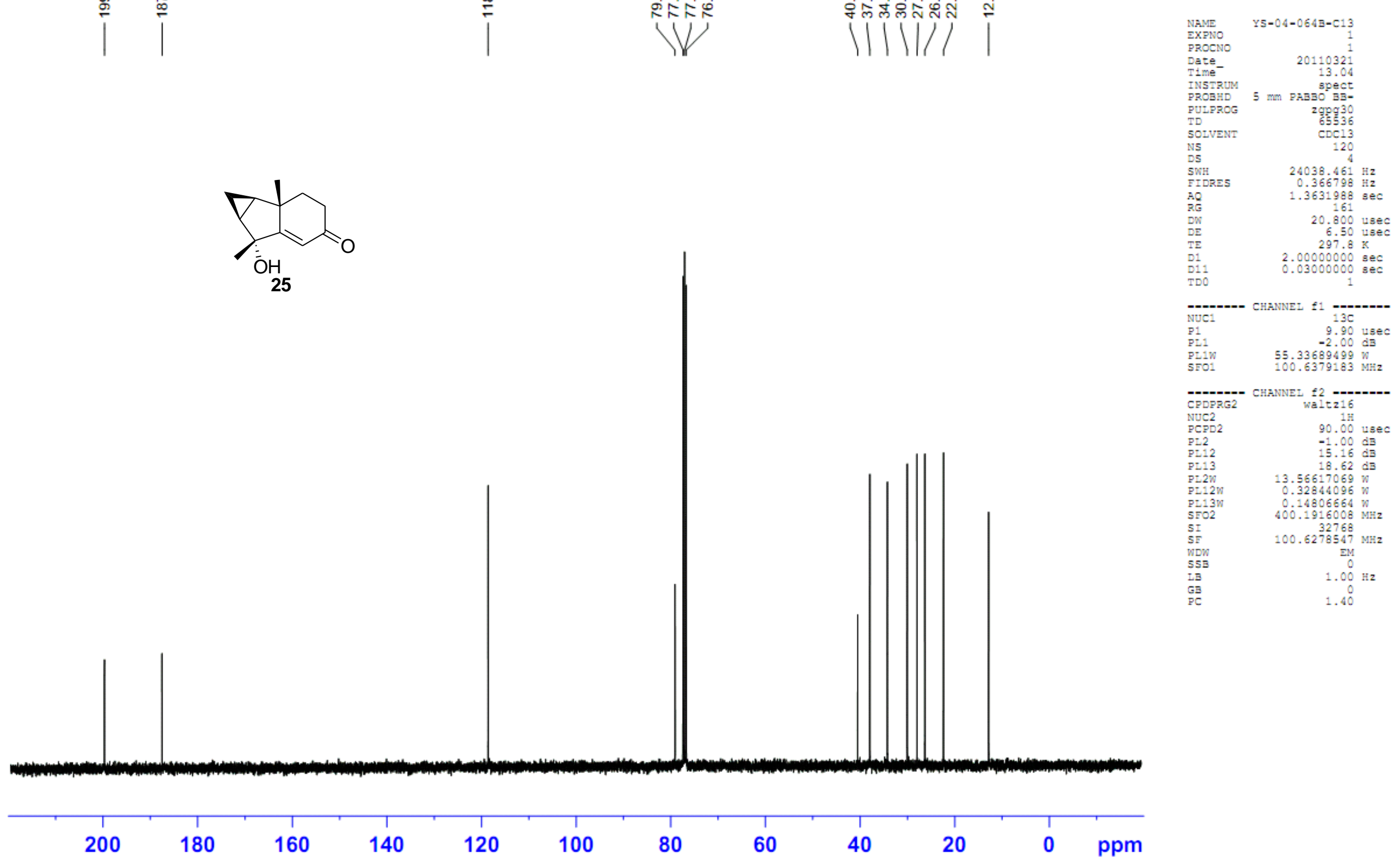


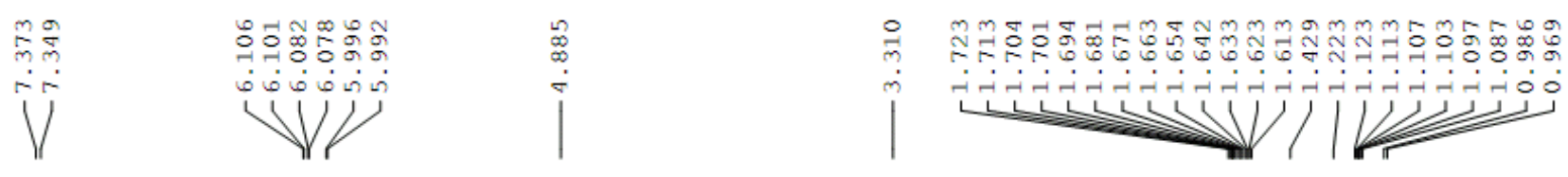

Bruker Advance III 400

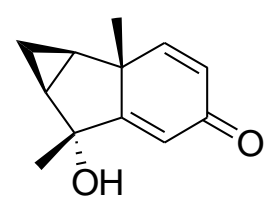

26

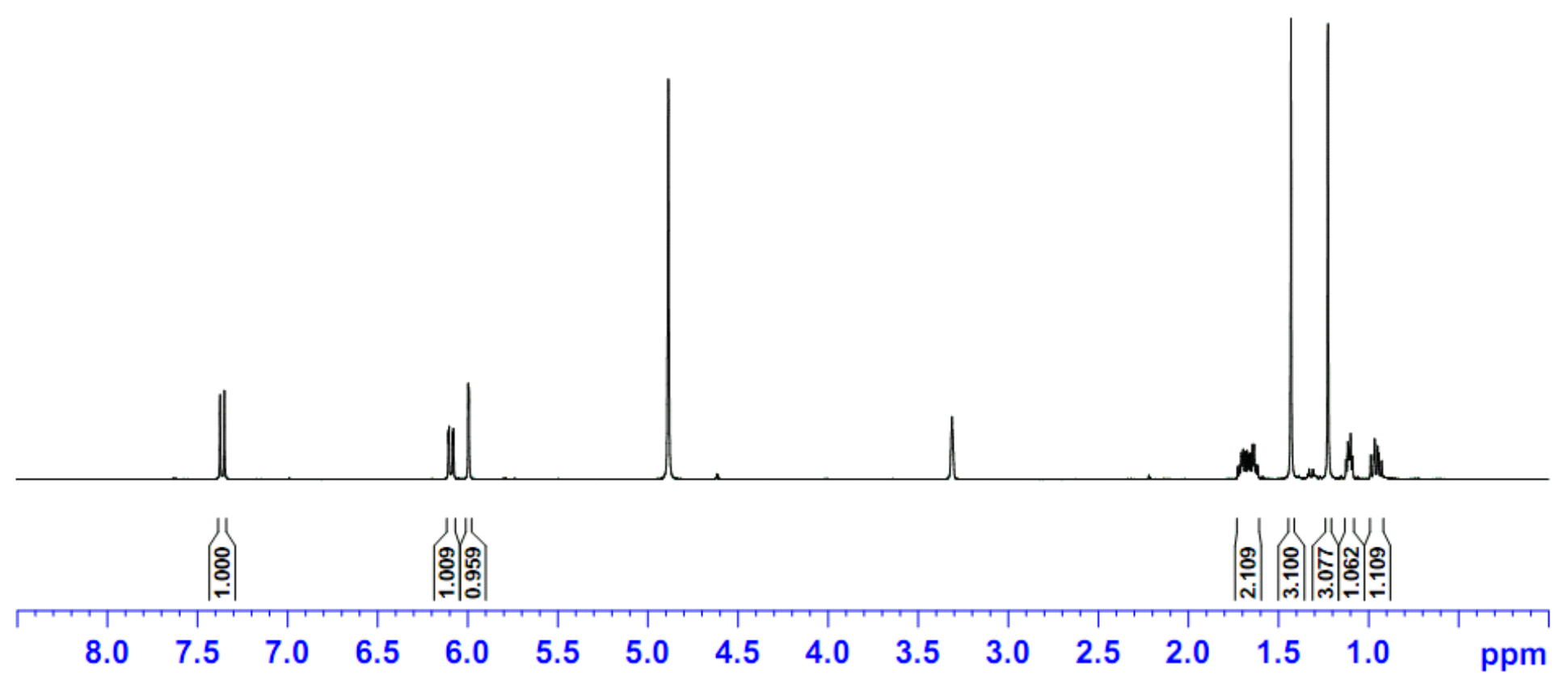




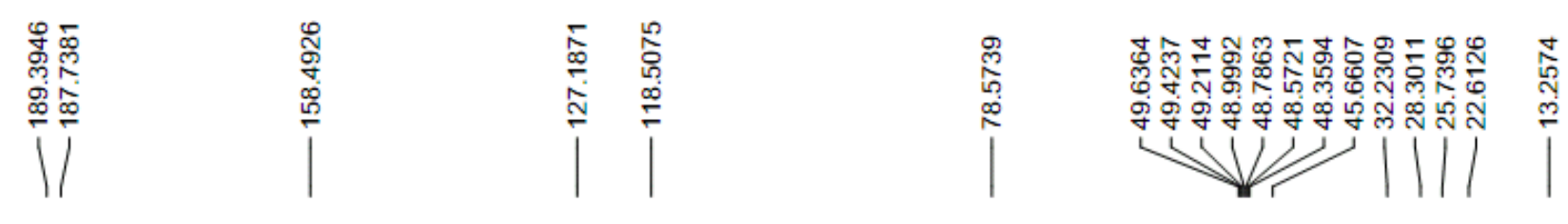

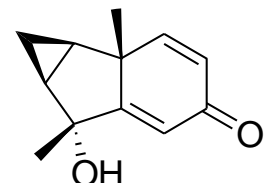

26
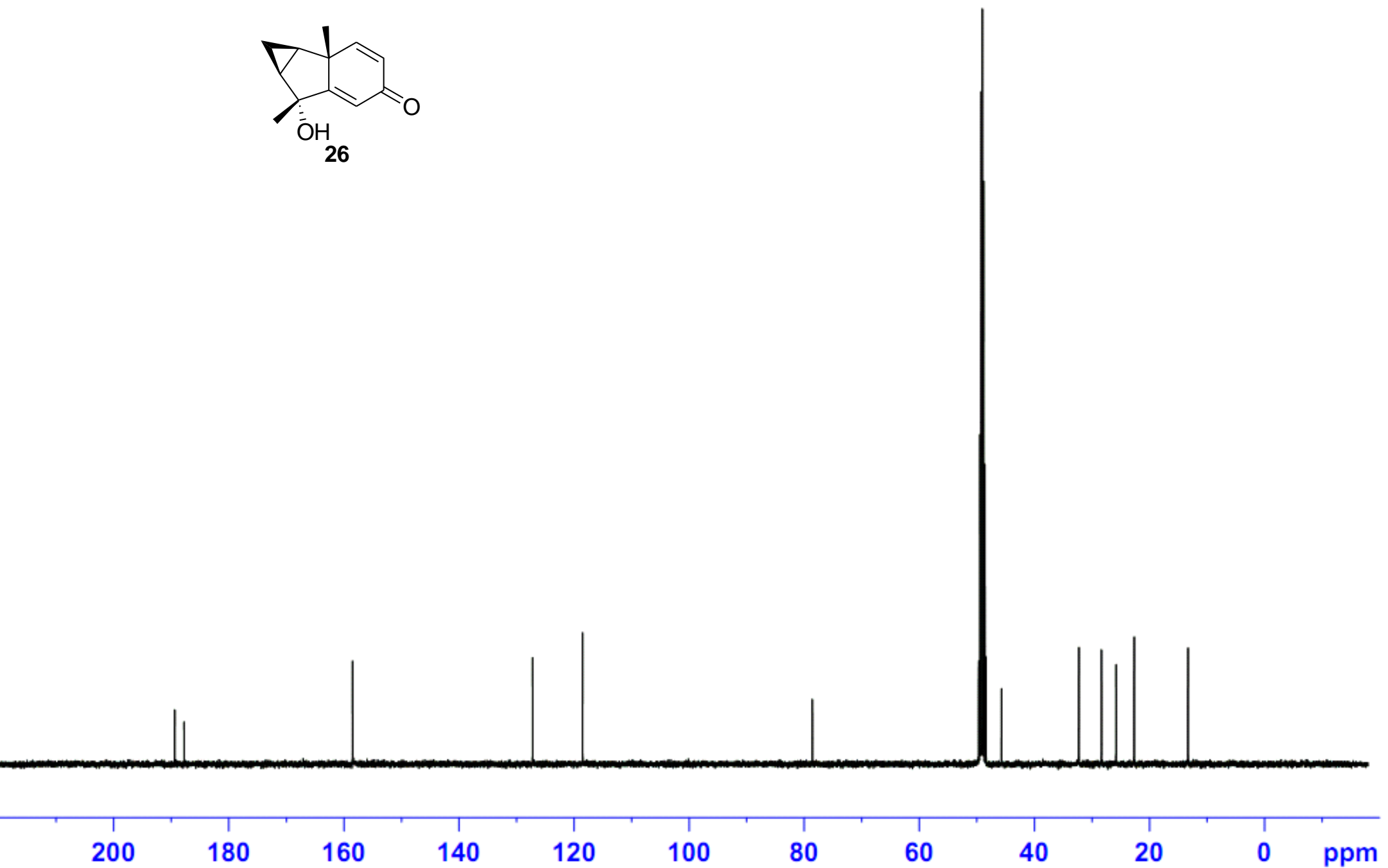

Bruker AdvanceIII 400

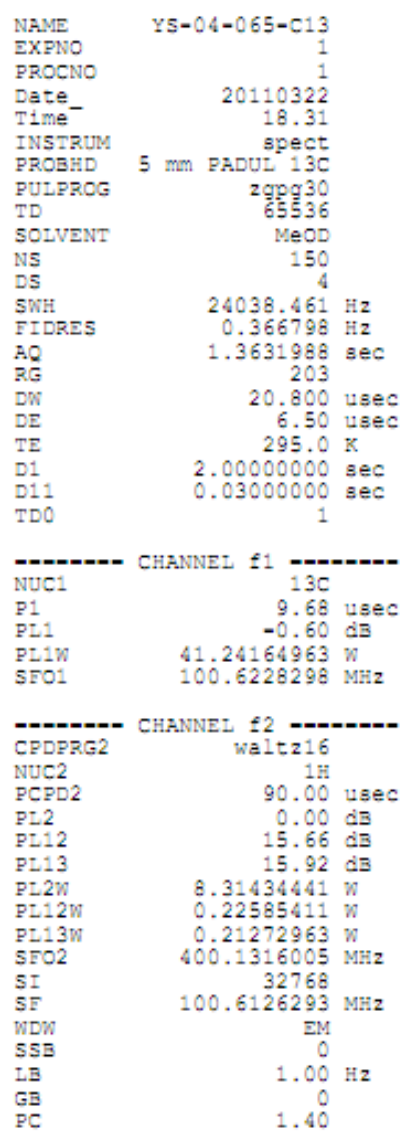




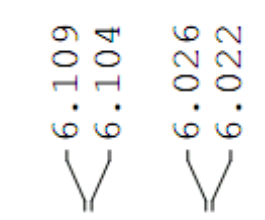

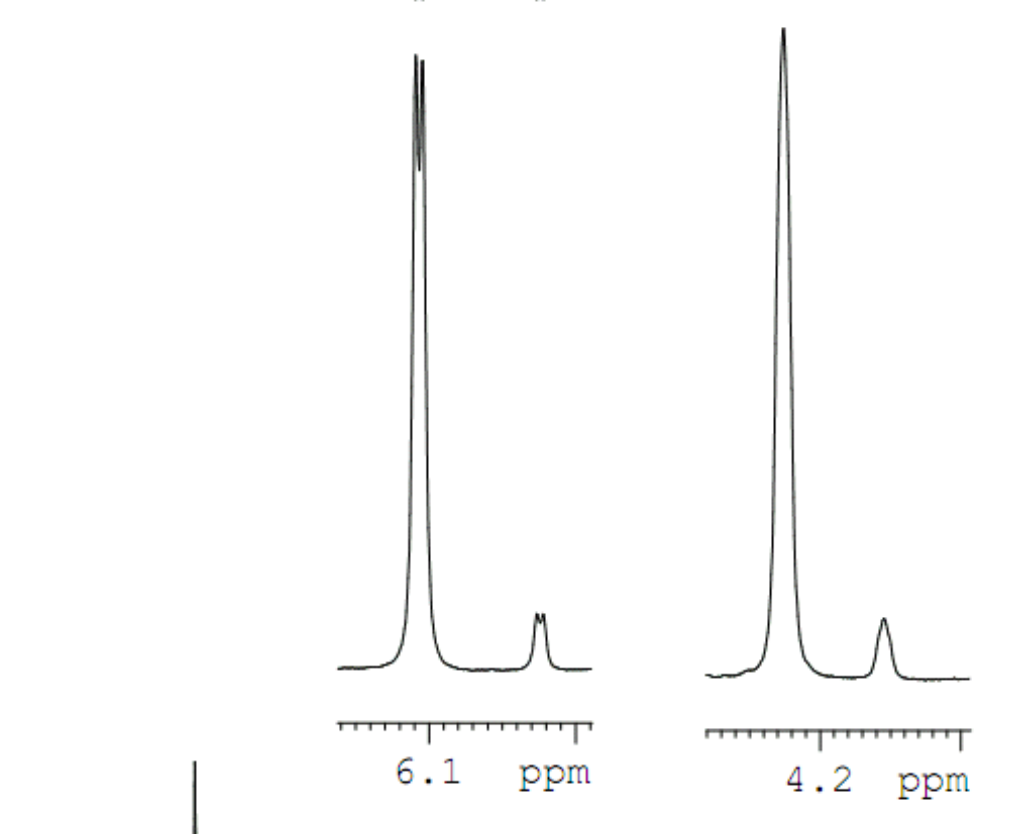
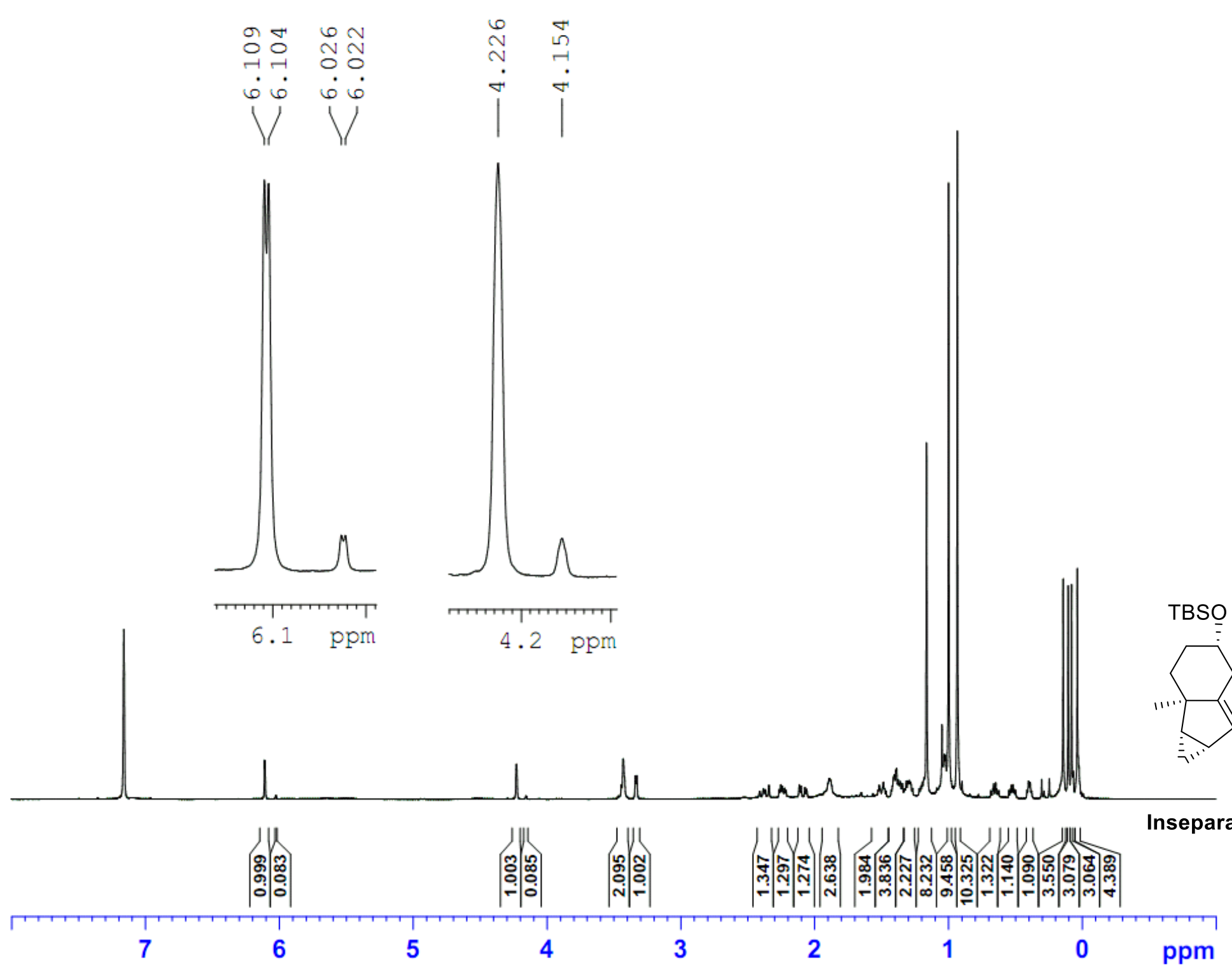

Bruker Advance III 400
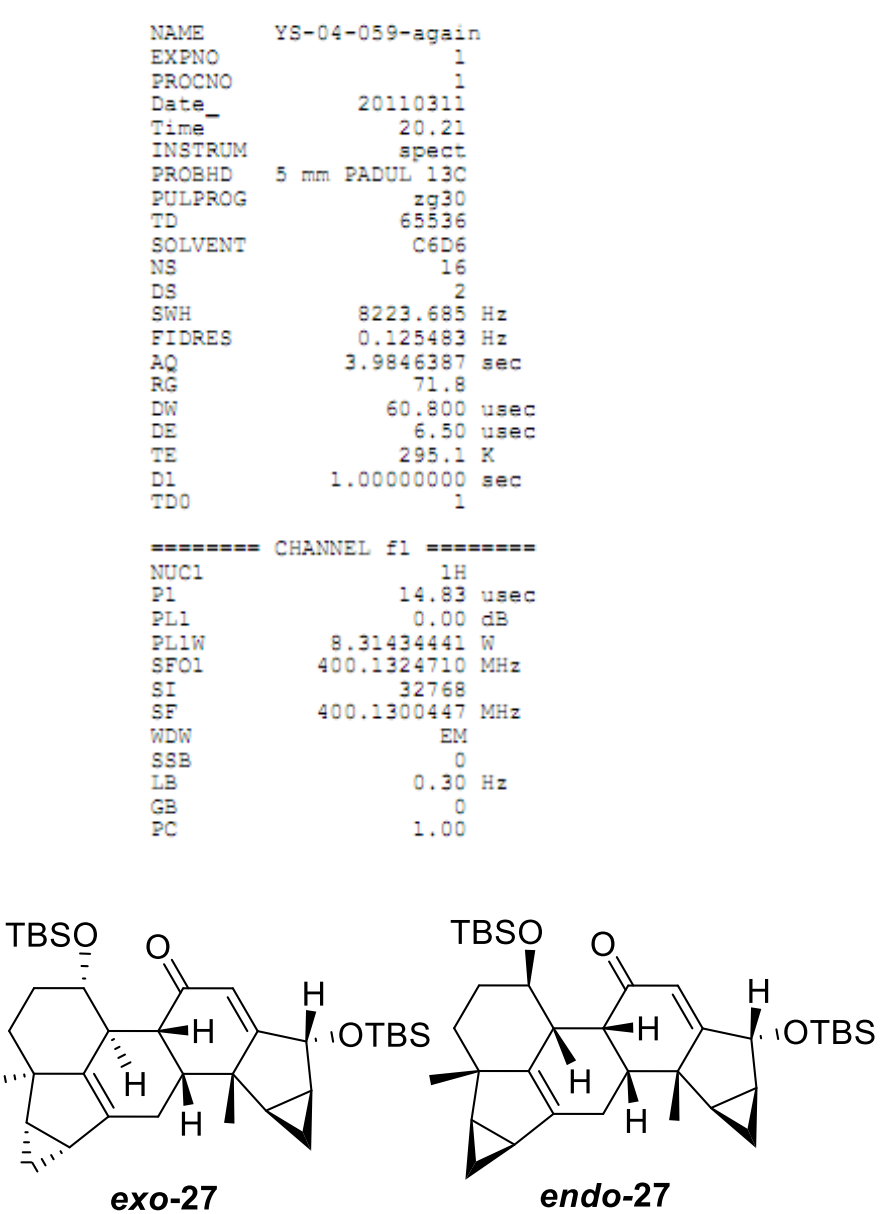

Inseparable mixture with the endo/exo ratio of 1:14 


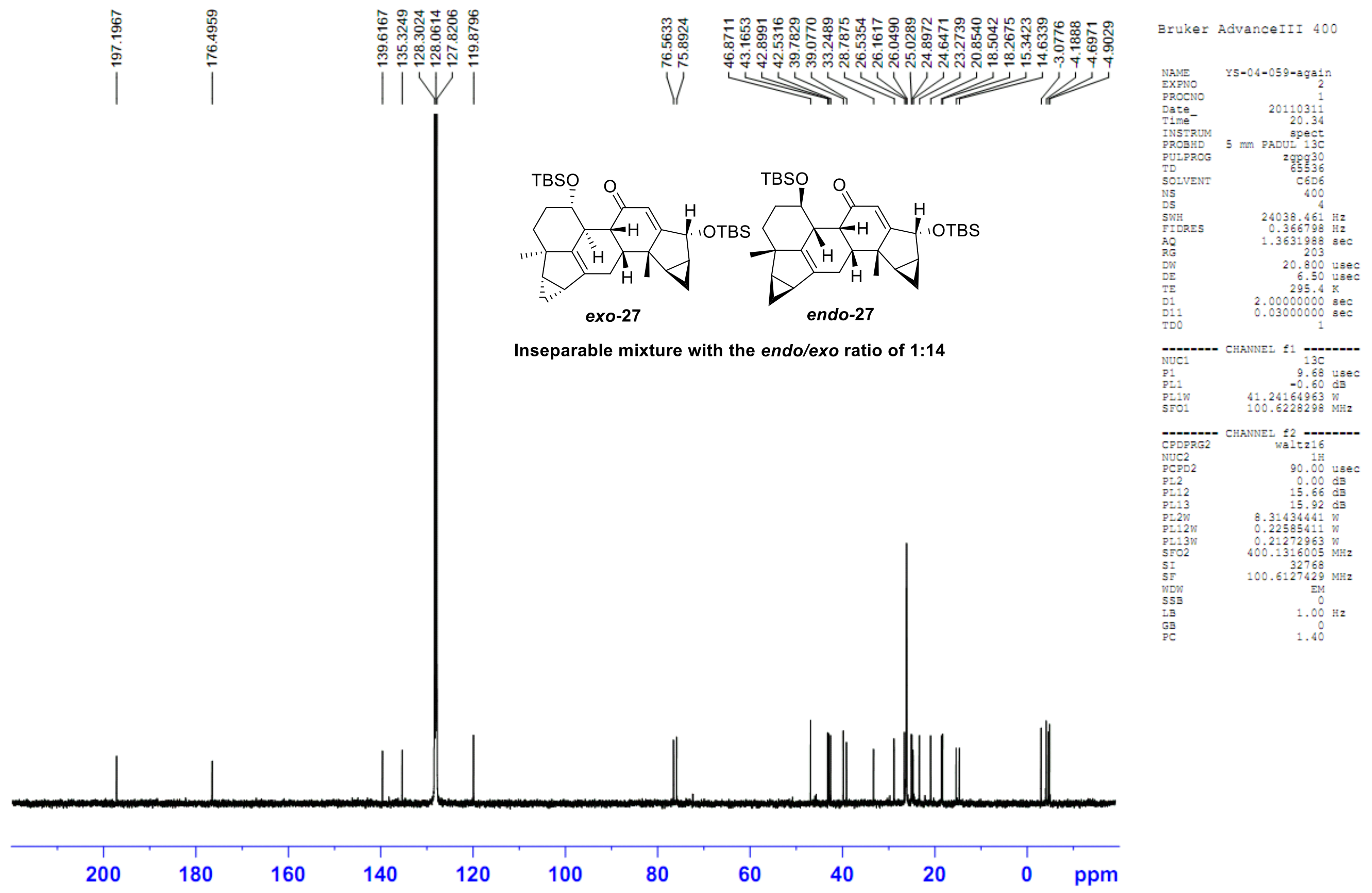




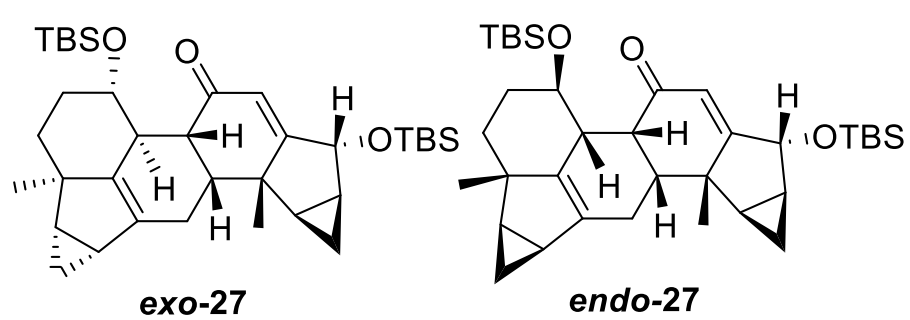

Inseparable mixture with the endo/exo ratio of 1:14

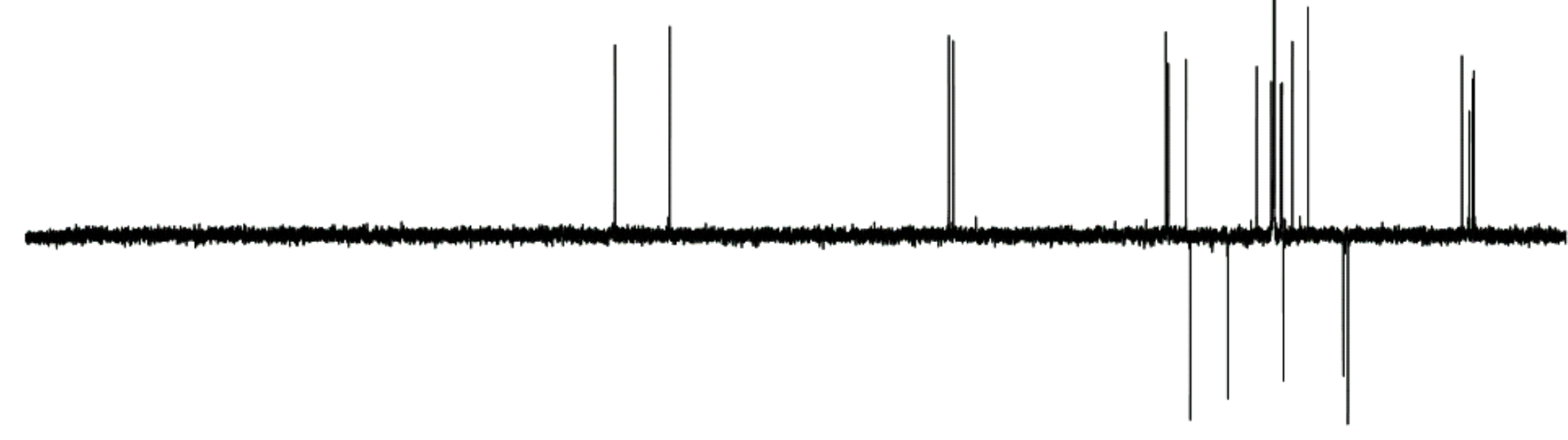

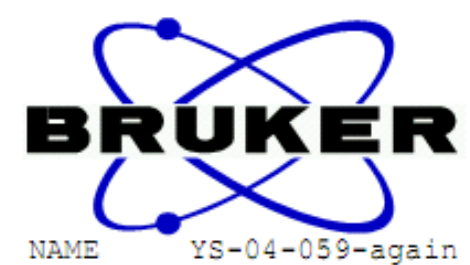

NAME EXPNO
PROCNO

Date_

Time
INSTRUM

PROBHD

PULPROG

TD

SOLVENT

NS

DS

FIDRES

AQ

RG
$D W$

$\mathrm{DE}$

CNST2

D1

D12

$\mathbf{x}=\mathbf{=}$
NUC1

P1

P1

PL1

SFO1

$======1$
CPDPRG2

P3
P4

PCPD2

PI2 2

PL12

L $12 \mathrm{~W}$

$\mathrm{SFO}$

SI

WDW

$S B$
S-04-059-again

$5 \mathrm{spect}$

dept 135

65536

C6D 6

$24038.461 \mathrm{~Hz}$

$24038.461 \mathrm{~Hz}$

$1.3631988 \mathrm{sec}$

$\begin{array}{r}203 \\ \hline\end{array}$

20.800 usec 6.50 usec

145.0000000

$2.00000000 \mathrm{sec}$

$0.00002000 \mathrm{sec}$

$==$ CHANNEL $f$

$=======0$

9.68 usec

19.36 usec

41.24164963 de

$41.24164963 \mathrm{~W}$
$100.6228298 \mathrm{MHz}$

waltz16
waNNEL

14.83 u

14.83 usec

29.66 usec

0.00 use

$0.00 \mathrm{~dB}$

$8.31434441 \mathrm{~W}$

40.22585411 W

32768
100.6127427

$100.6127427 \mathrm{MH}$

$\mathrm{EM}$

$1.00^{\circ} \mathrm{Hz}$

1.00
1.40 

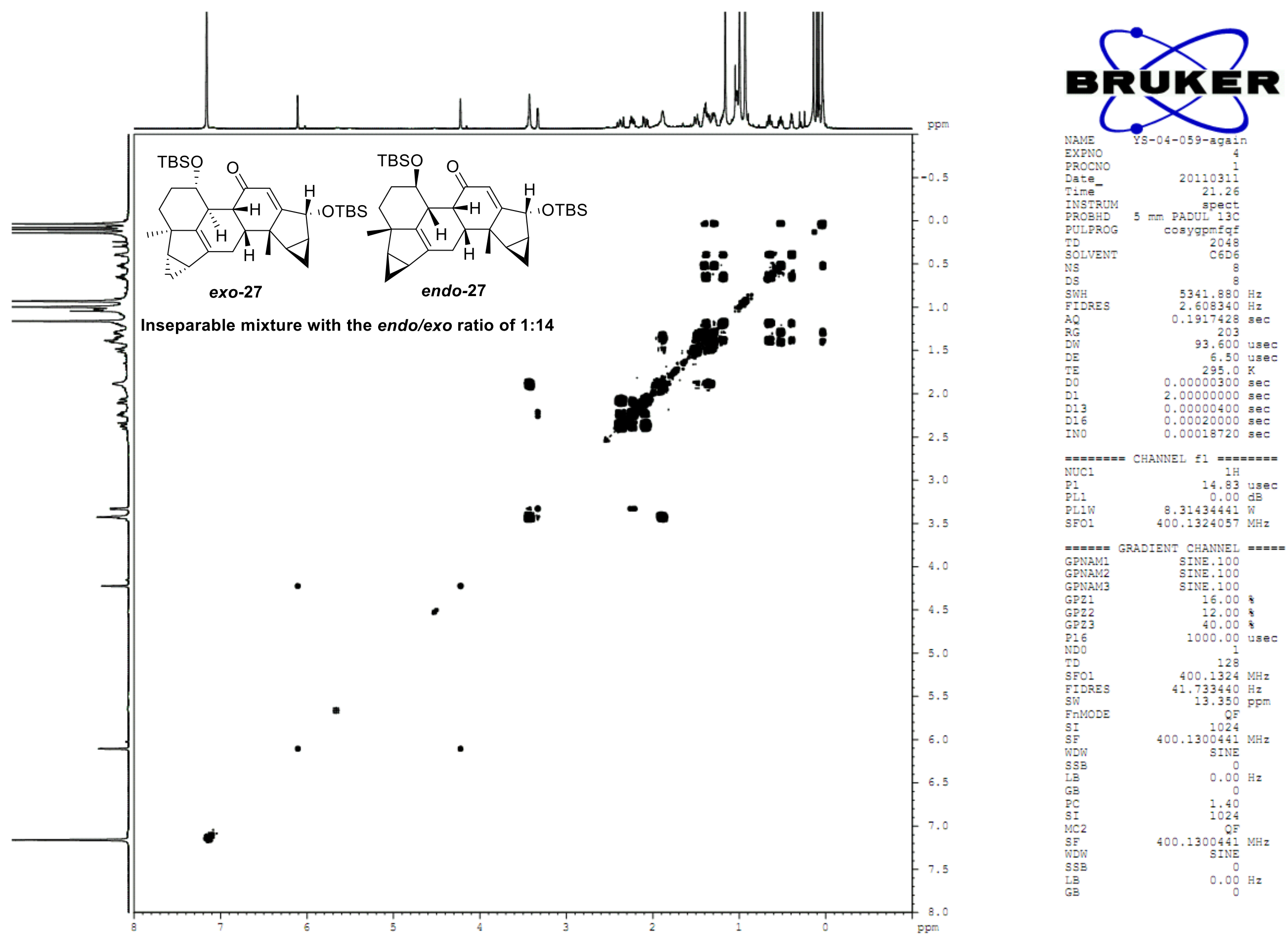


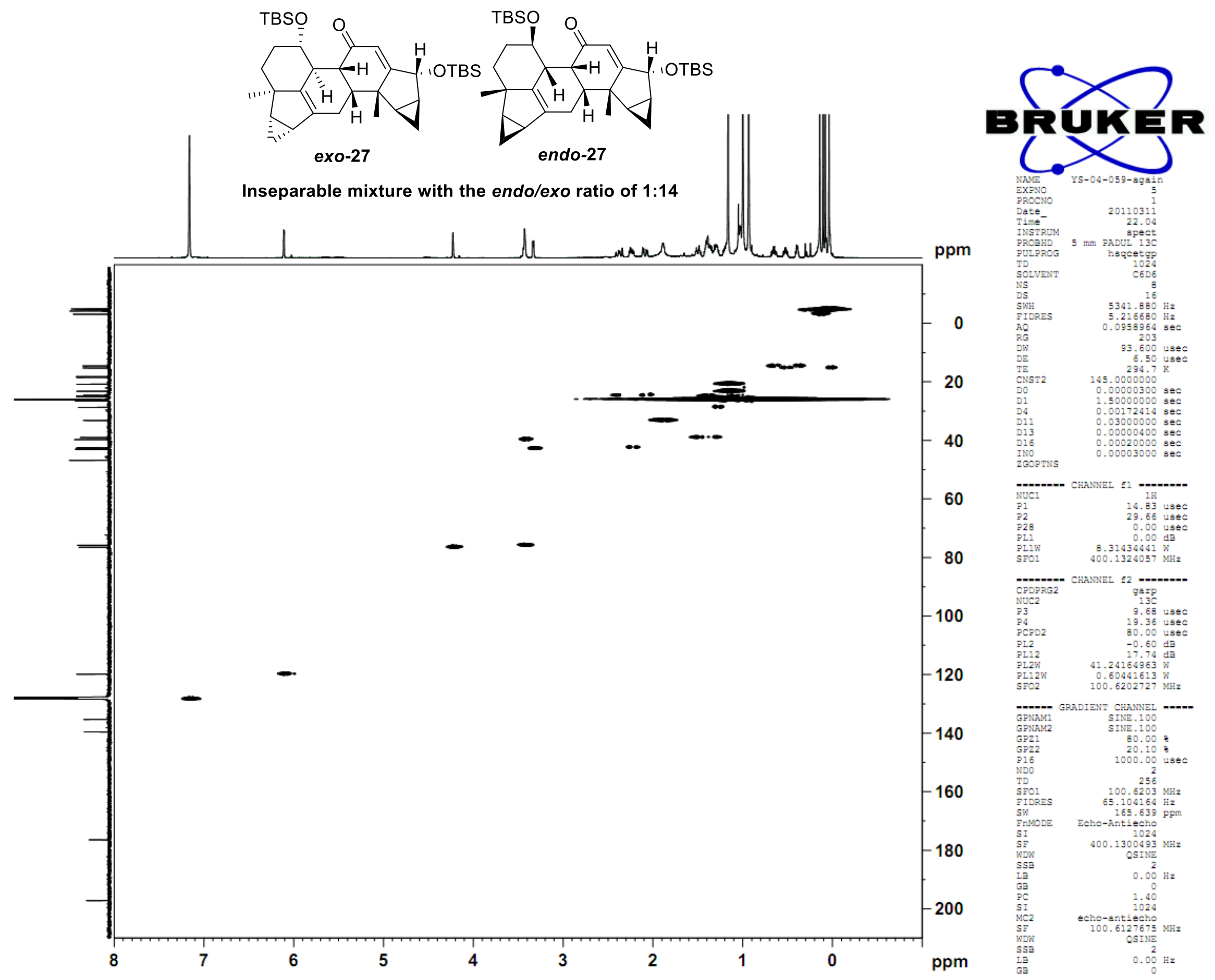




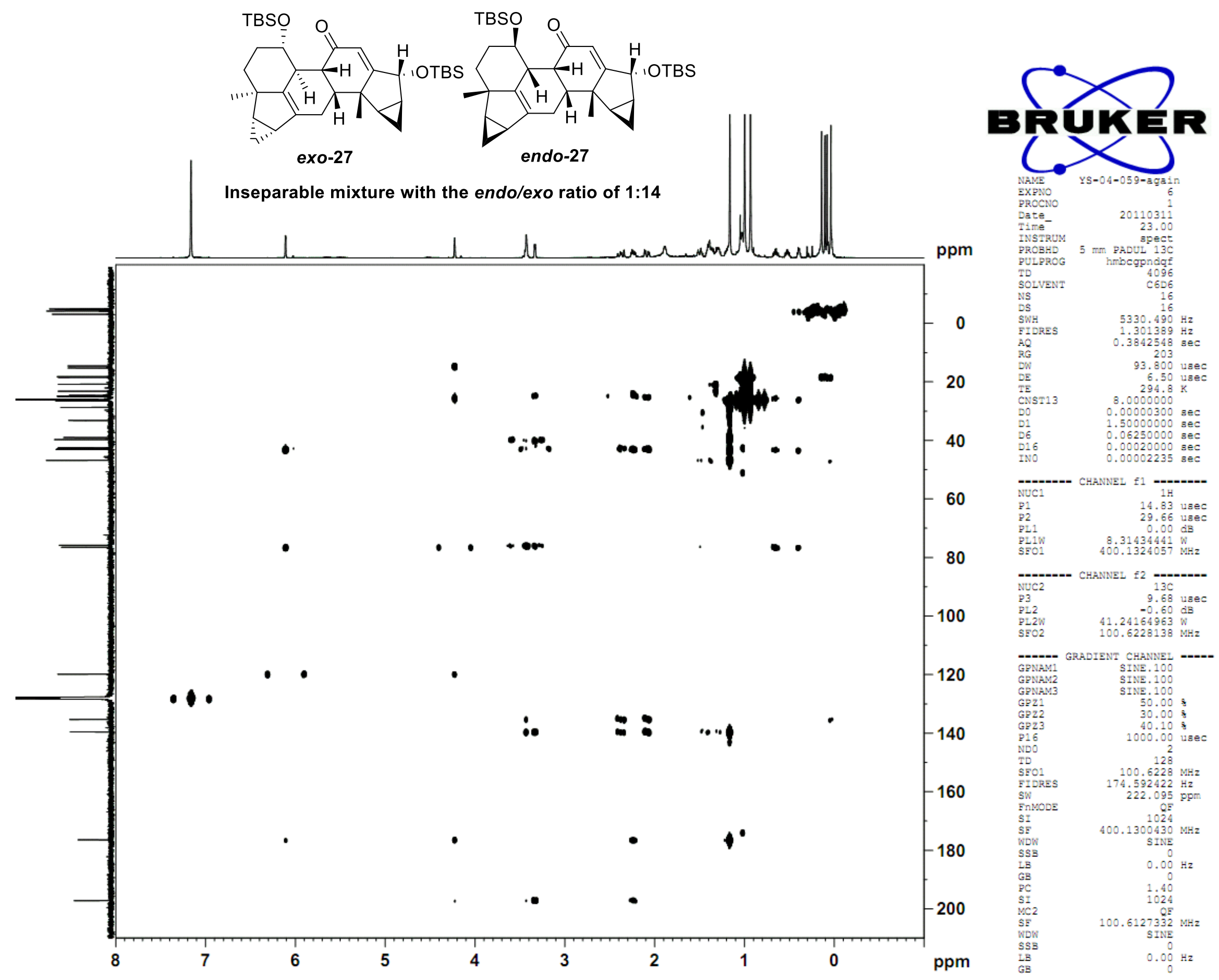



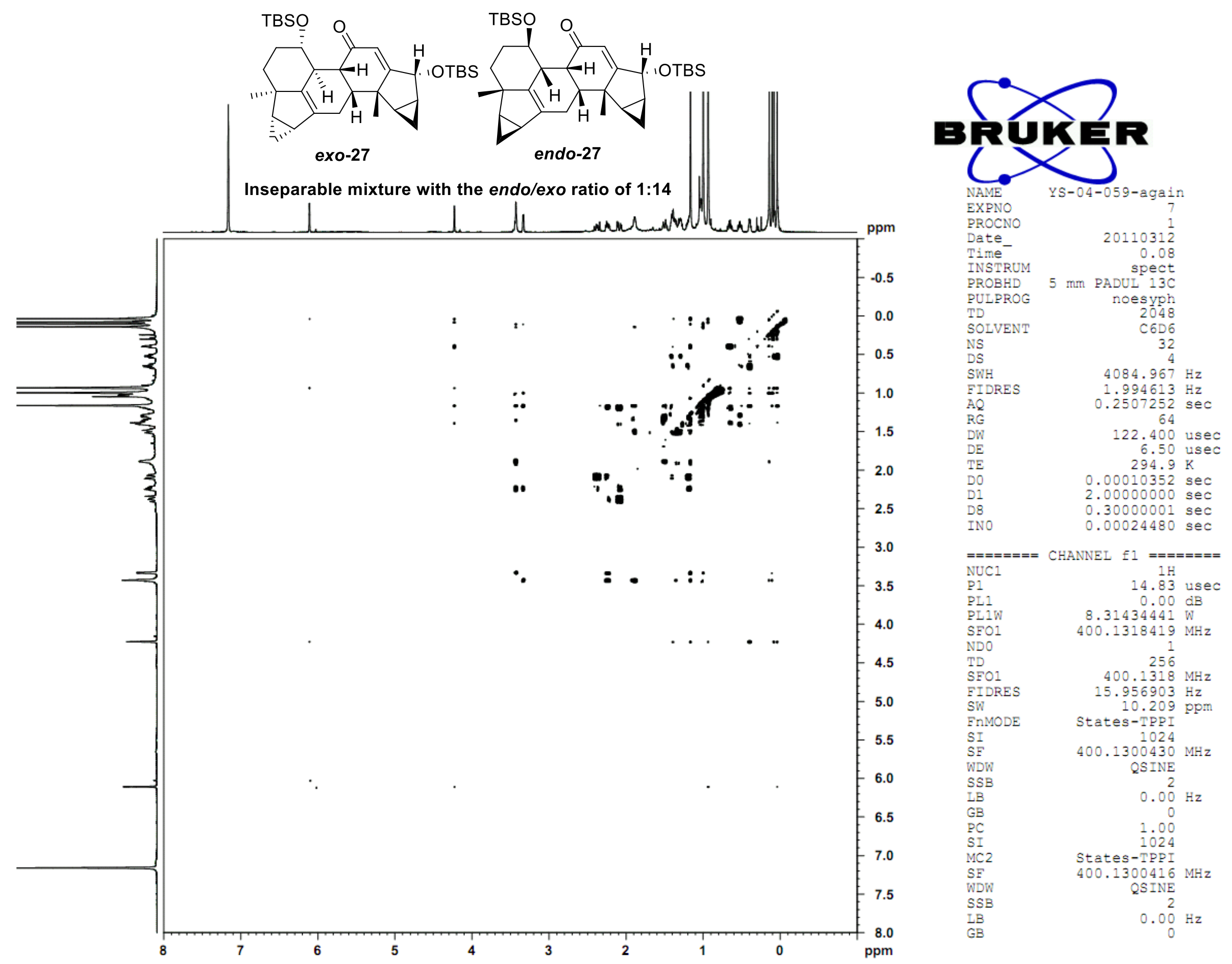


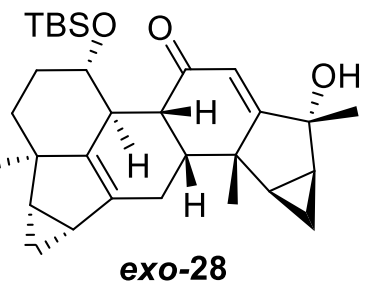

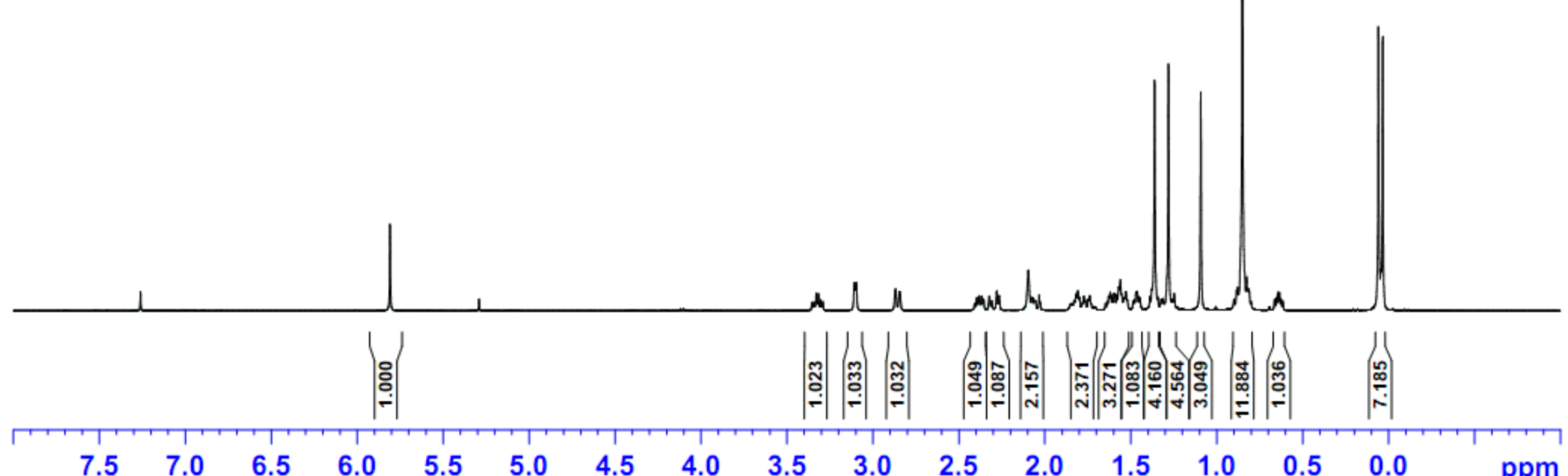

NAME
EXPNO

PROCN

Date-

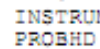

PULPRO

SOLVENT

Nos

SWM

AO

RG

$\frac{1}{\mathrm{TE}}$

TDO

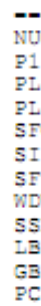

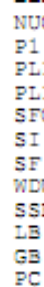

$5-04-066=$

$2011032 \frac{1}{20}$

6553

0233.685

$8223.685 \mathrm{~Hz}$
$0.125683 \mathrm{~Hz}$ $3.9846387 \mathrm{sec}$

60.800 usec

60.800 usec
6.50 usec

$1,00000000 \mathrm{kec}$

$$
1.00000000 \mathrm{sec}
$$

$$
\begin{array}{r}
14.00 \mathrm{usec} \\
-1.00 \mathrm{~dB} \\
13.56617069 \mathrm{~W} \\
400.1924713 \mathrm{MHz} \\
32768 \mathrm{~Hz} \\
400.1900138 \mathrm{MHz} \\
\mathrm{EM} \\
0 \\
0.30 \mathrm{~Hz} \\
0
\end{array}
$$

ppm 


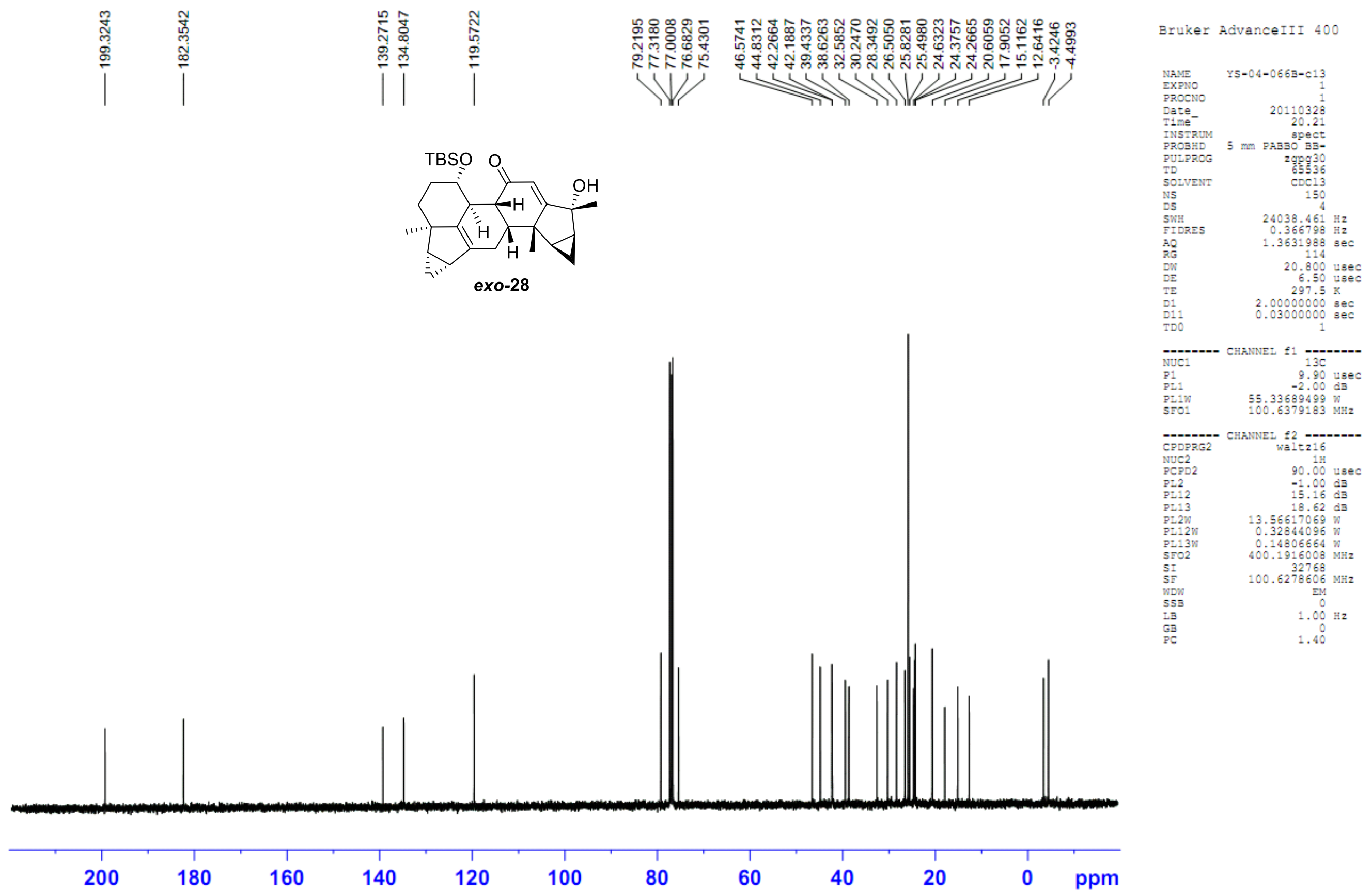



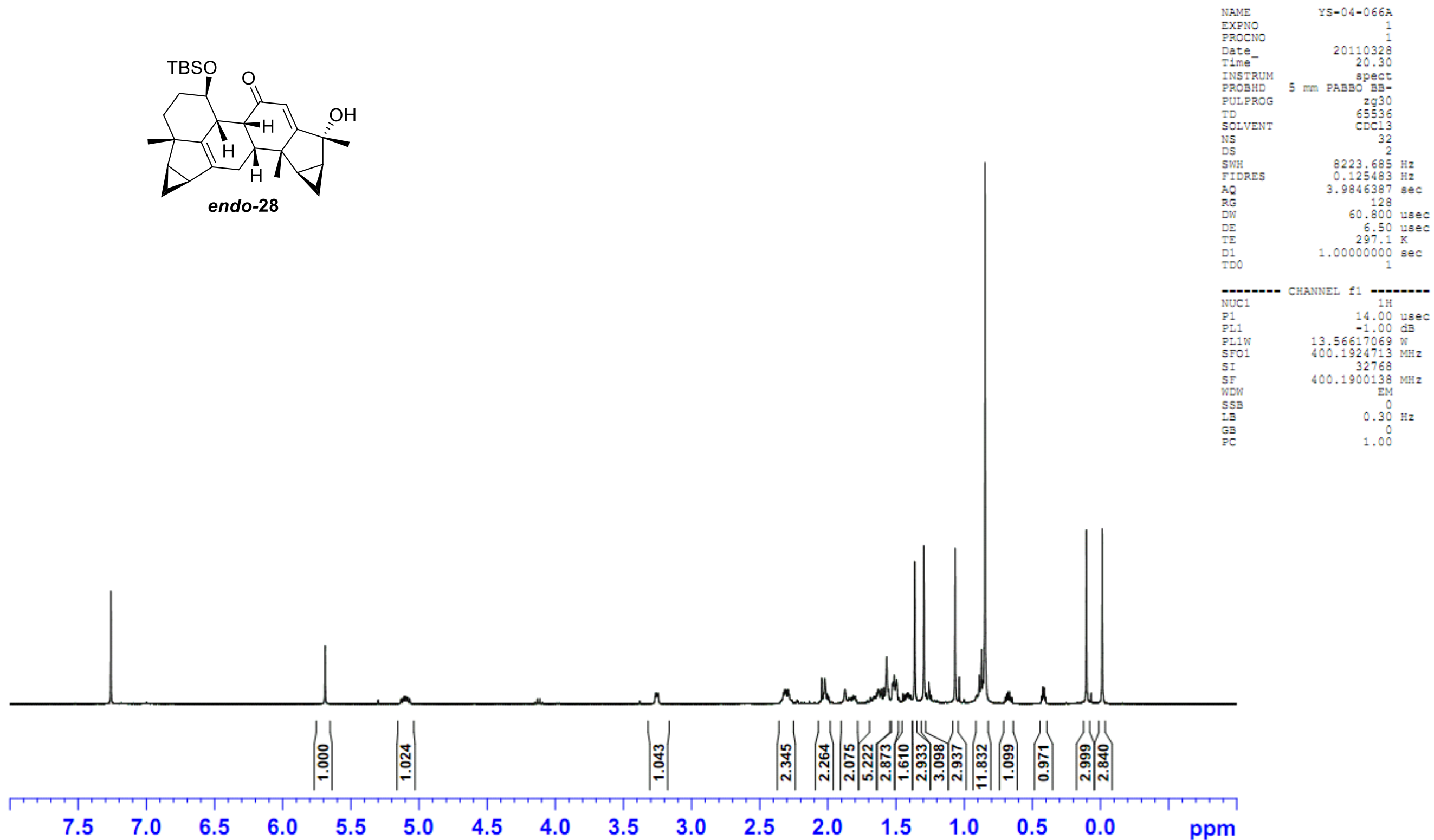


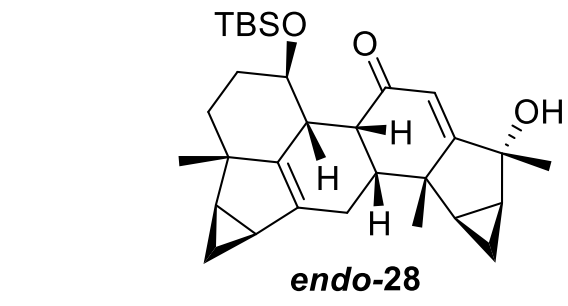

(n) 
Selected HMBC Correlations $(H \rightarrow C)$ and Key NOESY Correlations $(\hookrightarrow)$ of exo-27

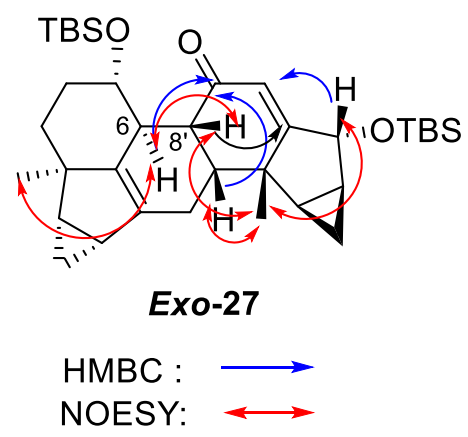


X-ray of allylic alcohol $\mathbf{2 0}$
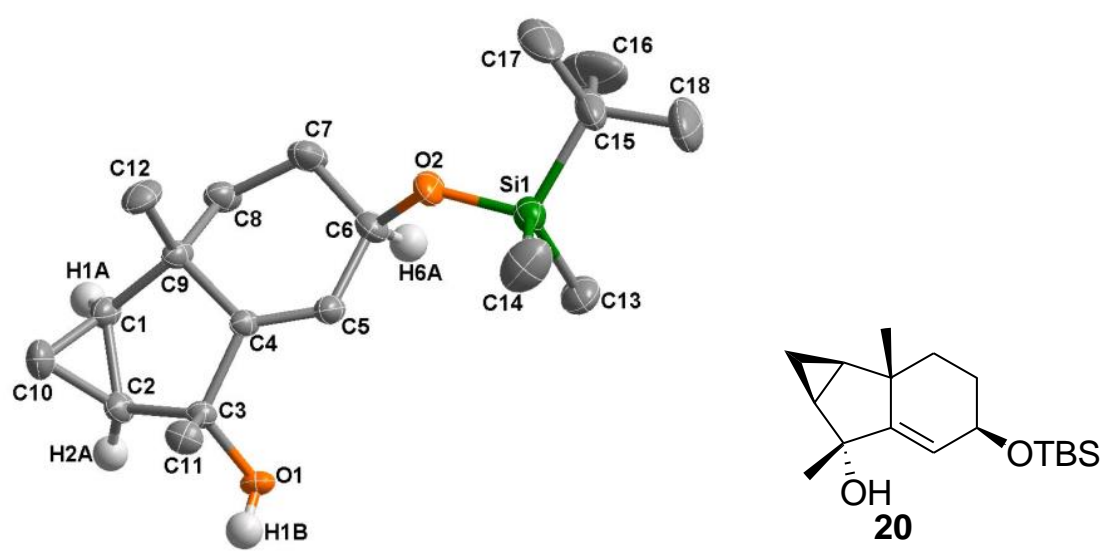

Table 6. Crystal data and structure refinement for YS-04-044A.

Identification code

Empirical formula

Formula weight

Temperature

Wavelength

Crystal system, space group

Unit cell dimensions

Volume

Z, Calculated density

Absorption coefficient

$\mathrm{F}(000)$

Crystal size

Theta range for data collection

Limiting indices

Reflections collected / unique

Completeness to theta $=25.25$

Refinement method

Data / restraints / parameters

Goodness-of-fit on $\mathrm{F}^{\wedge} 2$

Final $\mathrm{R}$ indices [I $>2 \operatorname{sigma}(\mathrm{I})]$

$\mathrm{R}$ indices (all data)

Largest diff. peak and hole
Ys-04-044A

C18 H32 O2 Si

308.53

296(2) K

$0.71073 \mathrm{~A}$

Trigonal, R-3

$\mathrm{a}=21.881(3) \mathrm{A} \quad$ alpha $=90 \mathrm{deg}$.

$\mathrm{b}=21.881(3) \mathrm{A} \quad$ beta $=90 \mathrm{deg}$.

$\mathrm{c}=21.626(3) \mathrm{A} \quad$ gamma $=120 \mathrm{deg}$.

8967(2) A^3

$18, \quad 1.028 \mathrm{Mg} / \mathrm{m}^{\wedge} 3$

$0.121 \mathrm{~mm}^{\wedge}-1$

3060

$0.5 \times 0.3 \times 0.2 \mathrm{~mm}$

1.43 to $25.25 \mathrm{deg}$.

$-26<=\mathrm{h}<=26,-26<=\mathrm{k}<=26,-25<=1<=25$

$69694 / 3608$ [R $($ int $)=0.0972]$

$99.9 \%$

Full-matrix least-squares on $\mathrm{F}^{\wedge} 2$

3608 / 0 / 190

1.035

$\mathrm{R} 1=0.0902, \mathrm{wR} 2=0.2521$

$\mathrm{R} 1=0.1242, \mathrm{wR} 2=0.2916$

1.269 and -0.534 e. $\mathrm{A}^{\wedge}-3$ 
X-ray of endo-down Diels-Alder cycloaddition product $\mathbf{2 8}$
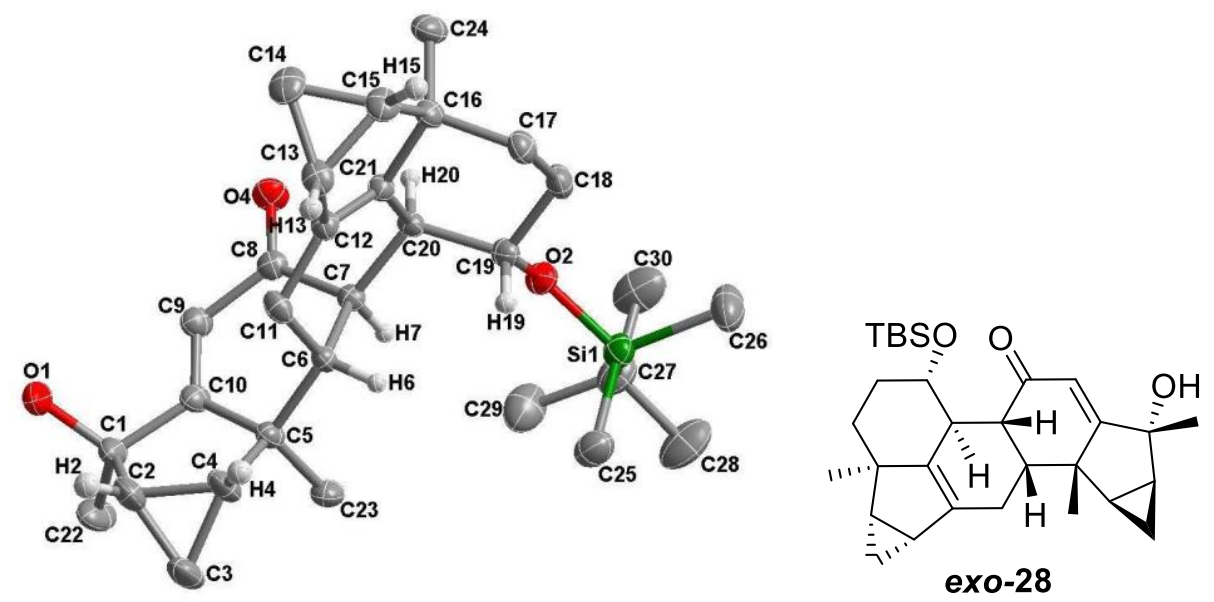

Table 1. Crystal data and structure refinement for YS-04-066B.

Identification code

Empirical formula

Formula weight

Temperature

Wavelength

Crystal system, space group

Unit cell dimensions

Volume

Z, Calculated density

Absorption coefficient

$\mathrm{F}(000)$

Crystal size

Theta range for data collection

Limiting indices

Reflections collected / unique

Completeness to theta $=25.25$

Absorption correction

Refinement method

Data / restraints / parameters

Goodness-of-fit on $\mathrm{F}^{\wedge} 2$

Final R indices [I $>2 \operatorname{sigma}(\mathrm{I})]$

$\mathrm{R}$ indices (all data)

Largest diff. peak and hole
YS-04-066B

C30 H43 O3 Si

479.73

293(2) K

$0.71073 \mathrm{~A}$

Monoclinic, P2(1)/c

$\mathrm{a}=16.731(8) \mathrm{A} \quad$ alpha $=90 \mathrm{deg}$.

$\mathrm{b}=12.758(6) \mathrm{A} \quad$ beta $=104.046(10) \mathrm{deg}$.

$\mathrm{c}=13.573(6) \mathrm{A} \quad$ gamma $=90 \mathrm{deg}$.

2811(2) $\mathrm{A}^{\wedge} 3$

4, $\quad 1.134 \mathrm{Mg} / \mathrm{m}^{\wedge} 3$

$0.111 \mathrm{~mm}^{\wedge}-1$

1044

$0.5 \times 0.4 \times 0.3 \mathrm{~mm}$

2.03 to $25.25 \mathrm{deg}$.

$-20<=\mathrm{h}<=20,-15<=\mathrm{k}<=15,-16<=1<=16$

$63889 / 5085$ [R(int $)=0.0975]$

$100.0 \%$

None

Full-matrix least-squares on $\mathrm{F}^{\wedge} 2$

$5085 / 0 / 307$

1.039

$\mathrm{R} 1=0.0743, \mathrm{wR} 2=0.2026$

$\mathrm{R} 1=0.0976, \mathrm{wR} 2=0.2263$

1.877 and -0.632 e. $\mathrm{A}^{\wedge}-3$ 